\title{
INFORMATION AND COMMUNICATION TECHNOLOGIES IN
} NETWORKS OF NONPROFIT ORGANIZATIONS

by

Eli Malinsky

B.A. York University, 1999

\author{
A thesis \\ presented to Ryerson University \\ in partial fulfillment of the \\ requirements for the degree of \\ Master of Arts \\ in the Program of
}

Communication and Culture

Toronto, Ontario, Canada 2005

(C) Eli Malinsky 2005

PROPERTY OF

RYERSON UNIVERSITY LIBRARY 


\title{
UMI Number: EC53046
}

\author{
All rights reserved \\ INFORMATION TO USERS
}

The quality of this reproduction is dependent upon the quality of the copy submitted. Broken or indistinct print, colored or poor quality illustrations and photographs, print bleed-through, substandard margins, and improper alignment can adversely affect reproduction.

In the unlikely event that the author did not send a complete manuscript and there are missing pages, these will be noted. Also, if unauthorized copyright material had to be removed, a note will indicate the deletion.

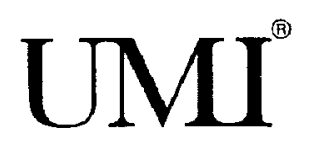

UMI Microform EC53046

Copyright 2008 by ProQuest LLC

All rights reserved. This microform edition is protected against unauthorized copying under Title 17, United States Code.

ProQuest LLC

789 East Eisenhower Parkway

P.O. Box 1346

Ann Arbor, Ml 48106-1346 


\section{Abstract}

This thesis explores the recursive interaction among technology, human action and institutional properties in three networks of nonprofit organizations. The aims of the research are two-fold: to make a theoretical contribution to literature on organizations and technology by applying concepts of institutionalism and the structurational model of technology to a unique organizational form; and, to make a practical contribution to the nonprofit sector by improving knowledge of how networks of nonprofit organizations interact with information and communication technologies.

The research process involved 13 interviews, 44 qualitative surveys and copious document and website analysis. The findings indicate that technology is not institutionalized uniformly within the network structures but instead comes to assume different roles within different parts of the networks. This leads to an extension of the structurational model of technology and also highlights the importance of flexible technologies that can be adapted to the variable circumstances of a single network structure. 


\section{Acknowledgements}

With thanks to my advisory committee for all of their support, and to the research participants for making this possible and for teaching me so much. 
To my parents. 



\section{Table of Contents}

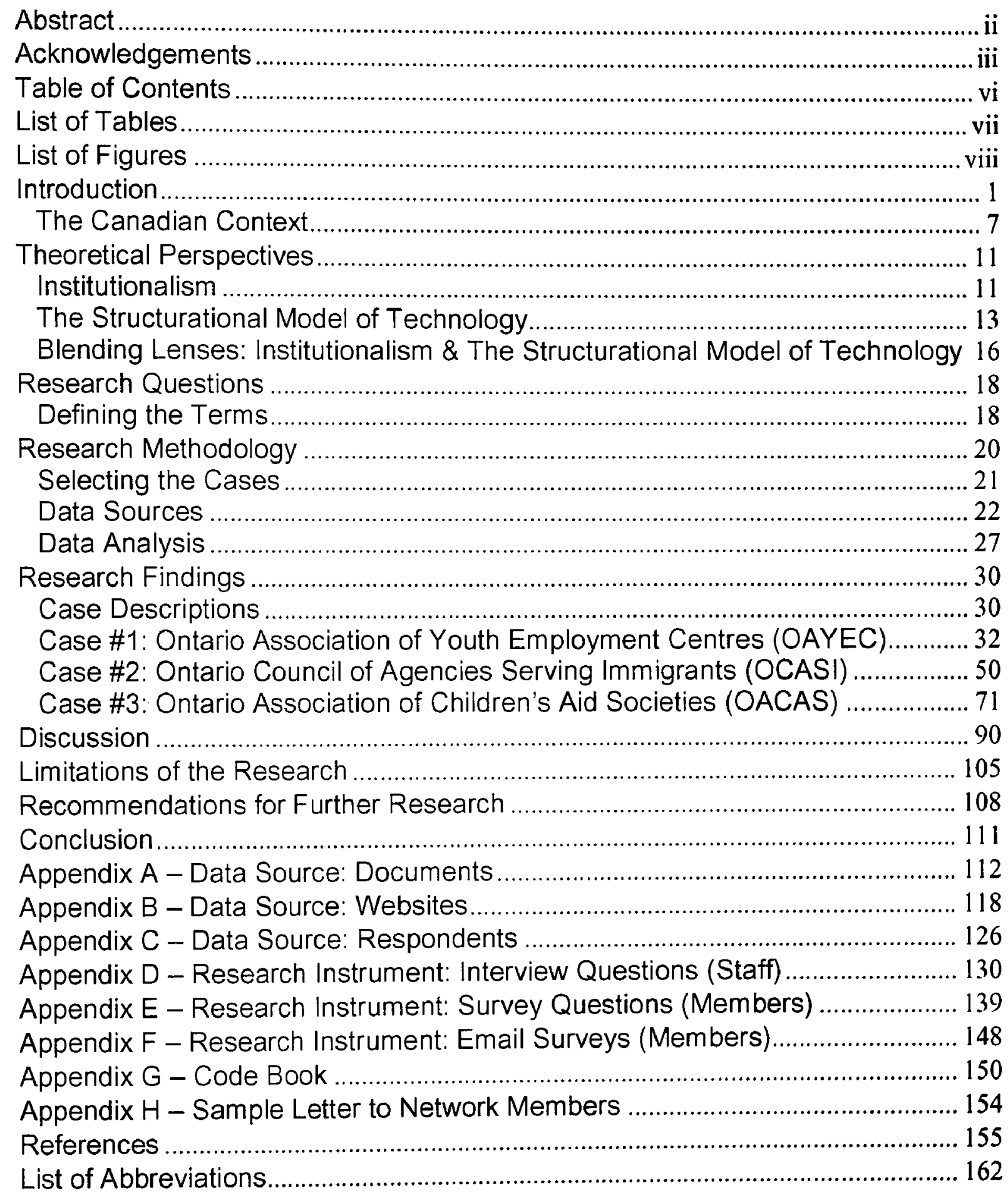




\section{List of Tables}

Table 1. Summary of Data Sources by Case

Table 2. Overview of Network Characteristics

Table 3. OAYEC Network Technology

Table 4. OCASI Network Technology

Table 5. OACAS Network Technology

Table 6. Structurational Model of Technology, Extended 


\section{List of Figures}

Figure 1. Structurational Model of Technology

Figure 2. OAYEC Technology Strategy

Figure 3. OAYEC Network

Figure 4. OCASI Network

61

Figure 5. OACAS Network

Figure 6. Structurational Model of Technology, Extended 



\section{Introduction}

Over the past two decades there has been increasing attention to network organizational forms (Knoke 2001; Nohria 1992: Podolny and Page 1998: Powell 1990; Thompson 2003). The mounting interest in network structures is reflected in civil society and recent years have witnessed a dramatic surge in the number and types of interconnections among nonprofit organizations (Anheier et al. 2001: Anheier and Themudo 2002; Keck and Sikkink 1998; Surman 2003; Tarrow 1998). Nonetheless, there is a meager body of work that critically assesses the interaction of technology and networks of nonprofit organizations. Armed with insights from two bodies of literature - theories of institutionalism and a structurational model of technology - this thesis explores the institutionalization of information and communication technologies (ICTs) in three networks of nonprofit organizations.

The research has two principal aims. The first is to provide insight into the deployment, use and impact of technology within networks of nonprofit organizations. The nonprofit sector is unique for its array of hybrid organizational structures and for the willingness of organizations to collaborate with one another. In light of the prevalence of network structures and the increasing reliance on ICTs to facilitate communication and collaboration, research that reveals the experiences of networks of nonprofit organizations can contribute to better deployment and use of technology. This is especially valuable given the sector's formidable capacity challenges. The second aim of the research is to contribute to theories of institutionalism and to the structurational model of technology by applying these concepts to a hitherto un-studied organizational form. Networks of nonprofit organizations are organizational structures that merit specific attention and can extend our understanding of the recursive relationship among technology, human action and organizational properties. 
Three research questions guide the thesis:

1. How are information \& communication technologies institutionalized in the network?

a. What are the roles and experiences of coordinating agencies?

$b$. What are the roles and experiences of network members?

2. How do network charactristics shape the use of information \& communication technologies?

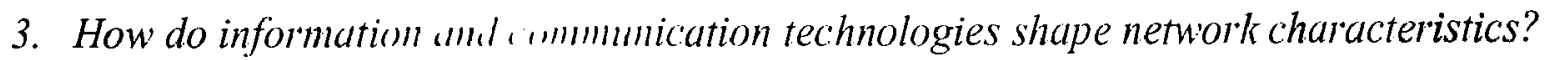

These questions ar: pur und through a collective case studies methodology that relies

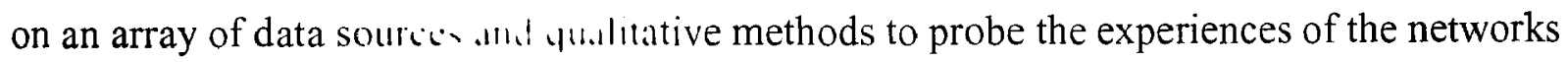
under review. Thirteen $\ldots 1, \cdots \cdots, \cdots$ h, sle been conducted with representatives of the three participating agencies and $.4+1.1 .1+4+$ telephone surveys have been completed by their members. Buttressed h! d.t.ul.il d.cument and website analysis, as well as two short focus groups and 27 email surw... cumplcted by staff at member agencies, this thesis provides a comprehensive assessment w the participating networks and their experiences in attempting to institutionalize new technolugies.

This report begins with a literature review that examines the various domains of study germane to the investigation. including literature on network organizations, civil society networks, the Canadian nonprofit sector and the two principal theoretical lenses. This review is followed by a methodology section that outlines how the cases were selected, the data sources and collection methods used. and the processes of data analysis. Each of the cases is reviewed in turn according to the three research questions and a general discussion provides a cross-case analysis and situates the findings among the extant literature. Limitations of the research and suggestions for further study are followed by a conclusion that summarizes the salient findings and reiterates the theoretical and practical contributions of this thesis. 


\section{Background}

Over the past three decades there has been increasing attention to network organizational forms (Knoke 2001; Nohria 1992; Podolny and Page 1998; Powell 1990; Thompson 2003). Although initially interpreted as a hybrid of hierarchies and markets (Williamson 1975), subsequent research and a mushrooming body of literature have found network arrangements to be sufficiently unique to warrant their own position as a distinct type of organizational structure (Lipnack and Stamps 1994; Nohria 1992; Powell 1990; Thompson 2003). Indeed, some students of organizational theory have argued that networks represent the next epoch of organizational form (Anheier and Themudo 2002; Castells 2001; Lipnack and Stamps 1994).

Nonetheless, there is no consensually agreed upon definition of "network structure" and the term is applied to an astonishing array of organizational arrangements. Perhaps the single most common feature of the literature is each author's lament of the lack of a coherent framework and each author's attempt to resolve this impasse by adducing their own definition. A careful reading, however, does reveal some consistency across the literature. Most generally, networks are considered to be a mode of coordination characterized by integration across vertical, horizontal and spatial boundaries. They are decentralized, flexible, and selfadaptive structures that feature multi-directional relationships and rely on norms of trust and reciprocity. Constituent units retain their individual autonomy but participate in processes that affect the network as a whole.

The increasing prevalence of network arrangements has largely been attributed to the processes of economic globalization (Ching, Holsapple and Whinston 1996; Knoke 2001; Nohria 1992; Symon 2000). The rapid growth of global markets and the fast paced changes 
associated with the new operational environment have required flexible structures that are capable of succeeding in variable conditions and contexts. Networks have developed as a means to contend with these conditions and a substantial body of empirical studies has supported this conclusion by charting the rise of organizational networks in a variety of industrial sectors.

Several authors have focused their attention on the relationship between information and communication technology (ICT) ${ }^{1}$ and the emerging forms of network organization. In The Rise of the Network Society, Castells (2001) argues that ICTs, although not entirely responsible, are facilitating the primacy of the network as the dominant organizational form of the Information Age, permitting the material implementation of network logic in organizations and processes. Others, however, are less sanguine, questioning the assumed relationship between technology and the rise of network organizations (see, for example, Symon 2000). Still, it is generally conceded that new technologies, if not drivers, are at minimum enablers of this development. ICTs, characterized by their flexible, multi-directional and both synchronous and asynchronous communication processes permit the coordination of employees, departments, and organizations across space and time with unprecedented ease. Not only do these technologies permit organizations to communicate more easily, but developments in collaborative technologies have also enabled new forms of cooperative work across geographic distances (Bradner and Mark 2002; Munkvold 1999; Pendergast and Hayne 1999).

The increasing interest in and prevalence of network structures is reflected in civil society - that arena outside of the market and government in which NGOs, activists and

\footnotetext{
'Information and communication technologies include any devices that will store, retrieve, manipulate, transmit or receive information electronically in digital form.
} 
voluntary groups operate. Recent years have witnessed a dramatic surge in the number and types of interconnections within civil society (Anheier et al. 2001; Anheier and Themudo 2002; Keck and Sikkink 1998; Tarrow 1998), allowing otherwise impoverished or isolated civil society organizations to access additional resources and multiply their influence (Bartling 1998; Pace and Panganiban 2002). Indeed, it has been claimed that the network structure is the signature organizational form of global civil society (Anheier and Themudo 2002). The reasons for this are varied. The global environment is characterized by change and diversity, and civil society actors, like for-profit institutions, benefit from adaptive structures capable of accommodating varying political and cultural contexts. Further, individual organizations operating in multiple environments incur high transaction costs; these costs are mitigated when the resources and expertise of other organizations are accessed through joint initiatives. Civil society organizations, which are typically under-resourced, stand to gain particular benefit from such arrangements.

Although civil society networks existed well before the advent of ICT, the introduction of these technologies have enhanced the ease with which such networks have been established by facilitating coordination among geographically disparate organizations (Castells 2004; O'Brien 2002). The use of ICT has permitted greater fluidity and diversity in collaborative initiatives and recent years have seen the adoption, evolution and disbandment of new organizational forms at an increasing pace (Anheier et al. 2001; Anheier and Themudo 2002; Clarke \& Dopp 2001; Garrido 2003; Surman 2003). These technologies enable civil society actors to share information, maintain communicative ties, and reach new members across spatial and temporal distances with unprecedented ease (Diani 2000; Hajnal 2002; Keck and Sikkink 1998; Naughton 2001), and offer new opportunities for otherwise isolated social 
actors to join forces and assert a stronger role in political decision-making (Anheier $e$ al. 2001; Frederick 1992; Holland and Lockett 1997; Pace and Panganiban 2002).

Some authors posit a natural symmetry between civil society networks and ICT. Bach and Stark (2004) propose an affinity between the flexibility and adaptability of civil society organizational structures and the network properties of ICT. Warkentin (2001) further argues that the inherent qualities of the internet facilitate the development of global civil society's network relations and that the historical development of the internet is paralleled in the growth of global civil society. Both authors see ICT and civil society organizations as co-evolving agents, reinforcing and shaping each other's growth. The proliferation of connections among civil society actors in recent years is thus seen in part as a result of new technologies, which have facilitated a movement from isolation to increasing collaboration.

Nonetheless, the bulk of research investigating this topic is concerned with sensational but unrepresentative examples of ICT use among a few prominent international advocacy networks (Malinsky 2004). Cases such as Jubilee 2000, the NGO Coalition for an International Criminal Court, the International Campaign to Ban Landmines, and the Zapatistas movement have consumed a disproportionate amount of academic attention. While these examples of ICT use for international campaigning are most certainly noteworthy, there has been insufficient attention to the role of technology in supporting networks of civil society organizations in their everyday work. Only a handful of studies address this topic. Warkentin (2001) documents the use of technology among several networks of civil society organizations, including Greenpeace, Rainforest Action Network and Oxfam. Lebert (2002, 2003) looks specifically at the challenges faced by Amnesty International as it incorporates new technology into existing practices and Burt and Taylor $(2000,2003)$ explore the impact of 
technology on the internal and external relationships of Friends of the Earth UK and the Samaritans. But the interaction of technology and organizational networks within civil society merits far greater and far more critical study; the rich variety of network relationships among civil society organizations has barely been explored.

\section{The Canadian Context}

The Canadian context presents an interesting backdrop to this investigation. Since the launch of the Connecting Canadians Program in 1998 the federal government has introduced several initiatives to support the adoption of communication technologies within Canada's nonprofit and voluntary sector ${ }^{2}$. A central plank of the Connecting Canadians initiative, the Voluntary Network Support Program, was intended to build the technological capacity of the voluntary sector and successfully connected 10,000 voluntary organizations to the internet before its end in 2002 (Connecting Canadians Website 2004). In 2000 the Government of Canada launched the Voluntary Sector Initiative, comprising seven Joint Tables of representatives of the government and voluntary sector. One of these, the Information Management and Information Technology Joint Table, was established to investigate and respond to the technology needs of the voluntary sector. The IM/IT Joint Table examined previous studies and reports on the needs of the sector, conducted its own needs analysis study in 2001 , and set up working groups to examine issues and solutions related to successful implementation of technology (Voluntary Sector Initiative Website 2004). Finally, the Community Learning Networks Initiative, a program of Human Resources and Skills Development Canada's Office of Learning Technology, supports community-based pilot projects "which demonstrate innovative and sustainable uses of existing network technologies

\footnotetext{
${ }^{2}$ The labels nonprofit sector and/or voluntary sector are preferred to "civil society" in the Canadian context.
} 
to upgrade skills and knowledge of adult learners in Canadian communities" (Office of Learning Technologies Website 2005). This program funneled financial support to nonprofit and community organizations across Canada to create such learning opportunities in their communities.

In Ontario, the Ministry of Citizenship and Immigration's Volunteer @.ction.Online program is the lone provincial government initiative investing in technology and technology support for the voluntary sector. Launched in 1999, Volunteer@ction.Online (V@O) was a four-year funding initiative that aimed to improve the technological capacity and effectiveness of Ontario's voluntary sector. Over the course of its operations the V@O has granted over $\$ 11.5$ million in funding to 110 voluntary sector projects comprising over 975 partners. Volunteer@ction.Online has created thousands of information resources and tools, trained over 3,000 volunteers and staff in use of technology, and has supported the online recruitment of over 85,000 volunteers (Volunteer @ction.Online Website 2005).

These initiatives have contributed to the adoption of ICTs among Canada's nonprofit and voluntary organizations, and a growing body of accompanying studies has revealed a sector that has recently become "online" and is beginning to explore ways to make better use of new technologies (Ludgate and Surman 2004). By and large, this research has taken the form of quantitative studies documenting the adoption rates and uses of internet technology among nonprofit organizations (Leverus 2002) and professional associations (O'Connell 2005). Although no research has specifically addressed technology as a means to support networks of organizations in Canada, Surman (2001) reports that early pioneers of ICT use in Ontario's voluntary sector have demonstrated that "through smart, thoughtful, collaborative 
online work, nonprofits can better face challenges such as dwindling resources, the duplication of efforts and the need for coordinated delivery of services" (pp. 3).

This finding is particularly relevant given the current operational environment of Canadian nonprofit organizations. Since the mid-1990s the Canadian voluntary sector has shouldered increasing responsibility for the delivery of social services as a result of financial retrenchment within the federal and provincial governments (Hall and Reed 1998). As governments have withdrawn from the provision of social programs citizens have increasingly relied on Canada's nonprofit and voluntary sector to fill the resulting gap (Evans and Shields 1998; Meinhard and Foster 2003). The sector's ability to meet the needs of Canadian citizens and communities, however, has been constrained by changes in the funding practices of governments and foundations. In recent years there has been an increasing trend toward targeted grant-making in which funders pay for the delivery of prescribed projects (Hall et al. 2003; Scott 2003). Moreover, core funding for administration and infrastructure has become increasingly difficult to secure, wreaking havoc on long-term planning and hampering the ability of nonprofit organizations to pursue their missions.

These changing conditions suggest the ground may be ripe for increasing collaboration within the sector. As nonprofit and voluntary organizations contend with new economic realities they may be seeking to share resources and facilitate collaboration through territorial and subsectoral networks. Although no existing research has conclusively demonstrated that the number of networks is increasing within the Canadian nonprofit sector, there is some anecdotal evidence that this is the case (see Canadian Federation of Voluntary Sector Networks Website 2005; Hatton 2002). Scott (2003) notes that funders are increasingly seeking evidence of collaboration and Hall et al. (2003) report that members of the voluntary 
sector cite an increasing trend toward mandated collaboration. Indeed, both the Community Learning Networks initiative and the Volunteer @ction.Online program required some form of inter-organizational collaboration as a condition of receiving funds.

Further, one can speculate that in the face of competition for scarce funding collaboration is more likely within the nonprofit and voluntary sector than in the private sector given the primacy of social goals over goals of profit maximization. In their study of the impact of changing social, political and economic conditions on Ontario women's voluntary organizations, Meinhard and Foster (2003) discovered that these groups were more likely to embrace a strategy of collaboration over one of competition. Similarly, in their 2005 research on Ontario's rural voluntary sector, Barr and Stowe discovered that rural nonprofit organizations look to collaboration as a means to contend with their capacity challenges and cite the value of technology in facilitating contact with other organizations across geographic distances.

If the sector is moving toward increasing collaboration and ICT has a role in facilitating this process, then research on this topic is not only timely but instructive, providing direction to networks of nonprofit organizations that seek to use ICTs in pursuit of their missions. This research project intends to fill an existing gap by tapping into a rich field of Canadian networks to learn about their experiences in using ICTs, revealing the real impact of technology as grounded in existing practice. In relying on and extending established theories of organizations and technology use, this research further intends to contribute to notions of institutionalism and structuration by probing into the unique case of nonprofit networks. 


\section{Theoretical Perspectives}

Two theoretical perspectives will help to frame the investigation. The first, institutionalism, is a theoretical perspective that has emerged from organizational theory. The second, a structurational model of technology, focuses attention on the recursive relationship among, technology, human actiwn and organizational characteristics. The combination of these two lenses creates a pincirtul instrument with which to investigate the interaction of technology and networh... m.npwlit organizations.

\section{Institutionalism}

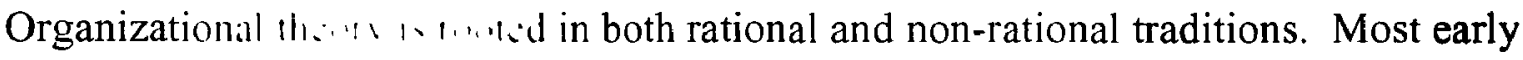
organizational theory $\cdots$.1. were the conscious result . : Hhincy concerns. For decades, all organizational characteristics were interpretcd in this light. Since the 1960 s, however, organizational theorists have discovered that not all organizational action is driven by rational concerns. Instead, they found that orginizations engage in activities and evolve structures that are determined more by the demands of institutional players and other environmental conditions than by the exigencies of efficiency. Institutionalism arises out of this non-rational tradition. Institutional theorists claim that organizational action and structure are a response to the institutional environment in which they operate, as organizations strive to gain legitimacy through one of several routes. When pioneering a new organizational form or introducing new practices, organizations will adopt and institutionalize those forms and practices that are accepted, and thus legitimized, by the environmental actors on whom they are dependent (Hannan and Freeman 1977; Meyer \& Rowan 1977; Stinchcombe 1965). Most organizations 
however, adopt established structures and procedures in order to gain legitimacy. As a result, organizations working in a common environment come to resemble one another in structure and activity. DiMaggio and Powell (1991) identify three distinct processes at the root of such organizational isomorphism: 1) Coercive processes refers to the formation of structures and practices in response to the requirements of actors on which organizations depend; 2) Normative processes are those that stem from the expectations or rules established by members of that community; and, 3) Mimetic processes refers to the modeling of practices of successful organizations within the organizational field.

The more an organization adheres to such institutionalized practices the greater that organization's chance of success (Meyer and Rowan 1977). These practices are themselves the outcome of the processes of institutionalization - the means by which "social processes, obligations or actualities come to take on rule-like status in social thought and action" (Meyer and Rowan 1977: 342). Organizational form and activity are institutionalized as actors adhere to recognized processes and configurations. Over time, these practices become ossified and persist as patterns of behaviour and organization that prescribe certain actions and limit others. Organizational characteristics are therefore not determined solely by workplace efficiency, but are also a result of the adoption of established and approved patterns of behaviour.

The processes of institutionalization do not exclusively apply to organizational structures. For institutional theorists an institution can be any social pattern that has attained a certain state of permanency or formality. Institutions act as "socially constructed templates for action, generated and maintained through ongoing interactions" (Barley and Tolbert 1997). In this regard, "templates" for behaviour include such institutions as marriage, academic tenure 
and the business handshake. All institutions facilitate certain types of action while constraining others (Jepperson 1991; Tolbert and Zucker 1996; Zucker 1987).

Technological innovations are themselves structures which undergo processes of institutionalization. Understanding the institutionalization of technology within a given organization, or network of organizations. helps us to uncover the means by which the technology becomes embedded in organizational processes and by which it prescribes and limits certain behaviours and organizational properties. However, the application of concepts of institutionalism to the role and impact of technology in organizations requires a particular refinement of theories of institutionalism; institutionalism inadequately attends to the processes of institutionalization and to the interdependence of action and structure, generally focussing instead on the diffusion of particular practices (Tolbert and Barley 1997). In order to investigate the institutionalization of technology more closely, therefore, it is helpful to borrow insights from models of technology that focus specifically on this domain. The structurational model of technology, as a lens for interpreting the role and influence of technology within organizations, helps us to understand the dynamic process of institutionalization.

\section{The Structurational Model of Technology}

The structurational model of technology was first proposed by Orlikowski and Robey (1991) and has been subsequently modified, extended and adapted though the contributions of other scholars (e.g. DeSanctis and Fulk 1999; DeSanctis and Poole 1994; Roberts and Grabowski 1996). The structurational model of technology synthesizes two dominant perspectives of the relationship between technology and organizations. The first, termed the technological imperative perspective, is a deterministic view which posits that technology 
shapes human action and organizational properties. The second, called the strategic choice perspective, claims that technology is shaped by organizational activities and properties. The structurational model of technology instead leverages Gidden's (1984) theory of structuration to posit a recursive interaction wherein technology and organizational form, and technology and organizational activity, are mutually informative. In other words, technology influences the form and activities of an ur:anization, and the form and activities of an organization influence the use of techmol,:-!

Orlikowski $(10) 2.1 \cdot 1.1 . m 11$ i $:$ three elements that are part of the processes of the structuration of technolı.:! hum.n .19ents, technology and institutional properties. These three elements interact in 1 . 1. J J $1: 1: n t$ ways. First, technology is the product of human

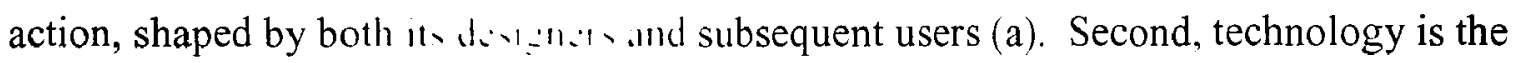
medium of human action. 1.whlt.1m!n: and constraining particular types of activity (b). Third, institutional characteristic sumdition the interaction of individuals with technology (c). Fourth, technology influencis an organization's institutional properties by reinforcing or transforming existing structures (d). This process is captured in the following figure:

Figure 1. Structurational Nodel of Technology (from Orlikowski 1992a: 410)

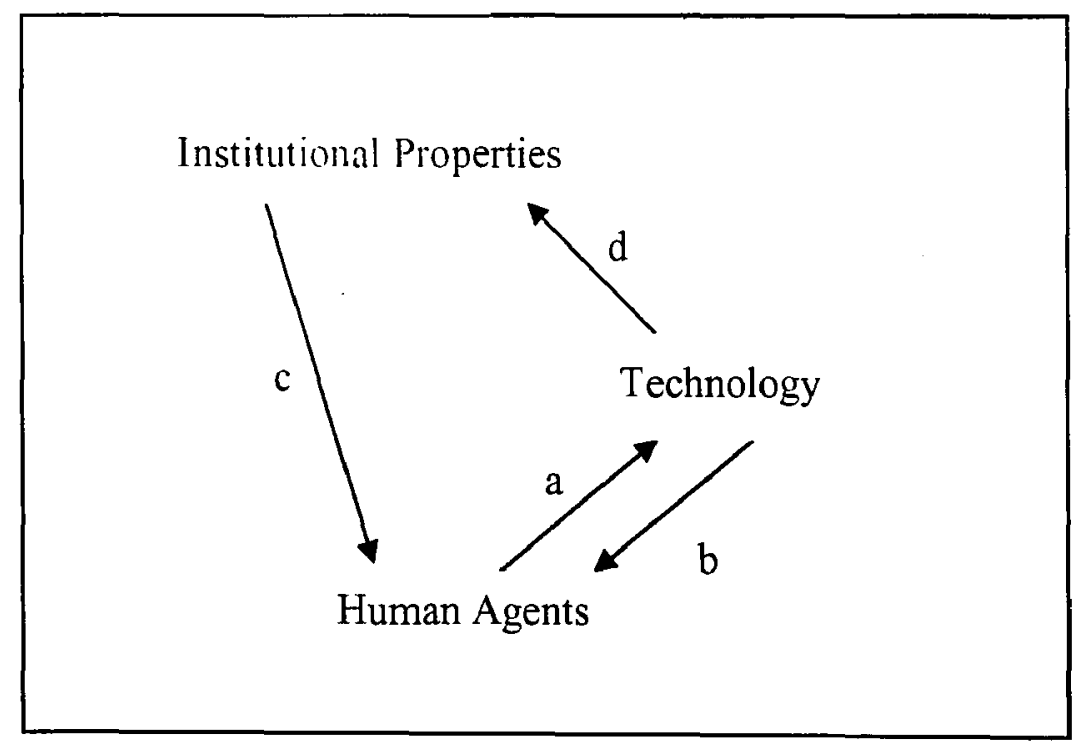


The structurational model of technology emphasizes the duality of structure; the notion that "structural properties of social systems are both the medium and outcome of practice that constitute those systems" (Giddens 1979: 69). As Barley (1986) notes,

Structure can be viewed simultaneously as a flow of ongoing action and as a set of institutionalized traditions or forms that reflect and constrain that action. More important than either realm. however, is the interplay that takes place between the two over time. Through this interplay, called the process of structuring, institutional practices shape human actions which, in turn, reaffirm or modify the institutional structure. Thus, the study of structuring involves investigating how the institutional realm and the realm of action configure each other. (pp. 80)

Technology as structure, therefore, is both the product of human action and the medium for human action. This is particularly true in the case of information and communication technologies, given their inherently modifiable characteristics (Orlikowski and Robey 1991; Roberts and Grabowski 1996). While a given software program or website feature may prescribe certain uses, these technologies can be appropriated and modified by users to a far greater degree than a more stable technology, such as a drill. Within an organizational context, ICT is employed as a tool to serve certain organizational interests but subsequently influences and is influenced by the organization through the process of its institutionalization. In the words of Orlikowski,

Technology is the product of human action, while it also assumes structural properties. That is, technology is physically constructed by actors working in a given social context, and technology is socially constructed by actors through 
the different meaning they attach to it and the various features they emphasize and use. However, it is also the case that once developed and deployed, technology tends to become reified and institutionalized, losing its connection with the human agents that constructed it or gave it meaning, and appears to be part of the objective, structural properties of the organization. (Orlikowski 1992a: 406)

A structurational model is particularly valuable for studying technology and organizations because it "sensitizes the observer to look for ongoing redefinition among structure, action, and technology" (Weick 1990: 18); the institutionalization of technology within an organization is an outcome of the interplay among these variables. This lends to institutionalism a more process-oriented perspective that allows us to consider the dynamics of institutions-in-formation and re-formation.

\section{Blending Lenses: Institutionalism \& The Structurational Model of Technology}

Clearly, there is a natural confluence between theories of institutionalization and structuration. Both address the ways in which certain social practices are routinized and both emphasize the facilitating and constraining features of these routines. Indeed, Barley and Tolbert (1997) have argued for further exploration into the connection between these two theories. Unfortunately, these theories are seldom applied in concert to the analysis of organizations and technology. Scholars employing the structurational model of technology have neglected non-hierarchical forms of organization and researchers focusing on institutionalism have paid scant attention to the role of technology. 
But this combination has the potential to reveal a great deal about the mutual influence of technology and organizational characteristics. Since Barley's 1986 work on the introduction of CT scanners in the radiology departments of two distinctly different hospitals it has become evident that use of technology is shaped by institutional characteristics and that technology itself can "occasion different organizational structures by altering institutionalized roles and patterns of interaction" (pp. 78). As Barley discovered, identical technologies can lead to different structural outcomes and this variability is a function of how the technology interacts with the social system rather than an attribute of the technology itself. Given the variety of organizational contexts in which a given technology may be introduced, even identical technologies can be institutionalized in radically different ways or may have disparate impacts on different organizations or units. Unfortunately, there are a limited number of studies exploring this topic. Moreover, there is no work exploring the institutionalization of technology within networks of organizations, nor within the nonprofit sector. This is a unique avenue that merits specific study.

This thesis will blend insights from these two perspectives to explore a hitherto unstudied area. The combination of ideas from institutionalism and structuration forms a trenchant instrument with which to explore the interaction among technology, human action, and organizational properties. Technology, as both an instrument and product of organizational activity and organizational form, will be investigated through an exploration of the recursive relationship among these variables in networks of nonprofit organizations, permitting a more nuanced understanding of how different networks of nonprofit organizations engage with, and are subsequently shaped by, information and communication technologies. 


\section{Research Questions}

The following three research questions are guiding this project:

1. How are information and communication technologies institutionalized in the network?

a. What are the roles and experiences of coordinating agencies?

b. What are the roles and experiences of network members?

2. How do network characteristics shape the use of information and communication technologies?

3. How do information and communication technologies shape network characteristics?

\section{Defining the Terms}

Information and communication technologies: As noted above, information and communication technologies are understood to include any devices that will store, retrieve, manipulate, transmit or receive information electronically in digital form. Within this broad category this research project concentrates on internet-based technologies and software (e.g., email, websites, listservs, discussion boards, shared document editors, chat rooms, instant messaging, etc.). The focus is on the means by which these technologies are used by the coordinating agency to support and engage with their membership.

Network: A network is understood to be any association of independent nonprofit organizations working in a common subsector (e.g.. Health, Arts, Sports and Recreation, etc.) that is served by a coordinating agency - i.e., a third party "hub" or convening organization whose mission is to advance the interests of the network members. Although these organizational structures go by many names - alliances, coalitions, councils, partnerships, associations, etc. - they are all types of network structure, comprising independent units that 
have voluntarily entered into collaborative relationships for their mutual benefit.

Network characteristics: This term is intended to capture the wide array of factors that characterize and influence organizational structure and behaviour. This includes, but is not limited to, operational environment, funding, history, structural arrangements, policies, goals, activities, and organizational culture. 


\section{Research Methodology}

The case studies approach is particularly well suited to the intentions of this project, which are exploratory and descriptive. Case studies are used in circumstances "where the investigator has little control over events, and when the focus is on a contemporary phenomenon within some real-life context" (Yin 1989: 13). As such, the case study approach is appropriate to a study of networks of nonprofit organizations. Nonetheless, there is a common instinct among case study researchers to justify their choice of methodology. As a qualitative technique, case studies have been criticized for their inherent subjectivity, lack of rigour, and an inability to generalize beyond the cases at hand. While these arguments have some merit, there are circumstances in which case studies are not only justified but necessary. The study of emerging phenomena requires a flexible research tool capable of probing into contextual circumstances to produce the detailed data necessary for holistic understanding. Moreover, when conducted properly, case study research adheres to specified procedures which ameliorate accusations of inordinate flexibility or subjectivity (Yin 1989).

Broadly, "qualitative research is aimed at the description of individual cases and the discovery, formulation and typification of characteristics with a view to theory building" (Van den Bulck 2002: 68). Although case studies inevitably involve some trade-offs with respect to generalizability, they do produce inroads into theory development and help to define an agenda and direction for further research. This is particularly so when a collective case studies approach is adopted. The decision to study multiple cases relies on the belief that "understanding them will lead to better understanding, perhaps better theorizing, about a still larger collection of cases" (Stake 1994: 137). As such, it is the explicit purpose of this research project to produce a "thick description" of the cases at hand with the aims of 
contributing to theories of technology and organizations and identifying avenues for further exploration and exposition.

\section{Selecting the Cases}

A lengthy list of potential case study candidates was created through three main sources: The Ontario Ministry of Citizenship and Immigration's Volunteer @ction.Online listing of funding recipients; contact with personal acquaintances in the nonprofit sector; and, the investigator's own collected lists of nonprofit organizations. Based on the research interests of the investigator, the following criteria were applied to the initial list of candidates:

- Coordinating agencies must have a specific mandate to support independent nonprofit and voluntary organizations

- Member agencies must be autonomous - i.e., no legal or contractual obligations to the coordinating agencies

- Coordinating agency websites must show evidence of ICT use to support network members

- Advocacy (i.e., goal- or policy-oriented) networks are excluded

- Single organizations with subunits in multiple geographic regions (i.e., a federative model) are excluded

- Coordinating agencies must be willing to endorse the project and facilitate access to network members

- For the purpose of parity, three networks covering the same geographic region are preferred

- Coordinating agencies located in Toronto are preferred so that on-site interviews can be arranged

- Case study candidates should represent three different nonprofit subsectors

Five cases were identified as suitable for the research study based on the application of the above criteria to the initial list of potential candidates. Two of these coordinating agencies operated in the employment sector and it was decided that only one should be involved in the 
study. After further investigation, another candidate was found to have an insufficient number of members to ensure that adequate data could be collected. This further refinement identified the following three candidates, which have participated in the study:

- Ontario Association of Youth Employment Centres (OAYEC)

- Ontario Council of Agencies Serving Immigrants (OCASI)

- Ontario Association of Children's Aid Societies (OACAS)

\section{Data Sources}

This thesis includes a mix of qualitative research methods, striving for a holistic interpretation of the cases under review. Resting on the assumption that "case studies are likely to be much more convincing and accurate if they are based on several different sources of information, following a corroborating mode" (Yin, 1999: 98), the following data sources were used in the research project:

Documents: All available documentation from the organization websites was downloaded and reviewed. Representatives of the coordinating agencies were also asked to provide as much documentation as possible about the organization, including annual reports, operating budgets, organizational charts, membership policies, extant research, and communication and meeting records. The investigator also conducted a library search to identify any third-party documentation about the networks, although this process revealed only press releases and references to policy positions. A complete list of documents reviewed for each case is available in Appendix A.

Websites: Each of the participating networks had at least one website. The websites were reviewed for content, structure and features. The content of public access discussion boards 
were analyzed and member-only discussion boards were reviewed where access was granted by the coordinating agencies. Statistics of website usage were also reviewed where available. Appendix B contains the site maps of each of the participating agencies main websites.

\section{Interviews with representatives of coordinating agencies: Thirteen in-person, semi-} structured interviews have been conducted with representatives of the coordinating agencies. In all cases, the Executive Dircilurs were interviewed along with three to four other staff members who were in a p.w11w.11 l. comment on member relations or technology deployment

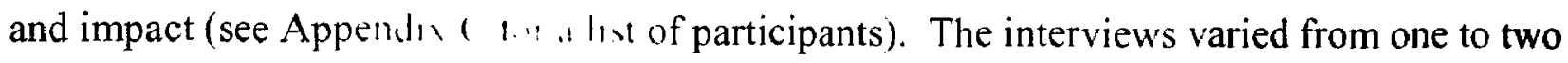

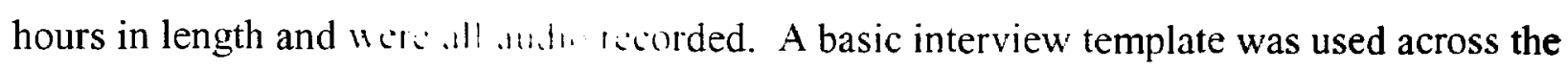
three cases and the diffel.m. sample in Appendix D, $1 / 1,1.1 . \cdots$ intatives of the coordinating agencies consented to using their real names in this repunt

Surveys of representatives of network members: Semi-structured telephone surveys have been conducted with members of each of the participating networks. An endorsement letter apprising network members of the research project was sent by the coordinating agencies to the principal contact in their member agencies; in two cases by post and in one case by email ${ }^{3}$ (see sample in Appendix H). The investigator called within two weeks of receipt of the endorsement letter to arrange thirty-minute telephone surveys.

Efforts were made or ensure as adequate as possible representation of the membership, seeking variety in region and agency size, and other key variables specific to each case as identified through the coordinating agency interviews and document review. An electronic file

\footnotetext{
${ }^{3}$ The Executive Director of OAYEC suggested that email would be a more appropriate and effective medium for contacting OAYEC's members.
} 
containing member contact information was provided by each of the coordinating agencies. This file was sorted by region and the investigator began calling the members, in the order they were sorted (alphabetically by agency name) within each region. Initially, no messages were left; members were called in order until at least one member per region had consented to the survey. At that time, the representation was reassessed and more targeted calls were made (for example, in the case of OCASI both region and participation in the Immigrant Settlement and Adaptation Program (ISAP) were key variances. Therefore, once one member from each region had consented to the survey, the investigator determined whether these agencies were ISAP funded and then endeavoured to contact another agency in the same region with the opposite ISAP designation). Finally, as the member surveys progressed and other variances became evident, or certain comments required further investigation, the investigator made targeted calls to probe these issues and characteristics more deeply.

Given the size of the membership and the number of staff working at the member agencies (varying from four to 400 ) it was realized quite early in the research process that the investigator would be constrained in his ability to solicit the perspectives of staff at multiple levels within the agency. It was therefore decided that the Executive Directors would be the principal contact but that they would be asked about staff use of technology. As part of the email confirming the survey appointments, respondents were asked the following: "If you have the opportunity, it would be helpful if you could speak with your staff to get an idea of who is using the [name of network] website(s) and the reasons why they are doing so." This issue was then probed as part of the survey. In the initial contact with OACAS Executive Directors, four of the respondents inquired about inviting another senior level staff member to participate 
in the survey. This request was approved and four of the OACAS surveys were conducted with the Executive Directors and a second staff member.

Additionally, in two of the cases - OCASI and OACAS - a follow-up email was sent to the respondents to solicit additional staff reactions (See Appendix F). This was done based on an existing infrastructure to support front-line staff in these two cases (this was not the situation for OAYEC). Therefore, in the case of OACAS, Executive Directors were sent an email survey with the request that it be forwarded to supervisors of OACAS front-line staff. This email surveyed the Front-Line Staff Supervisors on their own use of the OACAS Member's website and inquired about use of the website among their staff. Twenty-four responses were received, 19 of which were from a single agency. Similarly, Executive Directors of OCASI's member agencies were sent an email survey with the instruction to forward the questions directly to their front-line staff. These questions inquired about frontline staff use of the OC.ASI Settlement.Org at Work website and four responses were received.

Approximately fourteen members of each network participated in the interviews and all but a few of the calls were audio recorded (see Appendix C for a complete list of member respondents by case). As with the interview questions for representatives of the coordinating agencies, a basic interview template was modified to suit each of the three cases (see sample interview questions in Appendix E).

Ethnography/Focus groups with network members: At the outset of the project a request was made to the Executive Directors of each of the coordinating agencies to moderate a focus group with members. Due to the expense of hosting focus groups, the difficulty of getting adequate participation for student research, and the challenge of reaching members across the province, the investigator requested that, if possible, a focus group be added to an 
existing membership meeting. Two opportunities arose to observe and participate in member meetings. The first was a meeting of OAYEC's Central Region Executive Directors. The investigator observed the entirety of this meeting and was given the opportunity to conduct a brief 30-minute focus group with the nine attendees. Attendees were also given a short paper survey that repeated some of the scale questions used in the member telephone survey.

The second opportunil! wals a meeting of the OACAS Inter-Agency Human Resource Committee, comprising [ Mrik, w and Managers of Human Resources from 25 of OACAS' 52 member agencies from ack.... th. prowince. The investigator observed the portion of the meeting relating to the $11 u m 1.11$ R $\cdots$ urces Electronic Forum and was given the opportunity to ask a few questions of th. mi.m.... Detailed notes were taken during both meetings and a tour of the member agem! wh.1 the meeting was held, was provided.

Table 1. Summary of Ibala suurce by Case

\begin{tabular}{|l|c|c|c|}
\hline \multicolumn{1}{|c|}{ Data Source } & OAYEC & OCASI & OACAS \\
\hline $\begin{array}{l}\text { Number of Documents } \\
\text { (See Appendix A for complete list of documents) }\end{array}$ & 25 & 18 & 21 \\
\hline $\begin{array}{l}\text { Number of Websites } \\
\text { (See Appendix B for site maps) }\end{array}$ & 1 & 2 & 2 \\
\hline $\begin{array}{l}\text { Number of interviews with Staff at } \\
\text { Coordinating Agencies } \\
\text { (See Appendix C for list of respondents) }\end{array}$ & 14 & 16 & 4 \\
\hline $\begin{array}{l}\text { Number of Telephone Surveys with Principals } \\
\text { of Network Member Organizations } \\
\text { (See Appendix C for list of respondents) }\end{array}$ & N/A & 4 & 23 \\
\hline $\begin{array}{l}\text { Number of Email Surveys Completed by } \\
\text { Staff of Network Member Organizations } \\
\text { (See Appendix C for list of respondents) }\end{array}$ & 1 & N/A & 1 \\
\hline $\begin{array}{l}\text { Number of Meetings Attended I } \\
\text { Focus Groups Held }\end{array}$ & 4 & 5 \\
\hline
\end{tabular}




\section{Data Analysis}

All the documents gathered were diligently read and detailed notes were taken. For each case, an electronic file was created and illustrative or important text was excised from the documentation and added to the file. Website statistics were accessed in two of the three cases and key findings from this data source (e.g., most visited web pages, most downloaded documents, etc.) were also added to the file, as was website content and a description of the website features and structure. Following this process each case had a 25-30 page file containing excerpts gathered through the documentation and website review. This file was coded as part of the analysis process.

Notes were made during each of the interviews. All interviews with representatives of the coordinating agency were audio recorded and transcribed by the investigator. Additional notes were made in the margins of the transcripts during this process. No transcripts were made of the member interviews but detailed notes were taken and the audio recordings were used to verify statements of the participants. All transcripts and handwritten notes were content analyzed. Twenty-three codes were used in this process and were primarily grouped into three categories: Network Characteristics (statements describing the coordinating agencies, members, their relationship and the operational environment); Technology Deployment and Use (statements on the experiences of implementing technology, including intended benefits, challenges and changes in use); and, Technology Impact (statements addressing the impact of technology on the coordinating agency and network members). The codes were based on the research questions and also emerged from the interviews and the coding process itself (see Code Book in Appendix G). Member responses were colour coded 
by major defining variables (e.g., region) so that the impact of these factors could be more easily assessed.

Once all of the material, notes and transcripts were coded, each case had an electronic file of 100-130 single-spaced pages. The cases were analyzed separately to ensure that the findings were not influenced by those of the other cases. The data within each code was grouped and reviewed for emergent themes and patterns. Because the code book was developed out of the research questions the grouped responses within each code could be easily assigned to the questions. However, given the abundance of data only the most salient themes, corroborated by multiple sources, were introduced to the discussion below.

Originally, the research project considered the role of technology rather broadly. As the analysis proceeded, however, it became apparent that it was not possible to discuss and analyze technology in this way. The research required a separate focus on each of the specific technologies employed in the network as they were institutionalized differently and to varying degrees. It was also originally intended that the findings reported below would be organized by research question to enable greater comparison among the three cases. However, the investigator felt this interfered with the ability to appreciate each case holistically before drawing conclusions about the findings. Moreover, while the abbreviations and circumstances of each case are of intimate familiarity to the researcher, the reader might have trouble appropriately differentiating among the cases if they were to be interspersed.

The following section summarize the research findings. An initial table provides an overview of the network characteristics and is followed by separate findings for each case, organized by research question. The research findings are enlivened with descriptive or representative quotes from the research participants (see Appendix $C$ for a list of symbols used 
for respondents). These sections are followed by a discussion that enables cross-case comparison and situates the findings among relevant literature. 


\section{Research Findings}

\section{Case Descriptions}

The following table provides an overview of the key characteristics and technology strategies of the three participating networks:

Table 2. Overview of Network Characteristics

\begin{tabular}{|c|c|c|c|}
\hline & OAYEC & OCASI & OACAS \\
\hline Sector & Youth Employment & $\begin{array}{l}\text { Immigrant and Refugee } \\
\text { Settlement }\end{array}$ & Children's Aid \\
\hline Founded & 1988 & 1978 & 1920 \\
\hline Mission & $\begin{array}{c}\text { OAYEC supports and } \\
\text { advocates for a sustainable } \\
\text { youth employment delivery } \\
\text { network. }\end{array}$ & $\begin{array}{l}\text { The mission of OCASI is to } \\
\text { achieve equality, access and } \\
\text { full participation for immigrants } \\
\text { and refugees in every aspect } \\
\text { of Canadian life. }\end{array}$ & $\begin{array}{l}\text { OACAS, in support of its members, } \\
\text { is the voice of child welfare in } \\
\text { Ontario, dedicated to providing } \\
\text { leadership for the achievement of } \\
\text { excellence in the protection of } \\
\text { children and in the promotion of } \\
\text { their well-being within their families } \\
\text { and communities. }\end{array}$ \\
\hline Core Activities & $\begin{array}{l}\text { Knowledge Transfer; Public } \\
\text { Policy; Professional } \\
\text { Development; Strategic } \\
\text { Communications }\end{array}$ & $\begin{array}{c}\text { Advocacy; Technology; } \\
\text { Public Education; } \\
\text { Policy and Research; Training } \\
\text { and Professional } \\
\text { Development }\end{array}$ & $\begin{array}{c}\text { Knowledge and Information } \\
\text { Services; Accreditation; } \\
\text { Professional Development; } \\
\text { Advocacy }\end{array}$ \\
\hline $\begin{array}{l}\text { 2003-4 Operating } \\
\text { Budget }\end{array}$ & $\$ 1.7$ million & $\$ 2.4$ million & $\$ 2.5$ million \\
\hline $\begin{array}{l}\text { Number of Permanent } \\
\text { Employees }\end{array}$ & 5 & 15 & 32 \\
\hline $\begin{array}{l}\text { Number of Member } \\
\text { Organizations }\end{array}$ & 70 & 170 & 52 \\
\hline $\begin{array}{l}\text { Diversity of Member } \\
\text { Organizations }\end{array}$ & $\begin{array}{l}\text { Moderately heterogeneous. } \\
\text { All members provide youth } \\
\text { employment services but } \\
\text { many are multi-service } \\
\text { agencies that provide } \\
\text { additional services to youth } \\
\text { or to other populations. }\end{array}$ & $\begin{array}{l}\text { Extremely heterogeneous. } \\
\text { Member organizations offer } \\
\text { diverse services to immigrants } \\
\text { and refugees, such as legal } \\
\text { services, family counselling } \\
\text { and language training. }\end{array}$ & $\begin{array}{l}\text { Extremely homogenous. All } \\
\text { members are Children's Aid } \\
\text { Societies or Family and Child } \\
\text { Services Agencies legislated by the } \\
\text { provincial government. }\end{array}$ \\
\hline Membership Fees & $\begin{array}{l}\text { \$750 Full Membership; } \\
\text { \$650 Auxiliary Membership }\end{array}$ & $\begin{array}{c}\text { Sliding scale fees from } \\
\$ 0-\$ 750\end{array}$ & $\begin{array}{l}\text { Based on percentage of member } \\
\text { operating budgets; "hefty" }\end{array}$ \\
\hline
\end{tabular}




\begin{tabular}{|l|c|c|c|}
\hline Membership Structure & $\begin{array}{c}\text { Members are divided into } \\
\text { four geographic regions: } \\
\text { Central, Southwest, Eastern } \\
\text { and Northern. }\end{array}$ & $\begin{array}{c}\text { Members are divided into } \\
\text { seven geographic regions: } \\
\text { Toronto, Central East, Central } \\
\text { West, South, Eastern, North, } \\
\text { and West. }\end{array}$ & $\begin{array}{c}\text { Members are divided into } \\
\text { six geographic regions ("Zones"): } \\
\text { Central, Eastern, Northeast, } \\
\text { Northern, Southwest, and Grand } \\
\text { River. }\end{array}$ \\
$\begin{array}{l}\text { Members are also divided on the } \\
\text { basis of staff role (e.g. Human } \\
\text { Resources professionals, Directors } \\
\text { of Training, etc.). }\end{array}$ \\
\hline $\begin{array}{l}\text { Year that Technology } \\
\text { Strategy was Initiated }\end{array}$ & 2001 & 1997 & 2001 \\
\hline $\begin{array}{l}\text { Degree of } \\
\text { Dependency on } \\
\text { Government Funding } \\
\text { for Technology } \\
\text { Development }\end{array}$ & High & High & Low \\
\hline $\begin{array}{l}\text { Degree of Member } \\
\text { Involvement in } \\
\text { Technology Strategy }\end{array}$ & High & High & Low \\
\hline $\begin{array}{l}\text { Degree of Technology } \\
\text { Training and Support }\end{array}$ & Moderate & Low & Moderate \\
\hline $\begin{array}{l}\text { Degree of Technology } \\
\text { Promotion }\end{array}$ & Moderate & High \\
\hline
\end{tabular}




\section{Case \#1: Ontario Association of Youth Employment Centres (OAYEC)}

\section{Research Question \#1}

How are information and communication technologies institutionalized in the network?

A. What are the roles and experiences of coordinating agencies?

B. What are the roles and experiences of network members?

OAYEC's movement toward an electronic platform to communicate with and support its membership began with a grant from the Volunteer $@$ ction.Online $(\mathrm{V} @ 0)$ program in 2001. In that proposal, OAYEC explicitly indicates the intent of the new site: "By using dynamic self-publishing tools that are interactive, OAYEC's website content will become decentralized and member-driven, allowing OAYEC to shift its role from one of project coordination to information facilitator. The shift is illustrated by the diagram below."

Figure 2. OAYEC Technology Strategy

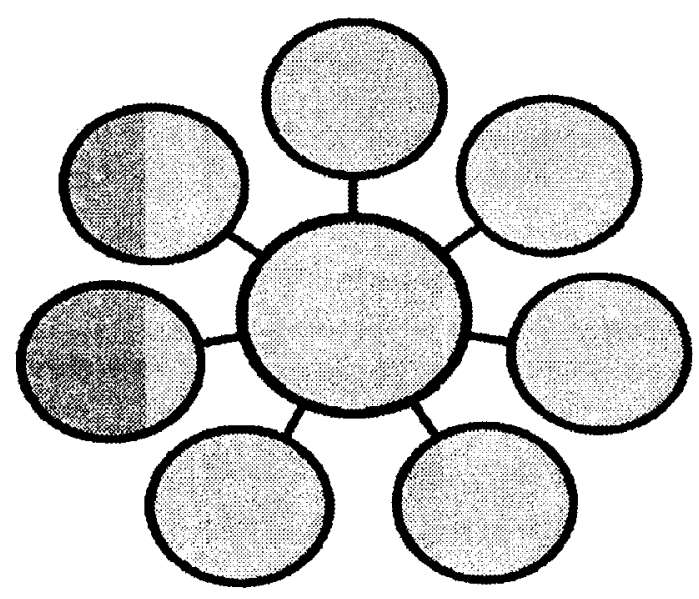

Before

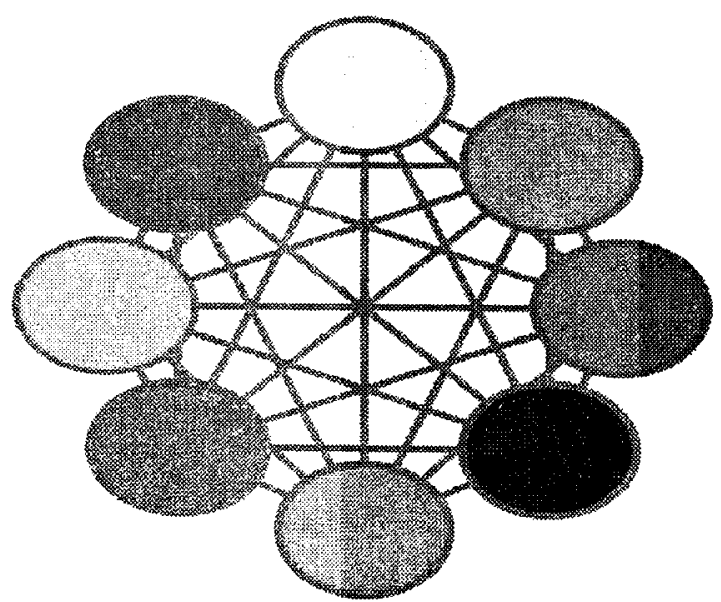

After

This model was not the brainchild of OAYEC staff but of a consultant group hired to assist in the development of the V@O application. The goal was to move away from a hub model to 
one in which OAYEC assumed a facilitative role, building and supporting an infrastructure that fostered bilateral communication and exchange among the membership. However, none of the staff currently at OAYEC were involved in the development of the proposal, the previous Executive Director having retired in the intervening years. A new hire, DY, assumed responsibility for leading the project after inheriting the vision from the consultants and former staff:

So when I stepped in there was this map of what particular pieces were supposed to be part of the website and the internet strategy. But when I came in I found that there wasn't enough work done around researching what the needs really were, like enough assessments around talking to members themselves, really analyzing what the organization itself needs and figuring out what pieces would really be helpfil for the organization at that point. (DY. Research and Communications)

While in some respects constrained by the vision laid out in the proposal, DY began by soliciting member input into site design and development. In line with OAYEC's philosophy of member-driven activities, an invitation was extended to all members to join an Electronic Advisory Committee that would guide the site development. Composed of diverse members from all four regions as well as representatives of OAYEC and the consultant group, the aims of the Advisory Committee were both to ensure that the project would meet the needs of OAYEC's members and to help secure buy-in to the goals of the project. Through telephone interviews and paper surveys DY also solicited feedback from the broader membership to get a sense of their technological facility and interests.

A key component of the proposal was training and support for the membership. DY gave presentations at the regional managers meetings and at conferences, and convened eleven training workshops in regions across the province to train staff at member agencies in how to use the tools OAYEC had developed and to assist them in integrating the internet in their work 
with youth (Volunteer @ction.Online Final Report 2002). The current uses of the revamped

site, however, do not necessarily match their original intent. The following Table outlines the different technologies employed within the OAYEC network, indicating their initial purpose and subsequent use or modification by members.

Table 3. OAYEC Network Technology

\begin{tabular}{|c|c|c|c|}
\hline Technology & Description & $\begin{array}{c}\text { Original Intent of } \\
\text { Coordinating Agency }\end{array}$ & Modification and/or Use by Members \\
\hline $\begin{array}{l}\text { Shared } \\
\text { Resources } \\
\text { Database }\end{array}$ & $\begin{array}{l}\text { A dynamic } \\
\text { database of youth } \\
\text { employment } \\
\text { resources }\end{array}$ & $\begin{array}{l}\text { Active contribution of } \\
\text { content and ongoing use } \\
\text { by member agencies. }\end{array}$ & $\begin{array}{c}\text { Member agencies do not contribute to the } \\
\text { database, primarily due to lack of resources. } \\
\text { This section of the site is static and minimally } \\
\text { used. }\end{array}$ \\
\hline Website & $\begin{array}{l}\text { Contains events, } \\
\text { news and jobs } \\
\text { listing features }\end{array}$ & $\begin{array}{l}\text { Active contribution of } \\
\text { content and ongoing use } \\
\text { of these features by } \\
\text { member agencies. }\end{array}$ & $\begin{array}{l}\text { Members do not contribute to these features of } \\
\text { the website. The website is rarely accessed by } \\
\text { members and is primarily used to obtain contact } \\
\text { information of other member agencies. }\end{array}$ \\
\hline Workspaces & $\begin{array}{c}\text { Discussion Boards } \\
\text { with varying levels } \\
\text { of access }\end{array}$ & $\begin{array}{l}\text { Topic-specific themes to } \\
\text { facilitate exchange } \\
\text { among members. }\end{array}$ & $\begin{array}{l}\text { Topic-specific boards are completely unused. } \\
\text { Discussion boards were reconceived as } \\
\text { Workspaces to enable geographically dispersed } \\
\text { groups working in a common area to } \\
\text { communicate. The Southwest Managers } \\
\text { Workspace and Northern Managers Workspace } \\
\text { have seen tremendous success and are used to } \\
\text { discuss a variety of operational, sector } \\
\text { and project-specific issues. }\end{array}$ \\
\hline Updates & $\begin{array}{c}\text { Quarterly email } \\
\text { bulletin }\end{array}$ & $\begin{array}{l}\text { To provide ongoing } \\
\text { sector and OAYEC- } \\
\text { specific information } \\
\text { to members, and } \\
\text { to drive members } \\
\text { back to the site. }\end{array}$ & $\begin{array}{l}\text { Original e-bulletins were relaunched as Quarterly } \\
\text { Policy Updates and Quarterly Knowledge } \\
\text { Transfer Update in response to member's } \\
\text { preferences. Members generally value the } \\
\text { Updates and indicate it occasionally links them to } \\
\text { the website. }\end{array}$ \\
\hline Email & Electronic mail & $\begin{array}{l}\text { To facilitate member } \\
\text { involvement in the } \\
\text { development of } \\
\text { policy positions. }\end{array}$ & $\begin{array}{l}\text { The network uses email for policy participation } \\
\qquad \text { as it was intended. } \\
\text { The Eastern region has institutionalized email as } \\
\text { a means for inter-agency communication. }\end{array}$ \\
\hline
\end{tabular}

Two primary findings concerning the institutionalization of technology emerge from the experiences of the OAYEC network. The first is the high degree of influence that members have on the institutionalization of technology in the network. For example, the 
original V@O proposal envisioned the Shared Resources Database as an opportunity for member agencies "to share news. events and resources using same application as the Content Sharing Constellation [a shared database of employment-related information to which several provincial associations contribute]" (Volunteer @ction.online Program Application 2001). However, OAYEC quickly ran into problems when it encountered the challenge of finding ten member agencies with the inkisis and financial resources to join the partnership. The Content Sharing Constellation partmir wire each umbrella organizations serving Ontario's employment agencies. "h1. (1) 1 : C"s member agencies directly provided services to youth. The fit was simply inapp inpull: In hopes of salvaging the basic concept of a shared database OAYEC decided to concint.n. nnl on the resources aspect of the initiative and an invitation was made to all of OAlHC - m.mhirs to participate in the reconceived resource database.

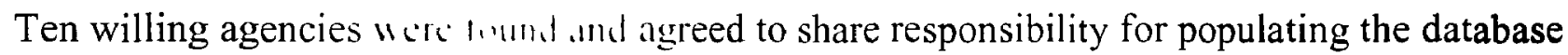
with resources.

Unfortunately, the project's initial success faded over time. Although the database was conceived as an opportunity for members to submit content, that content still required vetting and input by staff at OAYEC as members were unable to access the back-end of the database. Because the initiative was sustained on project funding,

once the project was arer and I didn't have access to the same financial resources it w'asn't as carr to continue to entice folks to use it. And we talked about possibly a monthli fee. which all organizations were at least willing to consider... but w' conddn t recover our costs. and it just ended up petering out (DY, Research and (ommminications).

While the idea was conceptually a good one, the initial submission of resources has ended and the database has become a static feature of the site. In the interviews with members no respondents mentioned the resource library as a reason for visiting the site. 
Similarly, the OAYEC website has not been used by members as originally intended. According to the original proposal, OAYEC envisioned that the news, jobs and events features of the website would be actively used by members who would contribute their own resources and information. However, the content of these features is primarily driven by the Content Sharing Constellation. Although members are able to contribute their own content to these resources, such member supplied content is negligible. As with the rest of the site, the news, jobs and events listed are targeted toward staff at member agencies, but these features haven't garnered the response anticipated at the proposal stage. According to the website statistics, jobs, news and events receive fewer visits than the Workspaces and resources sections of the website. Member respondents identified the Workspaces as their primary reason for visiting the site, with only two indicating they visit for news and no respondents indicating they access the jobs or events features. The overwhelmingly most common response by members regarding their use of the site is to search for contact information of other agencies to provide referrals to clients or to contact their colleagues. This use of the site was not anticipated by OAYEC.

According to the $\mathrm{V} @ \mathrm{O}$ proposal the Workspaces were originally envisioned as topicspecific discussion boards. Based on her observations of other discussion boards in Ontario's employment sector - which she referred to as "virtual dust bunnies" - DY realized that this feature needed to be reconsidered in order to have any positive effect on the OAYEC network:

I realized that the only way they were going to be used is if there are these groups geographically dispersed that have work that needs to be done. and so we decided to reconceive them as workspaces so that it already sort of suggests that it's not about, sort of. in your spare time " $c$ ' mon. let's talk about youth issues. " but instead it is set up for very particular purposes - for small groups to get work done. That was the idea behind them. which I think kept them more alive than they would have otherwise. (DY, Research and Communications) 
OAYEC's Executive Director was fully behind this modification and the Northern region presented the first opportunity for OAYEC to test DY's hypothesis regarded geographically disperse workgroups. This region, which contains the most geographically dispersed membership in the network, was unable to meet in person as frequently as other regions due to the time and expense of traveling. a particularly salient issue following funding cutbacks. When OAYEC learned that representatives of the Northern region had been in discussion with a technology company to solve their dilemma, DY and MW conceived of the Workspaces as a member benefit and offered the Northern region's members free use of a private forum in which they could control access and use. The Northern Managers' Workspace has been actively used since that time and more recently a Southwest Managers' Workspace has seen similar success.

Finally, OAYEC has modified the format of its e-Bulletin in response to the preferences of members, transforming it into a Policy Update and Knowledge Transfer Update, each of which is distributed quarterly. In this case, as with the examples above, we may observe that member's own needs, interests and capacities have had a role in determining how technology is institutionalized in the network. Unlike solitary organizations in which a hierarchical structure enables decision-makers to enforce certain practices upon staff and departments, the autonomy of network members resists such efforts. Thus, the proposal's original vision of an interwoven network model in which OAYEC assumed only a facilitative role met the stubborn reality of member's own interests and capacity limitations.

The second major finding to emerge from OAYEC's experience is that technology is not uniformly institutionalized in the network but finds different roles in different 'pockets' of the network. This can be most readily observed with the OAYEC Workspaces. Only the 
Southwest Managers' Workspace and the Northern Managers' Workspace are being used to any extent. In both cases, managers from these regions have come to rely heavily on the Workspaces as a means of inter-agency exchange and support. Interestingly, representatives of both the Northern and Southwestern regions indicate that they have independently formulated protocols concerning use of the Workspaces. In particular, the Northern Managers committed to avoiding redundant replies ("I agree") and the Southwestern Managers agreed to use the notification fealurc and \it the Workspace whenever a notification was received. The Workspace has taken such. 1 h.l. in the Southwestern region that one respondent reports the region "no longer reall! u...

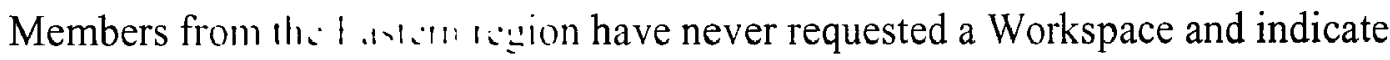
limited familiarity with th: 1..11us: Instead, they have established an email distribution list for the principals at all memher information, concerns. and his practices. When asked why they haven't considered using the Workspaces, respondents gencrally indicated that email seemed much easier as it was immediately accessible from their inbox and did not require any additional effort. The Eastern region has institutionalized email in much the same way as the Northern and Southwestern regional managers have institutionalized the Workspaces, using the technology for ongoing exchange concerning issues relevant to organizational management and service delivery.

The Central region. on the other hand, does not make much use of email and has never made any use of the Workspaces. Although a Toronto JobConnect ${ }^{4}$ Workspace was created in response to a request from a member, there wasn't a single posting "because no one was interested in it at all" (SD, Senior Research Analyst). And, as one member indicates, "I once

\footnotetext{
${ }^{4}$ JobConnect is a provincial employment program delivered by approximately $80 \%$ of OAYEC's member agencies.
} 
sent an email to all members of the Central region to get feedback on an issue...but the Central region doesn't really use email to share or collaborate" (C-1). Thus, technology has been firmly institutionalized in the Northern, Southwest and Eastern regions as a means of interagency communication, while the Central region has not made use of any technology for this purpose. The varying degrees to which the different regions adopt and adapt to the technologies of the OAYEC network appear to be a reflection of the network characteristics. This issue is addressed in the following section.

\section{Research Question \#2}

How do network characteristics shape the use of information and communication technologies?

The characteristics of the OAYEC network have substantially influenced the ways in which technology is deployed and used. ICTs have been integrated into the goals of the Association, supporting OAYEC's mission statement and four core functions. Beginning with OAYEC's advocacy role, technology is used within the network to collaborate with members in the development of policy positions. This use of ICTs not only supports one of the core functions and strategic goals of OAYEC, but also reflects OAYEC's value of an active and influential membership. The core functions of knowledge transfer and strategic communications are also supported through technology as OAYEC has used its communication platform to conduct research and disseminate the findings and other information of relevance to the sector. Indeed, it is only the core function of professional development in which technology has been minimally integrated. Although providing conference registration on the website and some information regarding professional 
development opportunities via the events calendar, these functions are minimal and OAYEC

has not yet investigated e-training or other uses of technology to directly support the professional development of its members.

OAYEC's focus on senior level staff at its member agencies also explains the lack of support given to front-line counsellors through the electronic communication infrastructure.

I'd like to do a lot more for front-line workers. That's tough though. I don't know that we'll ever be able to achieve that unless we start offering a lot more for them. Like I said, a lot of what we offer is geared to managers and a lot of the work we do is done through managers. (SD. Senior Research Analyst)

Because OAYEC serves its network via the principals at its member agencies there has been little opportunity or effort to use technology to directly support front-line counsellors.

Deployment of technology within the Association is also a reflection of the internal leadership and structure of OAYEC. SD, Senior Research Analyst, works closely with JB, Technical Support, to develop OAYEC's technology plans, with SD creating the conceptual plan and IB developing the appropriate technological strategy to support that vision. Within the leadership of OAYEC, however, there has been variable support for technological innovation and implementation. Commitment to technology by OAYEC's Board and Executive Director has been described as "patchy," and in particular senior staff have been accused of being slow to realize that technology requires an ongoing investment of time and resources.

I don't have nearly enough time to devote to [technology]. It 's like the last thing on my priority list. And that's what I'm taking about when I talk about leadership. I'm not criticizing the leadership of this organization at all, I'm just saying that in order to lead an organization you have to identify areas that have the biggest return on their investment in staff time, so if technology and online communication is not necessarily way up there on the list. there's really not a whole lot I can do. I can try and push it as much as I can at an organizational level. that it should be a priority, but at the end of the day, sometimes its just not, often it's just not. So I really have to focus on my communication and 
making a strong case. And if it's already at the bottom of my priority lost. then taking the time to make that case is also very difficult. So that's been a huge frustration and a huge struggle for me. (SD. Senior Research Analyst)

DY similarly complained that the lack of organizational support was a major source of frustration, which she illustrated with the following anecdote:

So we set up an OAYEC member's discussion and the idea was that all communication for all membership would be funneled through this particular Workspace. So here's an example of how OAYEC as an organization didn't quite support the project. Because in order for that to work it means we have to funnel all of our communication there so that OAYEC's members get in the habit of logging on to get the information that they need. But the problem is that several of the staff would say. "well, they 're not going to check it. so I'm just going to email everybody so that way I know that they get the information." so they go out and email the conference proposal or the Ministry announcement. and so it basically says to the members that they don 't need to log in because they re just going to get emailed the information. So it ended up flopping. (DY. Research and Communications)

DY reports that it was difficult to convince OAYEC's leadership that technology was not something separate from the organization's day to day activities but a tool to be integrated with and to augment the work of the Association.

Part of OAYEC's inability to engage in more long-term technology planning and investment is a result of the organizations' dependency on project funding. Like most other nonprofit organizations in Ontario OAYEC does not have discretionary funds with which to pursue such core activities. As noted above, once the funding for the Shared Resources Database ran out the project basically ran into the ground. In a similar vein, OAYEC has used its project funding for the new youth website to hire an expert web developer. Although there is a strong desire to involve this expert in developing a strategy for the organization's website as a whole, commitments to the project leave little time for involvement beyond the task at hand. Such organizational constraints bear upon OAYEC's ability to freely develop and deploy communication technology. 
More generally, the varying operating cultures of the different regions of OAYEC's membership have shaped the deployment and use of technology within the network. In particular, the Central region, covering the Greater Toronto Area, is the least cohesive of the regions, with members seldom engaging with one another outside of the regional meetings, which generally show the lowest attendance of all the regional meetings ${ }^{5}$. Both OAYEC's Executive Director and Senior Research Analyst identify competition for resources and clients as the principal reasons behind the lack of camaraderie and cohesion in the Central region. This observation is corroborated by the fact that the Greater Toronto Area has the greatest density of agencies. This situation does not recur in other regions,

because in the rest of the province you have usually one major youth employment provider per major community, so there's no sense of turf. there's no sense of competition... they re not sharing clients, they're not sharing employers. And so they share very easily with each other. They share information easily. They're always calling each other saying "how' do you handle this issue" They share policies very easily back and forth. that kind of thing. So they do mutual surveys from time to time. they'll send an ad hoc survey around. like to check on staff salaries. So, yeah. a lot of sharing. on fairly intensive operational issues in the rest of the province. but not in Toronto. (MW. Executive Director)

This willingness to collaborate with colleagues among OAYEC's other regions is borne out by the comments of the members themselves. When asked to rate themselves on a scale from one to five in response to the question: "How important is it for your organization to be able to communicate and collaborate with other members of OAYEC?" the Northern region averages a perfect 5, the Southwest region 4.7, the Eastern region 4.63, and the Central region 3.63. The emphasis of the Northern regions' members on communication and collaboration with other agencies may stem in part from their extreme isolation, in which there are few

\footnotetext{
${ }^{5}$ Interestingly, during the Central Region meeting that I attended, six of nine attendees were from outlying areas of the GTA, and only three were from Toronto proper, despite the fact that 16 of 22 central region members operate within city limits.
} 
opportunities to share advice and information. Members outside of the Central Region report frequent contact with one another in between meetings. primarily by telephone and email. The content of their exchanges generally concerns discussions around Ministry guidelines, project delivery, and internal operations and problem solving.

In all cases, members tend to speak primarily with agencies within their own region and, with the exception of the Central Region, report high degrees of collegiality and camaraderie. "Most of my relationships are within the region. We face similar issues and the mechanisms are in place for us to build relationships (N-2)." Interestingly, however, those members who have been in the sector for a long time and in particular have attended several Conferences or participated on the Board, indicate they have formed personal relationships with members from across the province and as a result tend to exchange more frequently with members outside of their region.

The four clusters of members in Figure 3 depict the four regions of OAYEC, three of which are deeply interconnected and one of which (the Central region) is not. The Central region is also depicted as somewhat further from the coordinating agency than the other members of the network, reflecting the relatively lower degree of importance that this region places on its membership in OAYEC. There are some interconnections among the other three regions and all members are relatively closely connected to the coordinating agency. 


\section{Figure 3. OAYEC Network}

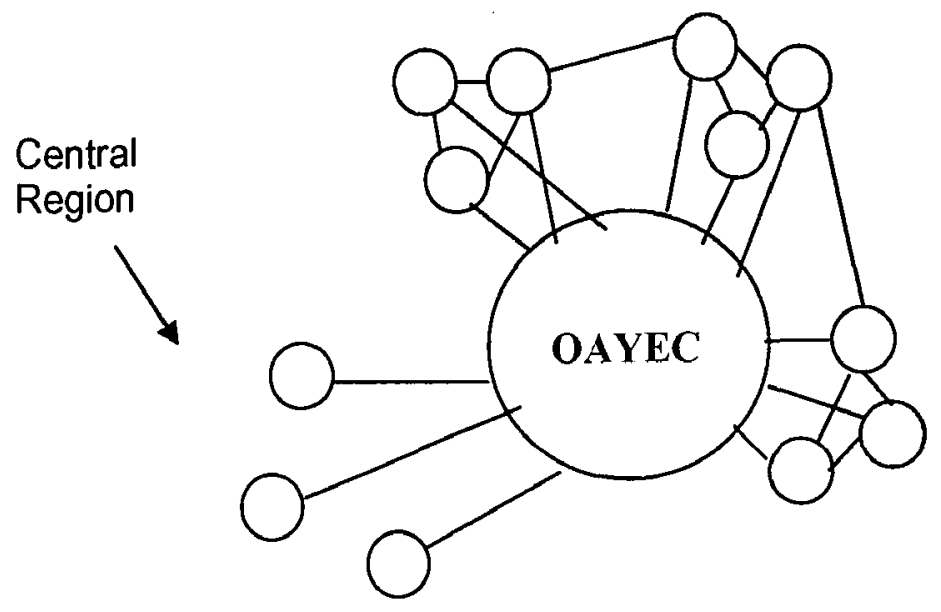

These organizational characteristics clearly shape the institutionalization of technology. The Northern and Southwestern regions, with their high degree of cohesion and strong existing interconnections, have institutionalized the Workspaces as a means of inter-agency communication. The new technology has been of particular benefit in the Northern region where members are geographically separated by significant distances. The Eastern region's use of email also reflects the high degree of cohesion within this region. Eastern region principals have institutionalized email as their preferred means of exchange and have used this technology to buttress their pre-existing relationships. The Central region, on the other hand, makes no use of technology to facilitate regional communication, a reflection of its lack of cohesion and camaraderie. Broadly, the familiarity of all network members with the technology offered by OAYEC reflects the relative closeness between the coordinating agency and its members.

Clearly, the characteristics of the OAYEC network have shaped technology use within the Association. The primary goals and functions of OAYEC are reflected, for the most part, in the technological infrastructure that has been developed. OAYEC's main point of contact in 
its member agencies has been the focus of OAYEC's technology strategy, as is evident from the preponderance of material directed at senior staff. Variable internal support for communication technology has made it difficult to develop long term strategic plans, as has OAYEC's reliance on project funding. Finally, OAYEC's regional structure has influenced the take-up of technology across the network and use of these communication vehicles is a reflection of their geographic distances and respective operating cultures.

\section{Research Question \#3}

How do information and communication technologies shape network characteristics?

The last few years have seen an increasing reliance on technology in the OAYEC, network. This has had some impact on the activities of OAYEC and its members and has affected the relationships they share with one another. With respect to technology's influence on what OAYEC does, this impact can be most readily seen in changes to the ways in which OAYEC conducts its research.

One big way we're using the internet is through online surveys. We use Survey Monkey so we have changed our membership surveys to be all online, and we 've done another bunch of larger surveys. and there's a whole new program called Higher Prospects and that is based on a study of five hundred young people and we ve done a pilot study of over five hundred young people, so that has made a huge difference. We would have never done that scale of surveying without Survey Monkey. (MW. Executive Director)

In addition to increasing the efficiency and reach of its data collection methods, the internet has also helped OAYEC to distribute and disseminate the findings more fully, not only to its membership but to all its target audiences, including government and others working in the employment sector. 
Technology itself has also become an area of interest to OAYEC. As technology has become more prevalent in the youth employment sector OAYEC finds itself supporting and advising its members with regards to technology adoption and use. As indicated above, OAYEC has delivered several technology training workshops to its members and has endeavoured to keep members apprised of how technology could be used to support their work, primarily through the dissemination of original research on the topic.

Members report little impact on their own activities as a result of OAYEC's technological platform. Several members did indicate that the Workspaces and website have improved their access to information, but by and large members were silent when asked how their own agency had changed as a result of technology. Far more considerable has been the impact of technology on their relationships with one another. Again, we see some variance among the different regions, most notably a discrepancy between the Central region members and all others. The Central region had little to say about the influence of technology on their relationship with other members, but representatives from the other regions were overwhelmingly positive in their assessments. In a sampling from each of these regions:

My relationship with other members has been strengthened as a result of electronic communication. I interact more as a result of the Workspace and email. Some postings are strictly business but it also has a sense of friendliness and contributes to increased camaraderie. At our meetings we usually refer back to postings or emails that have been exchanged. (SW-1)

Email has really helped maintain the Eastern region. It has made a dramatic impact on the sense of cohesion and rate of exchange within the region (E-4)

[The Workspace] has allowed me to keep in touch with other OAYEC members, mainly in the North. You may have one or two members that you call. but now with the alternative medium there is more access to more members. (N-4) 
This increased sense of cohesion was echoed frequently. In addition to binding the regions together more closely, ICYTS have also increased the number of members with whom they are in contact.

The Southwest Workspace is new and it has already has widened my network. I used to call a few favourites but now' I get feedback from a broader audience $(S W-5)$.

The Workspaces are much better than the phone. I can reach more people and get multiple perspectives at once ( $S W-3)$

Both communication vehicles have allowed members to be in more frequent contact outside of scheduled regional meetings, allowing them to more easily solicit the advice and perspectives of their colleagues.

All of us in the Southwest have a Ministry consultant. Now instead of having to call that consultant I am able to ask other OAYEC members my question. We're also able to problem solve within the membership and find solutions that may not have been found in the past (SW-3)

The impact has been positive. For example. our organization had funding for a new federal program and I heard that another agency had done something similar. I put out a request on the Workspace and as a result we started working together. I couldn't have accessed this other individual without the Workspace. $(S W-2)$

Similarly, both OAYEC staff and several members report a change to their relationship with one another as a result of technology. Some respondents indicate that they are in more frequent communication with OAYEC. staff as a result of email, whereas previously they engaged with OAYEC only at regional meetings and the annual conference. Members also report greater satisfaction with OAYEC as a result of the communication vehicles that the agency has provided:

Prior to technology the only access I had to OAYEC was at the Conference. Now with email bulletins and the website, you know that OAYEC is doing stuff for you. It reminds you that OAYEC is doing something and tells you you 're 
getting more than a Conference out of membership. It 's important for an isolated community to be drawn into something bigger $(N-4)$.

The Workspaces heighten the sense that OAYEC is there for members. (N-3)

The Workspace is a good reminder that OAYEC exists. Without the

Workspaces it's possible w'e wouldn't remember OAYEC (SW-4)

These comments are perfectly echoed by OAYEC staff who indicate the Workspaces have built goodwill within the membership and have felt like a "gift" from OAYEC to its members, reminding them that OAYEC is "more than a conference planner." Indeed, investment in technology stems mainly from a desire to better serve their members and is employed as an incentive for members to become more engaged in the network. This is particularly observable through use of email to involve members in the Association's position taking.

[Technology has] played a huge role, a huge role. And it has the ability to play an even bigger role. Especially in the area of policy. Becanse I see it as a feedback loop. We are identifying issues from our membership. we 're acting upon them and developing messages that can work for the entire network and feeding them back to the network so they are the messages they can convey back to their communities and at a regional level. or even a provincial level too. (SD. Senior Research Analyst)

For all of its positive impact, there have been some negative outcomes of technology use within the OAYEC's network. The most frequently cited concern raised by both members and OAYEC staff is a reduction in face to face meetings as a result of the increasing reliance on email. This was a particularly salient issue for members in the Northern, Eastern and Southwestern regions, who indicated that there is now "less urgency" to meet and that electronic communication is "displacing" face to face contact. The loss of face to face contact was seen to impede relationship building and one member from the Northern region indicated that the Ministry has been using electronic communication as a justification for cutting 
meeting budgets. Overall, members are meeting in person less frequently as a result of communication technology.

The OAYEC network has been somewhat influenced by communication technology. Although its impact on the activities of members has been minimal, OAYEC has benefited from improved efficiencies in data collection and research dissemination. Most importantly, however, email and the Hurh spuces have had a dramatic influence on three of OAYEC's four regions, binding them clwa. for their challenges. The w.twn hhip between OAYEC and its members has also improved as members report an incrian, 1 ...ness and greater satisfaction with OAYEC as a result of the

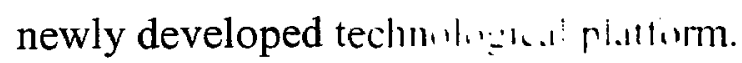




\section{Case \#2: Ontario Council of Agencies Serving Immigrants (OCASI)}

\section{Research Question \#1}

How are information and communication technologies institutionalized in the network?

A. What are the roles and experiences of coordinating agencies?

B. What are the roles and experiences of network members?

Today, OCASI is a leader in technology use and promotion within Ontario's immigrant and refugee settlement sector. OCASI began assuming this role in 1997 when it recognized the disparity in technological infrastructure and computer literacy among its members. Believing that improved access to computers would lead to greater efficiencies, improved service delivery and increased communication within the network, OCASI began advocating for an increase in the technological capacity of the sector. OCASI's advocacy efforts helped launch Citizenship and Immigration Canada's (C.IC) Ontario Administration of Settlement and Integration Services (OASIS) computerization project, which saw an investment of $\$ 12.5$ million in technology and technology support for the immigrant serving sector in Ontario. The intent of the initiative was to build the capacity of agencies delivering the federal government's Immigrant Settlement and Adaptation program (ISAP), Host, and Language Instruction for Newcomers (LINC) programs. According to an independent review of the program,

CIC's investment in technology for the settlement sector has radically transformed the capacities of ISAP/Host-finded agencies and enhanced LINC language training. Without such a significant contribution and commitment$\$ 12.5$ million over four years - the agencies would not have been able to make these technology investments. The OASIS Computerization Project provided not only a technology infiastructure for the settlement sector, but the essential tools and supports that encouraged its integration into the agencies (i.e.. training. technical support. and specialized information via Settlement.org Internet and Extranet sites). (Kerr, Simard and Powers 2002: 12) 
The OASIS Computerization Project helped CIC-funded agencies achieve a degree of technological capacity that would have otherwise been impossible. However, those agencies that were not funded through the ISAP, Host, or LINC programs were unable to benefit from this initiative and had to seek support for technology investments from other sources. For many, this was impossible and they continue struggling with inadequate technological infrastructure and training:

We have very minimal funding. Two thirds comes from fundraising and membership. We cannot afford any capital purchases. We are a very very small agency. Our computers are a real mess. They are all donated. Some have internet access. and the bilingual soffware we put on really seems to mess them up. We are trying to get money for new computers. (T-2-NI)

Our internet access is often down. We have really bad servers ( $N$-2-NI)

Of course, even for those agencies that benefited from the computerization project, adopting and adapting to a computerized environment was no easy task. OCASI staff note the challenge of convincing members that technology was a sound investment and commented on the degree of "hand holding" necessary to build the sector's comfort level with technology. This hesitation seemed to stem from two main factors: The older age of many leaders in OCASI's member agencies and the sector's emphasis on direct person to person contact in the provision of social services.

There was real resistance [to technology] at the beginning. And it was a comfort level. So there was a real sense of "where are we going with this? Why is computerization a priority for OCASI and now for the membership? We seem to be fine using the one computer that sits in the Executive Director's office and the work is getting done." (DD. Executive Director)

And later,

I think the ongoing piece we need to do as a provincial umbrella organization. and with our leader's within our membership. is to continue to change our culture. We need to create a culture where [technology] is part and parcel of. 
the work we do; that settlement work is really not about sitting behind a desk with your client in front of you So for us this is all part of looking at. what are other ways of delivering services? Should we have services available in libraries, or community centres. or in malls where we know there are large immigrant populations? How do we get information out to immigrants and refugees themselves, and how do we make them aware that this social service sector exists that they can access and can help them with their settlement and integration? So I think all of those things are tied in together. (DD. Executive Director)

The OASIS Computerization Project created two key resources which are managed by OCASI and continue to be used to this day. The first is Settlement.Org for Newcomers (www.settlement.org), a public website designed to provide settlement information to the general public, media, prospective immigrants, newcomers to Ontario, and other government and social service agencies. The second, the Settlement.Org Extranet, was established for the exclusive use of CIC-funded organizations and contained information for settlement workers and other agency staff to improve the delivery of services to immigrants. This resource has recently been relaunched as a publicly accessible website under the name Settlement.Org at Work (http://atwork.settlement.org/).

The Settlement.Org websites benefit from advice and direction provided by the Settlement.Org Steering Committee, a broad advisory group of representatives from across the sector who are familiar with technology and online service delivery, including representatives from the Ontario Ministry of Citizenship and from CIC who are able to communicate the government's priorities and identify emerging trends. Initially, the Steering Committee set the strategic direction and planning for Settlement.Org, but as OCASI has developed its internal capacity the group has receded into an advisory body, acting as a sounding board for OCASI's own ideas and providing support and advice on how best to serve OCASI's stated objectives. 
OCASI has also solicited input from its members when developing and deploying technology within the network, acknowledging that the perspectives of the Settlement.Org Steering Committee cannot sufficiently account for the diverse views and desires of the membership. Two technology-specific conferences were convened in the sector and provided OCASI with the opportunity to engage members and to receive feedback on the technology needs and interests of the sector. OCASI also conducted focus groups, surveys and interviews with staff at multiple levels within the member agencies to determine the information architecture and content needs of the two Settlement.Org websites. However, despite their efforts, there is considerable disparity in the relative uses of the two sites, with the Settlement.Org for Newcomers website achieving far greater penetration than its At Work counterpart. The following Table provides an overview of the OCASI network's key technologies, including the two Settlement.Org websites, comparing their original intent and subsequent modification or use by members.

Table 4. OCASI Network Technology

\begin{tabular}{|l|l|c|c|}
\hline Technology & Description & $\begin{array}{c}\text { Original Intent of } \\
\text { Coordinating Agency }\end{array}$ & Modification and/or Use by Members \\
\hline $\begin{array}{l}\text { Settlement.Org } \\
\text { for Newcomers }\end{array}$ & $\begin{array}{c}\text { A publicly } \\
\text { accessible } \\
\text { website }\end{array}$ & $\begin{array}{c}\text { To provide prospective and newly } \\
\text { arrived immigrants to Ontario with } \\
\text { the information they need to settle } \\
\text { into the province. }\end{array}$ & $\begin{array}{c}\text { The site is actively used by newcomers } \\
\text { and by settlement } \\
\text { staff at OCASI member agencies } \\
\text { to assist their clients. }\end{array}$ \\
\hline $\begin{array}{l}\text { Settlement.Org at } \\
\text { Work }\end{array}$ & $\begin{array}{c}\text { A publicly } \\
\text { accessible } \\
\text { website }\end{array}$ & $\begin{array}{c}\text { To provide online community, } \\
\text { professional development and } \\
\text { immigrant-serving agencies }\end{array}$ & $\begin{array}{c}\text { Extranet. Was severely under utilized and } \\
\text { a decision was made to relaunch as a } \\
\text { publicly accessible site in hopes of } \\
\text { increasing use. The new site remains } \\
\text { under utilized with only minimal traffic } \\
\text { from member agencies. Approximately } \\
\text { one third of respondents could not } \\
\text { correctly identify the site. }\end{array}$ \\
\hline
\end{tabular}




\begin{tabular}{|l|l|l|l|}
\hline $\begin{array}{l}\text { Settlement.Org at } \\
\text { Work Discussion } \\
\text { Boards }\end{array}$ & $\begin{array}{c}\text { Discussion } \\
\text { Board }\end{array}$ & $\begin{array}{c}\text { Intended to provide a forum of } \\
\text { exchange for staff in Ontario's } \\
\text { settlement sector. }\end{array}$ & $\begin{array}{c}\text { Almost wholly unused. This lack of } \\
\text { member interest was antlcipated by } \\
\text { OCASI based on their experience with the } \\
\text { Extranet. }\end{array}$ \\
\hline $\begin{array}{l}\text { Settlement.Org at } \\
\text { Work Bulletin }\end{array}$ & $\begin{array}{c}\text { Bi-weekly } \\
\text { email bulletin }\end{array}$ & $\begin{array}{c}\text { Emailed to staff at member } \\
\text { agencies to provide ongoing sector } \\
\text { OCASI-specific information, and } \\
\text { to drive traffic to the At Work } \\
\text { website. }\end{array}$ & $\begin{array}{c}\text { Members generally read the bulletin and } \\
\text { circulate it among agency staff when } \\
\text { received. Some respondents noted that } \\
\text { the Bulletin will lead them to the At Work } \\
\text { site. }\end{array}$ \\
\hline List & email listserv & $\begin{array}{c}\text { To communicate with and consult all } \\
\text { principals at OCASI member } \\
\text { agencies at one time. Some hope } \\
\text { the Issues List would evolve into an } \\
\text { ongoing venue of discussion. }\end{array}$ & $\begin{array}{c}\text { Respondents indicated the Issues List is a } \\
\text { valuable resource that keeps them } \\
\text { connected with OCASI and other } \\
\text { members. All exchanges are initiated by } \\
\text { OCASI and the List has not become the } \\
\text { free flowing discussion it was hoped. }\end{array}$ \\
\hline
\end{tabular}

Again, we may observe that the institutionalization of technology is not simply a matter of members adopting the communicative practices projected and encouraged by the coordinating agency. Members add a complicating layer to the processes of technology institutionalization and have by and large resisted many of the coordinating agencies efforts to institutionalize certain technologies. OCASI has had a particularly difficult time encouraging its members to make ongoing use of the Settlement.Org at Work website. The new site was officially launched in 2004 and hopes were high that it would achieve the goals the Extranet was unable to fulfill, better encouraging OCASI's membership to share information and form a more cohesive community of agencies. The Settlement. Org at Work website was intended to become the information and community-building portal for the entire sector in Ontario, providing the resources, support, and mechanisms for exchange that would allow agencies to better deliver services to their clients.

The results of surveys of network members indicate that the Settlement.Org at Work website is not being used as intended. Of all respondents, $31 \%$ could not identify Settlement at Work (i.e., had never heard of the site or confused it with Settlement.Org for Newcomers), another $14 \%$ had never been to the site or were unable to recall if they had ever visited, and 
another $17 \%$ indicated they access the site less than once per month. Among those who were knowledgeable about the site, the majority visited only when prompted by the Settlement at Work newsletter. Indeed, it is clear that the site is of limited use to the majority of respondents. When those who were familiar with the site were asked why they do not use it more frequently, respondents cited a lack of time, the priority of other matters, and the fact that the information is not immediately relevant to their day to day activities. Clearly, the site has not found a firm role within the network.

When those who correctly identified the At Work website were asked about staff use of the site, there was a fairly even split between those who were aware of staff use of the site and those who were not. Half of the respondents indicated that their staff make no use of the website while the other half indicated that their staff occasionally use the site to access information, resources and job postings. This is in marked contrast to use of the Settlement.Org website for newcomers, as member respondent unanimously cited its value to all levels of agency staff.

When asked specifically about the discussion boards only one of sixteen member respondents had ever used this feature of the website (and that individual was on the Settlement.Org Strategic Advisory Committee!). The vast majority of other respondents were unaware of the discussion boards or were unable to answer the question because they were unfamiliar with the entire Settlement.Org at Work website. Of those who did comment on the discussion boards, there was general accord that the purpose of the boards was to provide a venue of exchange for staff at settlement agencies in Ontario. This perception perfectly matches OCASI's intended purpose of the forums, but the fact remains that the boards are completely unused by respondents: 
I simply don't have the time. There's always a crisis and we don't have time for this sort of thing. (T-3-I)

I've never used them. That takes too much time. (CW-2-I)

I've never used them. I like to sit face to face and see people. not stare at a computer screen. (CW-I-NI)

I have never used discussion boards to exchange information and view sentiment of other staff. Partly because if there was any issue that warranted discussion I would prefer to use email. That's a sufficient and effective means for exchange (E-2-I)

I don 't think they 're a good fit for Executive Directors. They're too busy. They're also a lot older, so maybe in ten years as younger people start taking over $(E-I-I)$

When asked about use of the discussion boards among front-line staff at their agencies respondents indicated that they did not believe their staff was making any use of this feature. This claim was buttressed by settlement counsellors who responded to the email survey. All four of these respondents indicated they had never used the forums, primarily due to time constraints or lack of familiarity with the feature.

OCASI has had mixed success institutionalizing the OCASI's Issues List, a moderated listserv that circulates among all of the principals at OCASI's member agencies. The Issues List began informally in 2001 as OC.ASI sought a mechanism by which to communicate with and consult its entire membership at once. Typically, OCASI will initiate a discussion on the list by posing a question to its members about a "hot topic" or by inviting input into the development of a policy position. Use of the list is relatively infrequent and some of the requests for feedback fall flat, garnering only a minimal response from members. However, in some cases the OCASI Issues List has spurred substantial discussion, most recently around the professional development funding cuts that saw the cancellation of the 2005 OCASI Conference. When seeking advice from its members on how to address this issue, OCASI 
received unprecedented support from its members who rallied behind its lobbying efforts to reinstate the funding. As a feedback mechanism the OCASI Issues List permits OCASI to more easily communicate with its members and to involve them in its decision-making processes. The Issues List has helped ameliorate some of the disappointment felt by OCASI regarding the lack of use of the Extranet and At Work discussion boards, but there is still general consensus among OCASI staff that the Issues List could be used to greater effect. As it exists, the Issues List is a forum for soliciting feedback on specific questions, but has not evolved into a mechanism for sustained communication. OCASI staff remain hopeful that the Issues List can be used as a more general venue for debate and discussion, fostering an increased sense of community and sharing within the sector.

Technology is deployed in various forms within the OCASI network but in all cases is intended to improve the delivery of services among its member agencies. OCASI pursues this goal by deploying technology as an information resource for its members and as a means by which to facilitate exchange with and among members. Still, members have not responded to technology in the precise ways it has been intended, particularly in regard to its role as a venue for inter-agency communication. Despite the sector's commonalities and willingness to work together and collaborate at events such as the annual conference, OCASI has had tremendous difficulty translating this into an ongoing culture of communication. The frustration, and ongoing hope for improvements, is reflected among OCASI staff.

I'd like to see something ased [for exchange among members]. I don't know' that it has to be our discussion area. but I would like to see more discussion. And part of it is use trying to figure out - are we even trying to put the right tool up? Is this the right tool? (MC. Policy Analyst \& Communications Coordinator)

I'd rather it [the OCASI Issues List] be fill. I'd rather people were using it all the time. And I don't know if it's an audience thing. Y'know, you're going to 
get some people who prefer discussion lists and some people who prefer discussion area on websites, or whether particular discussions are better suited for one or the other. But I'd he happy to see the discussion list take off and just kill the discussion area and say, $y^{\prime} k n o w$ ' what, it doesn't work. let it die. And that's fine. If we need to just choose one. then I'm okay with that. We may not have enough people to support two concurrent systems... whatever system we gave them. if they were using it. I would be happy. (CW. Information Technology Transition Coordinator)

I would like to see [members] using [technology] in an interactive manner. Where there will be a combination of personal and electronic contact. But use it in an interactive manner in areas of professional development, policy development. I think we should devise a way that in certain areas we work with certain groups of people. We haven 't found the right way. (PM. Manager. Policy and Programs)

Despite their best efforts, technologies for inter-agency exchange have not been institutionalized within the OCASI network. The OCASI Issues List, while occasionally prompting a strong response and helping network members to feel more intimately connected with OCASI and with one another, has not generated the free flowing and self-sustaining discussion that OCASI staff had intended. The discussion boards have seen even less success and sit mostly unused on the At Work website. Use of the Settlement.Org at Work website varies among its members but most do not have a clear sense of its purpose and indicate that they rarely visit the site, almost exclusively when they are drawn in through the Newsletter. There is no evidence that the relative institutionalization of different technologies is dependent on region or other variables. While the institutionalization of technology is not uniform within the network, with some members making more frequent use of the Settlement.Org at Work website and OCASI Issues List than others, there is no clear pattern that suggests particular types of members are making more use of technology than others. 


\section{Research Question \#2}

How do network characteristics shape the use of information and communication technologies?

The characteristics of the OCASI network have varying influence over the deployment and subsequent use of information and communication technologies. Beginning with its core functions we see only a moderate relationship between OCASI's use of technology and these activities. This relationship is most apparent in the use of the OCASI Issues List to support the network's advocacy work, which respondents identify as their primary motivation for and benefit of membership. Nonetheless, use of technology for this purpose remains unsystematic with no formal provisions in place to guide the use of the Issues List. Professional development, the second most commonly cited reason for joining OC.ASI, does not seem to influence the deployment or use of technology in any substantial way. Although OCASI does offer notification of professional development opportunities on the events calendar of the At Work website, no respondents mentioned this feature as a reason for visiting the site. Still, OCASI has indicated an interest in providing e-training for its members across the province and is currently beginning an online pilot project to teach settlement workers about Ontario's health care system. Other key activities have not had any influence on the use of technology.

The goals of public education and research do not manifest in the use of technology other than the simple fact that information is disseminated through OC.ASI's websites.

The deployment of technology within the network is also a reflection of the human resources of the coordinating agency. Within OCASI a high proportion of staff occupy roles connected to technology. Among these staff are three people-CW, Settlement.Org Content 
Coordinator; DM, Web Coordinator; and, CM, Policy Analyst and Information Coordinator who lead the organization in the strategic visioning of technology use. These three individuals have played a pivotal role in the development and deployment of technology, leading the network with innovative ideas of how to facilitate communication and improve OCASI's support of its member agencies. Generally, the deployment of specific technologies and website features within OCASI is not the result of elaborate planning but the outcome of the collaborative sharing and "playing" among these three technology experts. They will frequently develop and test ideas to determine their worth and will bring the most promising innovations to the attention of managerial staff who will make the final determination of whether an idea should be supported and pursued. Representatives of OCASI's technology team indicate that their technology initiatives are usually supported by all levels of staff at the organization, but do comment that leadership within the organization is not strongly committed to the personal use of technology and therefore does not always model the behaviour that OCASI hopes to see from its members. This failure to wholly embrace and exploit technology is acknowledged by the Executive Director herself.

Perhaps the characteristic with the greatest influence over the institutionalization of technology within the OCASI network is the pivotal role of government funding. Citizenship and Immigration Canada has made a tremendous investment in the immigrant serving sector, outfitting all CIC-funded agencies with internal technological capacity and funding the development of both the Settlement.Org for Newcomers and Settlement.Org at Work websites. Without these initiatives the sector's technological capacity would be far more limited and there is no certainty that any online destinations would have been created. Moreover, OCASI's dominant position as technology leader within the sector has been completely 
determined by CIC's allocation of funding to the organization. Indeed, OCASI's dependence on CIC funding for its technology initiatives is reflected in the relative development and promotion of the two Settlement.Org website. Dependent on CIC for $80 \%$ of its funding, and with very meagre discretionary core funding with which to pursue its own interests. OCASI is at the mercy of the priorities of its funder. Thus, Settlement.Org for Newcomers has been actively promoted throughuut his province while the Extranet and Settlement.Org at Work website have received onl! rel.tucly modest financial and promotional support. This

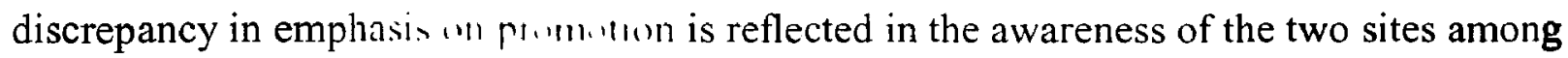
OCASI's members.

The overall structur.l . . miti:uration and culture of the OCASI network provides some additional clues as to the dilliwath (1) ASI has had in institutionalizing certain technologies. As depicted in Figure t. the $(x, 1>1$ network is large and diffuse. Members are relatively distant from OCASI and has: inl limited connections with one another.

Figure 4. OCASI Network

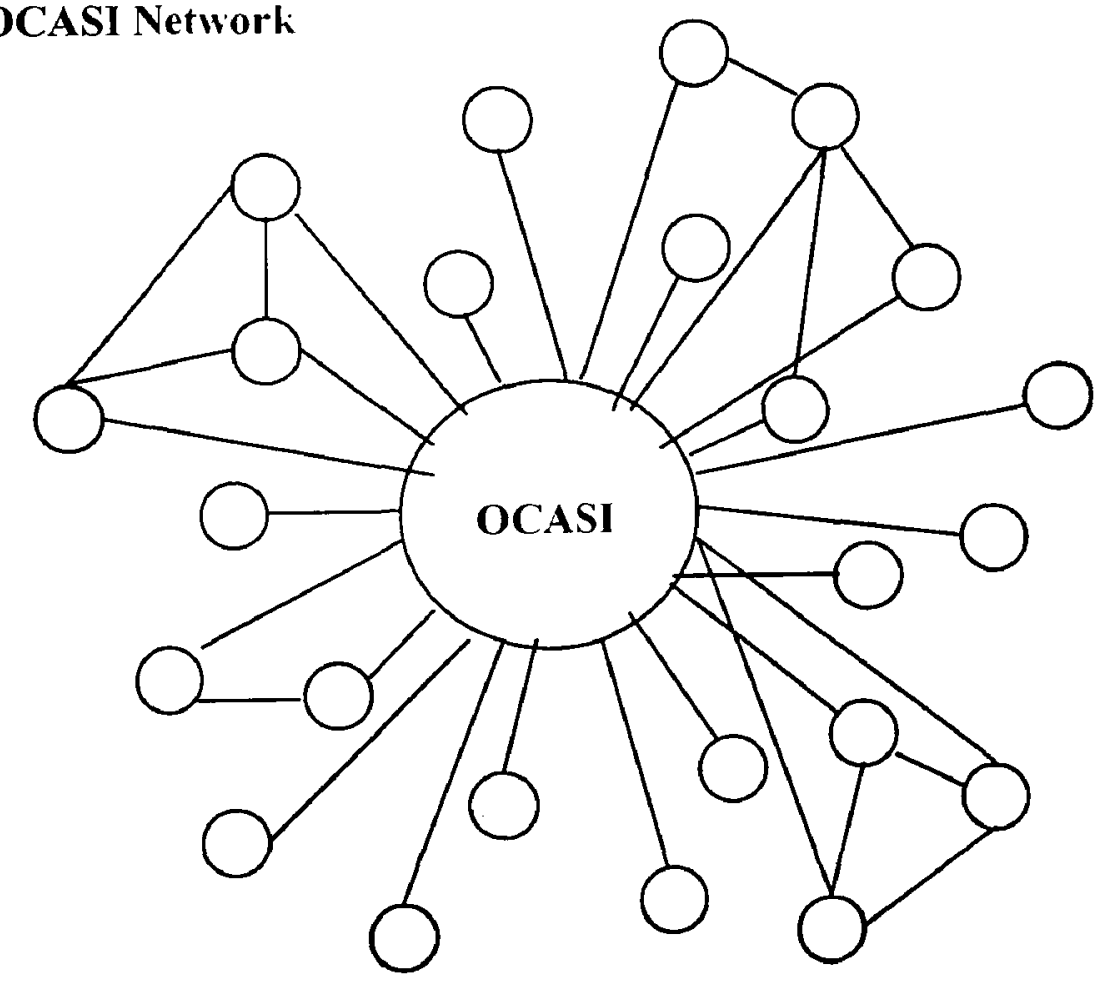




\section{This conclusion is derived directly from the comments of OCASI staff respondents and}

representatives of member agencies. As MC indicates,

[Our relationship with members is] not as good as it could be. I think we do a lot of things without consulting them as well as we should. We assume we know' what their perspective is some times and we don 't really tap into as much what their real positions might be or how to best express those. And it's a diverse sector of members so not everyone will agree. but I think there's a sense from some of the membership that OCASI's communication is not even just one-way. its no-way. They 're not informed enough about what we do and we don't pull enough out of them about what they want us to do on their behalf. So we go ahead on a lot of things assuming it's the position that the sector should take in some ways... and we need to drive the sector in some ways. I think that's important. but we also need to be driven by our members. (MC. Policy Analyst \& Communications Coordinator)

This perceived weakness is buttressed by the comments of members themselves. Although some members indicated a close and important relationship with OCASI, a significant number indicated a more arms-length relationship in which their involvement in the network was negligible:

We speak with OCASI every once in a while. when an issue comes up. Otherwise we don't really speak with them $(T-5-I)$

We don't really see much benefit of our membership. We are a small agency with a tight budget. We ve never sent anyone to [the Annual Conference]. In the past membership renewal was done automatically. but we didn't renew it this year. I really have no contact with OCASI. I once asked for assistance in getting ISAP funding but it never went anywhere. I rely on my own support network of local individuals and agencies (CE-I-NI)

We are a member, nothing hevond. There's no formal collaboration or agencyagency interaction. It's strictly an umbrella body/member relationship (E-2-I)

My lack of CIC funding makes me feel a little disconnected from the network. I can 't attend the meetings that are just for ISAP recipients and we don 't have a budget to attend the conference (W-I-NI)

We have a limited relationship with OCASI. We attend the Western region's meetings occasionally but. other than that. we don thave much contact. (W-2-I) 
In general, relationships among OCASI members were relatively few and relatively weak. Three principle reasons account for this. First is the significant variation of network members, with organizations offering such disparate services as language training, legal assistance, health services, and personal and family counselling. Second, OCASI members are in competition for ever-decreasing pots of funding. causing a strain on member relationships. Third, OCASI has demonstrated only a lukewarm commitment to its own regional structure. OCASI has divided its membership into seven regions but does little to support their interaction as it is incumbent upon the regional representative to convene regional meetings. As a result, regional meetings are irregularly held. with some regions barely meeting at all in a given year. Because this infrastructure is lacking, member respondents generally cite the conference as their key mechanism for interacting with one another. However, this conference is held only once per year and therefore does not foster sustained interaction. Unsurprisingly, most members report that their relations with other agencies in the immigrant and refugee settlement sector have been forged independently of OCASI. The fact that OCASI is unable to consistently support and develop strong and positive offline relationships with and among its members is reflected in the technology:

And as well, the reality at the time [of the Extranet] is that it wasn 't an online expression of what was happening offline, we weren't a cohesive community offline. Again. in person there was lot of sharing in face to face, but as an entity offline. it wasn't really happening. And so the idea that it would just be create online - well. I'm sure you know' schools of thought. when you build an online environment you don't just build it and they all arrive. In some cases it happens organically but it hadn 't already happened and this w'asn't organic, it was kind of a forced structure. So it never took off. (CW. Information Technology Transition Coordinator)

Use of OCASI's technological vehicles reflects the low degree of cohesion in the network. The limited use of the Issues List for ongoing exchange stems from the absence of a pre-existing 
culture of exchange and the lack of institutionalized mechanisms for face to face

communication. The arms-length relation between OCASI and many of its members partially explains members' lack of familiarity with the Settlement.Org at Work website, which is not as essential to their work as the Settement.Org for Newcomers website.

Overall, the institutionalization of technology within the OCASI network is the result of several organizational charicturistics. The networks' collective emphasis on advocacy manifests in the OCASI $1 \backsim 4 \cdots 1$ । 1 a a device used to circulate information on sector-wide issues and solicit feedbaih . 11 p. 14 , positions from its members. However, other

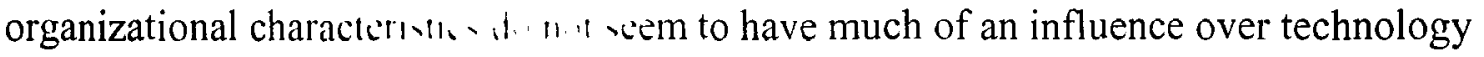
deployment; OCASI's cus .11:11, of professional development, research, and public education are not reflectcit m 1.2 trm ling use. Still, this may be a result of a lack of funding that specifically enables ( ) $M /$ h pursue these activities. OCASI's funding sources have an obvious influence on the dipluyment and development of technology in the network, precluding OCASI's opportunit! to freely employ technology as it envisions. The relative lack of cohesion within the network, evidenced by OCASI's inconsistent commitment to communication with its members, the low priority placed on inter-agency communication by members, and considerable variation among the members themselves, is reflected by the network's under-utilization of technology for collaboration and exchange. Several technologies, most particularly the Settlement.Org at Work website, have the potential for significant impact on the sector but have not yet been institutionalized, a reflection of both the operating culture and relative lack of resources to promote this feature. 


\section{Research Question \#3}

How do information and communication technologies shape network characteristics?

The most significant impact of technology on the OCASI network has been the change in OCASI's role within Ontario's immigrant and refugee settlement sector. OCASI is increasingly regarded not only as an advocacy and professional development organization but as a leader in and champion of technology to support the delivery of services to immigrants and refugees. As indicated by its members,

OCASI's use of technology is a model for my agency. The way they manage and present the information. I like that OCASI is caught up with technology and is helping other organizations to get caught up. (T-4-NI)

OCASI has helped us quite a bit with computerization. (T-3-I)

OC.ASI has received a massive infusion of funding from the federal government to support its technology initiatives. The most visible manifestation of this support is the Settlement. Org for Newcomers website, which itself points toward another impact of technology on the network. Previously, OCASI existed only to serve its members: suddenly, with the development of Settlement.Org for Newcomers, OC.ASI is providing services directly to immigrants and refugees. As noted by one staff respondent, this has the potential to create a conflict with its members whose responsibility is direct provision services. Nonetheless, none of the member respondents mentioned this as a concern, suggesting that OCASI has successfully positioned the website as a resource for members to better serve their clients.

Settlement.Org for Newcomers has also helped to raise the profile of OCASI within the sector and in many ways the website has become the public face of OCASI. But this is not 
without its drawbacks. OCASI provides much more value than the Settlement. Org for

Newcomers website alone but some of its additional services and roles have faded into the background.

Because Settlement. Org for Newcomers was so successful people also wondered - at heart it was a technological thing - but "are they competing with us more?" Becanse suddenly we were serving newcomers whereas our manclate is to serve agencies. which is a bit of a different thing. So some of the positioning of what OCASI was to members and again what our mission was started to come into question by some people. and because we didn't have as many successes on the other fronts - we were being shut out of some of the policy discussions and things like that - that became enhanced because all of a sudden "all I hear from them is technology. "At the same time, because we weren't as an entity really really taking advantage of the technology and because we don 't communicate well with oul' membership. but the Settlement. Org team does, that was another rift. Because they re not hearing about all the other stuff that OCASI's doing. In spite of being shut out of policy we 're doing all these other things. but those messages never got out even though we had the technology to do it. Whereas Settlement. Org [for newcomers] was every two weeks "we're doing this. and we d like your input." it's a very different perception sometimes, whereas OCASI has been extremely active in other things, but we get perceived of technology quite heavily because we ve branded it well. its well finded. we 're consistently messaging stuff out there. We re communicating very actively with members about that. So they see that but they don't see this other stuff. (MC. Policy Analyst \& Communications Coordinator)

More generally, technology has increased OCASI's access to information, allowing staff to be more informed about the ongoings of the sector and the broader political and legislative environment. As a result, OCASI is managing more information on behalf of its members than it had ever previously done. Members similarly report increased access to information and the improved efficiencies that result.

Technology has had a very positive impact on our organization. It's much easier to get information from [Settlement.Org] website. (T-1-I)

The websites have had an impact on my agency. They have all of the current information my staff needs. It's easy to get information and to get referrals. It 's very handy. (N-I-I) 
Absolutely. OCASI's electronic communication tools have had a strong impact. They 've really streamlined our access to information. Everyone now know's where to go. how to direct clients. what to expect. (CW-2-I)

It has enhanced the work of front-line staff by providing more access to information via Settlement.Org. It's also informed them of training opportunities. (S-2-I)

This last comment was confirmed by three of the four member agency staff who responded to the email survey.

Members generally report an increased sense of intimacy between OCASI and its member agencies as a result of technology.

The electronic vehicles have influenced our relationship with OCASI in a positive way. We feel more informed. part of the club. instead of being detached. We feel more attached to the group. Before. you wouldn't find out about things except at the Conference or by mail. Now' we instantly receive the information. $(T-5-I)$

We felt more isolated from OCASI before the technology. It has allowed us to feel more included. (CW-2-I)

Before. OCASI was a big, huge, distant organization. Now we have a better sense of who they are. The technology improves the service that OCASI provides. It 's now much easier to know' what's going on at OCASI. I can more easily stay apprised of their issues and positions (for example their recent meeting with the Ministry). (T-4-NI)

Technology has made conmunication with OCASI easier and faster. OCASI is more responsive now and we get more feedback. It 's easier to share concerns with OCASI. $(T-I-I)$

As a result of technology contact with OCASI is more effective. expeditious, and cost effective and I can address immediate and ad hoc issues. (E-2-I)

Settlement. Org has brought OCASI closer to front-line staff as they access resources and information from the site. It has helped OCASI become a bigger part of our organization. They're more relevant now. as I am more easily able to circulate the information I receive. $(S-2-1)$ 
OCASI staff report similar changes to their relationship with members, indicating it is much easier and faster to receive feedback and share information with members than ever before.

When asked how OCASI previously solicited feedback from its members, PM responded:

We used to do it by mail. We would send the questionnaire and ask them to return it. and then we'd keep phoning. We'd each get about 20 agencies to phone - each of the different staff. And you'd take a form and fill it out. (PM. Manager. Policy and Programs)

We may thus observe that new digital forms of communication are superseding older analog methods, with improved results.

Members report minor impact of technology to their relationship with one another.

Several respondents mentioned that they are in more frequent contact with other settlement agencies in their own regions and across the province, but most of these members indicated that this impact is a result of email in general and not a particular technology of the OCASI network. Still, a few members did mention that the OCASI Issues List does give them an opportunity to see the comments of their colleagues and to feel more closely connected with them, a perception that is shared by OCASI staff.

So in fact the relationship hetween OCASI and the members hasn't only gotten better with technology but the relationship anongst the members themselves. Because I can send out one note. everybody gets the same information at the same time, they are seeing each other's responses which help inform their own responses to how they think OCASI should move forward with it. (DD. Executive Director)

The most frequently cited concerns regarding the negative impacts of technology on the network were related to a reduction in face to face contact and the occasionally overwhelming glut of information that seems to consume inordinate amounts of time. Regarding the latter, members were concerned that the increasing reliance on technology seemed to be a doubleedged sword. 
Technology has probably added efficiency but it does consume a lot of time. We're on computers all the time. (E-1-I)

I receive so many emails it's overwhelming. It's too much to process - you might lose something. Although it's much faster: you are bombarded with information. It's an effort to save time. but it's time consuming as well. That's why I don 't participate in discussion bourds. (T-5-I)

All this electronic communication takes people away from their routines. (T-3I)

In an effort to compensate for this challenge OCASI has instituted a policy whereby the majority of member-directed emails are now sent by a single individual who can control for frequency and guard against the threat of communication overload. Less successful have been attempts to continue with in-person contact among members and between members and OCASI. This was seen as a significant loss by members.

The internet does not replace the dynamics of human contact. You lose something on the keybourd - it depersonalizes issues. Technology is good but it is not a substitute. You still need face to face contact for dynamism and the sense of community. (N-2-NI)

Electronic communication has taken over. We don't see each other as much any more. There 's less social interaction and I miss the contact of seeing others. $(N-1-I)$

Our region meets less frequently now and uses more email. Regional meetings are not as fiequent. (E-I-I)

You need balance. OCASI must be carefill not to rely too heavily on electronic: communication. It shouldn't be only one way. The lack of personal communication can be a problem; you need the personal touch. (S-I-NI)

Among the more sober assessments by one particular staff member at OCASI,

In many ways the technology has been the downfall of our relationship with our. members. The creation of these technologies to share information has led to us not talking to them as much directly. We're not calling them on the phone. we're not seeing them. we re not really talking to them at meetings. We feel like that responsibility has been shifted to the technology. So in some ways I think the technology has been a disappointed or a frustration to improvement. (CW, Information Technology Transition Coordinator) 
It is difficult to determine, however, whether technology has contributed to a decline in the budgets for face to face meetings or if a decline in the budgets for face to face meetings has contributed to increasing reliance on electronic communication. Nonetheless, it remains clear that OCASI does not visit its members as frequently as before and would likely be advocating for additional funding to support such personal contact if the technology did not exist as an alternative medium. As a final drawback to the reliance on technology it is worth conveying the observation of OCASI's Executive Director who indicates that

some members have said that because we are not physically present in the regions, the relationship tends to be between OCASI and the other EDs. When we were coming out into the regions, front-line workers, new people coming into the sector: had a better sense of who OCASI was and what OCASI does. So in fact in some agencies there may be settlement counselors who have no idea what OCASI is or that such a thing exists, or even that the agency they are working for is a member. So I think the lack of a presence or the absence of us being in the region they see that as a negative in terms of the profile of OCASI in terms of the various levels of the sector. (DD. Executive Director)

Clearly, technology has had some influence over the characteristics of the OCASI network.

OCASI has become increasingly active in the area of technology development over the past ten years and its flagship website has become the most obvious manifestation of OCASI's work, superseding many of its other activities in the eyes of members and the sector as a whole. Access to information has increased throughout the network, resulting in improved efficiencies and greater understanding of the sector but potentially leading to a sense of being overwhelmed. Members and OCASI staff generally report a moderate increase in their sense of closeness with one another as a result of technology, but lament the overall reduction in personal contact and agency visits. 


\section{Case \#3: Ontario Association of Children's Aid Societies (OACAS)}

\section{Research Question \#1}

How are information and communication technologies institutionalized in the network?

A. What are the roles and experiences of coordinating agencies'?

B. What are the roles and experiences of network members?

Five years ago, OACAS had a single static public website and no electronic communication vehicles specifically geared to its members. Today. OACAS has five websites and an intranet. The sudden growth of investment and emphasis on technology is primarily the result of several newly hired staff members who were determined to employ technology as a vehicle to support and lead OACAS member societies - a new Executive Director, Director of Information Services, Director of Communications and Quality Assurance, and Webmaster. Beginning with a revamp of the public site that allowed OAC.AS to easily update content using internal resources, OACAS then turned its attention to the creation of a member's only site that would provide all member Children's Aid Societies (CASs) with the information and support they needed to pursue their missions. The emphasis on technology was a deliberate decision, made in recognition that OACAS' audience comprises over 7,500 staff at its member agencies.

If you really want to have people to have a voice about what's going in child welfare. [and if] we want everyhody to have access to information about child welfare. then it seems to me that technology is the only way to go. We can't accomplish it any other way. (GL. Director. Information Services)

Nonetheless, OACAS has had a challenging time convincing its members that technology is in fact "the only way to go." 
And it has been an uphill battle with some of our members. particularly some of our influential members. around technology. Some of it is generational. some of it is just time. some of it I think is an innate resistance among human service professionals. Because this is one of the last kinds of. human services part of the whole environment, was one of the last groups to really get on board technology with any real commitment. (JL. Executive Director)

OACAS was frustrated by the inability of its members to make effective use of the platform it had created, while members were frustrated that OACAS has done an inadequate job preparing members for the drastic transition to electronic communication. In the words of one member:

When OACAS moved to electronic communication everyone was supportive in principle but $O A C A S$ was not sufficiently sensitive to member needs. They made too many assumptions. They should have done a needls assessment and taken things slowly. We had great difficulty convincing OACAS staff that we had a problem and OACAS kept insisting the problem was ours. (C-2)

OACAS has acknowledged this weakness in its deployment of technology:

I spent hours suying [to members] "go there to $x$ or y. "so I think where we might have messed up a bit at the beginning is thinking everybody is as enthusiastic as we were. which wasn't true. and I think we didn't do enough training or explanation... So again. I think that if we had thought about it more, we might have taken more time to disseminate the idea of moving to electronic communications a bit more and maybe done a bit more training about how to use it. (GV. Director, Communications and Quality Assurance)

In an effort to better engage its members and instruct them on the value and use of OACAS technological resources, OACAS has since actively worked to promote the website and its features to its members. At its Consultations, Zone meetings and other face to face encounters, OACAS staff have provided demonstrations of the site to its members. OACAS also places ads promoting the member's only website in The Journal, a quarterly publication that is disseminated throughout the member agencies. On the suggestion of the Webmaster OACAS has gone even further and employed technological tools to train its members. A series of CD-ROMs, online tutorials and short Flash movies have been created to assist members with the site or its specific features. In fact, little pop-up messages from the 
Webmaster appear on the site when completing forms or clicking on menu options, assisting

the user by providing ongoing support:

Again, with this portal website I just created for the OnLAC group I've created little tutorials like "click here for a little flash movie on how to register, " click here for how to make fortum post" or "click here on how' to enter a chat room. "So it really he'omes that you have to hold their hand. And if that's what we have to do. that 's what we'll do. (KK. Web Coordinator)

The following Table offers a briald overview of OACAS and member experiences in regard to three of OACAS' major cimmunn:ation vehicles: the Weekly Index, OACAS Member's website and discussion busd, Thise examples provide the opportunity to explore the

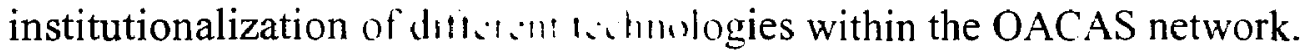

Table 5. OACAS Networh lechunolugy

\begin{tabular}{|l|c|c|c|}
\hline Technology & Description & $\begin{array}{c}\text { Original Intent of } \\
\text { Coordinating Agency }\end{array}$ & Modification and/or Use by Members \\
\hline Weekly Index & $\begin{array}{c}\text { Weekly mailing of index } \\
\text { of recent news items } \\
\text { and other relevant } \\
\text { materials of interest }\end{array}$ & $\begin{array}{c}\text { To provide ongoing sector and } \\
\text { OACAS-specific information to } \\
\text { members, and to drive } \\
\text { members back to the site }\end{array}$ & $\begin{array}{c}\text { The Weekly Index was originally } \\
\text { distributed with pdfs of materials. A } \\
\text { backlash from members caused OACAS } \\
\text { to circulate an Index rather than the } \\
\text { articles themselves. Most respondents } \\
\text { rely heavily on the Index, which was an } \\
\text { extension of a paper-based weekly } \\
\text { mailout called the "Thursday Mail." Initial } \\
\text { resistance to electronic dissemination } \\
\text { appears to have subsided. }\end{array}$ \\
\hline $\begin{array}{l}\text { Member's } \\
\text { Website }\end{array}$ & $\begin{array}{c}\text { Password protected } \\
\text { website }\end{array}$ & $\begin{array}{c}\text { An information repository and, } \\
\text { more recently, a platform for } \\
\text { inter-agency communication. }\end{array}$ & $\begin{array}{c}\text { No modification. On average, members } \\
\text { appear to be using the site with relative } \\
\text { frequency and have a clear sense of its } \\
\text { function. Use of the site is more frequent } \\
\text { at higher staff levels. }\end{array}$ \\
\hline $\begin{array}{l}\text { Discussion } \\
\text { Forums }\end{array}$ & $\begin{array}{c}\text { Password protected } \\
\text { discussion boards. } \\
\text { organized by staff role } \\
\text { (e.g., Human } \\
\text { Resources, Finances) }\end{array}$ & $\begin{array}{c}\text { To facilitate exchange among } \\
\text { staff in specific roles across } \\
\text { the province. }\end{array}$ & $\begin{array}{c}\text { The Human Resources discussion forum } \\
\text { has become fully institutionalized while } \\
\text { the Finances discussion forum remains } \\
\text { unused. Differences attributed to the } \\
\text { leaders, operating culture and nature of } \\
\text { work among the two groups. }\end{array}$ \\
\hline
\end{tabular}


The influence of member's interests and capacities on the institutionalization of technology in the OACAS network can be most readily observed in the Weekly Index. OACAS members had been long accustomed to "the Thursday Mail," a decades-long practice by which OACAS distributed a weekly compendium of hard copy reports, discussion papers, newspaper clippings and other information of relevance to each of its member EDs. The distribution of this material was a well institutionalized practice in the network and members would look forward to receiving their weekly supply of sector-related information. In 2001, OACAS decided that as a cost-saving and efficiency measure, and as a means improve the circulation of the contents among different staff at member agencies, the Thursday mail would instead be delivered electronically with scanned copies of all of the documents emailed directly to the inboxes of the EDs of its member agencies. It was at that time that OACAS first got a sense of the technical capacity and facility of its member agencies. There was an immediate backlash among members who were having enormous difficulty opening the material, did not have the capacity to accept and store such large attachments, or who were resentful of the fact that OACAS had shifted the burden of printing onto its member agencies. Members were well accustomed to the paper version and mostly resisted the new electronic means of delivery. OACAS did not anticipate such a reaction. In response, as the chorus of complaints grew louder, OACAS changed the format once again so that the material was emailed as an index of links - the Weekly Index - which linked users directly to the documents housed on the member's website. Again, the decision was made without forewarning to the network members, who were once again taken aback by the sudden change.

Well I think the transition I've described with the Thursday Mail from emailing PDFs, to hosting on the website. were different milestones that people reacted to. Probably stronger reactions in the beginning. I don't think we anticipated very well what those reactions were going to be and how negative they were 
going to be. Somebody accused us of assuming that "if we build it, they will come." and in fact I think they were right. I think that's what we did assume: "This is just so logical. why would anybody reject it. right." "And so we were a little bit surprised when lots of them were quite annoved and they said "I'm ased to having the Thursday mail in my hand. I don th like the idea that I have to depend on the computer now: and I don't like the ideas that we have to store it and that we have to print it." and then going and moring to the links and that was something I was here for. when we moved from mailing the files to mailing the links. and we didn't do any preparation of the people out there that we were going to do that, because to me. we weren t doing anything. All we were doing was instead of attaching the file to the email. was giving them a link to as document on one of our servers, but I misjudged again. I learned a lot about implementation planning since we 've been in a few of these projects. and we're being much more cautious now to change a few things about implementation planning. (GL. Director: Information Services)

The experiences with the Thursday mail left a lasting impression on OACAS. The launch of the Weekly Index taught OACAS staff that the needs of members had to be more deeply considered and that member agencies should be forewarned and involved in changes to OACAS' communication strategy. For some time, OACAS made an effort to accommodate those agencies who were reluctant to adapt to the electronic method and continued to provide hard copies of the documents to this recalcitrant population. In 2002, however, OACAS decided that these members would be forced to adjust to the new means of delivery and stopped sending hard copies to anyone in the network.

Members have also had limited influence on the development of the Member's website, which has been similarly directed by OACAS's internal team without consultation of the members. Nonetheless, member's impression of the website map perfectly onto the intent for the site indicated by OACAS staff. The most frequently cited responses regarding the role of the member's only site were "information," "education," and "communication."

Respondents generally found the site to be quite valuable, and a few in particular indicated that they had come to rely on the resource and didn't know "what we'd do without it." The 
majority of the respondents were usually drawn into the site by the Weekly Index but most had visited the site on their own instigation to find a piece of information they were seeking or to ensure that they were up to date on current issues.

As in the case of OAYEC. use of OACAS' technologies varies across the network. While the Weekly Index is read by most of the Executive Directors who participated in the survey, they use the Index in different ways. Some Executive Directors circulate the Index throughout their agencies whils whers keep the information to themselves or forward the Index only to senior staft 11 uhm the member agencies some staff who receive the Index read

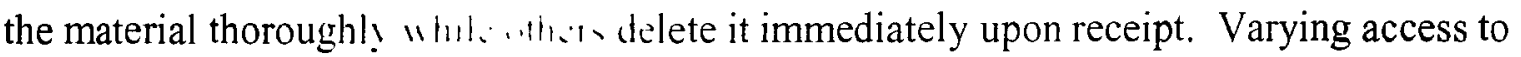
OACAS supplied inform.t1.......1f level can also be observed in the relative use of the website. Although the cum.nt. the member's site is mostly targeted toward staff at senior levels, OACAS staff harc mhind is that it is their goal to make the site a more valuable resource to other staff les find that EDs of the member ( $A$ Sis can pose a barrier to this goal:

And the thing that sruck me [ahout the comments of the front-line workers in the Communicatiom. tudit] was. "oh. I didn't know' you had a website." And the problem is that we werce afraid to promote the website becanse we didn't want to step on the ED's wes. because they are their own individual organizations and whether or not they granted their employees access to the website was up to them. So lie never actively promoted it. We never put out posters at the agencis.s. we never emailed the 7.000 front-line workers with an invitation to take a lowk. So that 's another challenge we're facing. We have this resource - this is mi full time job - and yet we're not promoting it as much as we could he. (KK. II') Conrdinator)

It 's interesting beculase part of the resistance we ve had to overcome is that some of the agencies out there are not giving all their staff access to the internet. and if you can 't have access to the internet you can't have access to the website. So what we've done is encouraged the EDs to come into to the modern age and that their staff need access. not only because they need access to our website. but because there's lots of good research out there. But now lots of them are starting to learn that. See, if there's any left at all there's 
probably one or two agencies that don't give their staff internet access. and that sort of indirectly helps spread the opportunity to have access to our own website. (GL, Director: Information Services)

When asked about the use of the site by other staff, and when considering the emailed responses received directly from these workers, it became quite clear that use of the site differed radically among agencies. In some agencies use of the site was quite common for most staff levels while in other agencies no staff were making use of the site, often a reflection of the leadership of that agency. In general, the site appears to be used most frequently by senior level staff with only a few respondents indicating that front-line child care workers were using the site to any real effect. This is corroborated by the 2005 OACAS Communication Audit, which confirms that the most frequent users are senior managers $(96 \%$ log on at least monthly) and middle managers ( $71 \% \log$ on at least monthly), and the least frequent users are Board members ( $59 \%$ never $\log$ on) and front-line staff ( $56 \%$ never $\log$ on). Clearly, the site is institutionalized differently among the different agencies and among different staff and departments within the same agency.

OACAS has expressed interest in using portal technology and other mechanisms to facilitate the exchange of communication and information among members and their initial foray into such technology has begun with the recent launch of two password-protected discussion boards on the member's website: one for Human Resources professionals and one for senior staff working in Finance. The Human Resources discussion board is being used extensively by Human Resources professionals throughout the province. The Finance discussion board, on the other hand, is languishing on the site with only a single comment that was posted during the forums' initial launch. Again, we can observe a lack of uniformity in the institutionalization of technology within the network. 
We see in OACAS an interesting pattern of technology deployment and use. Confident that technology was a necessary and improved means to support its membership, OACAS has created several technological vehicles to serve the goals of the Association. In a few cases, most notably the transition from the Thursday Mail to the Weekly Index, it was apparent that members were not ready for the changes that OACAS assumed would be minor disruptions and major improvements to the information services it provides. OACAS has since learned the value of more deeply considering the needs and capacity of its members.

The Weekly Index, after several format changes, has appeared to find its place among member agencies. The Index has been institutionalized differently among different agencies, with some users barely reading the contents and others actively disseminating throughout their agencies. Within the agencies, some staff make active use of the Index when received and others barely review the material at all. The member's website has been institutionalized as an information resource for all members and has become an integral tool for many agencies. Senior staff make predominant use of the site while only a few front-line workers visit and a significant number appear never to have heard about the site. The discussion boards, OACAS' first attempt to use the member's site as a vehicle for inter-agency communication, have had variable success. The Human Resources discussion board has been institutionalized as an essential element of this group's communicative practices while the finance group's forum sits on the site entirely unused.

\section{Research Question \#2}

How do network characteristics shape the use of information and communication technologies? 
The deployment and use of technology within the OACAS network is a reflection of the characteristics of the Association. This is most obvious in the member's website, which serves as an information repository for Children's Aid Societies from across the province. Since the 1940s, OACAS has identified itself as an "information clearinghouse" for its member agencies and its knowledge and information services represent the most substantial piece of OACAS' core work. This role has assumed enormous proportions as a result of electronic communication. The OACAS member's website is a massive archive, supplying its member agencies with the information resources required to effectively pursue their missions. Both OACAS staff and members agree that the central purpose of the site is to provide this information, reflecting the Association's long-standing tradition of serving its members in this capacity. OACAS' other main activity is its advocacy work. Here, we see only minimal use of technology for this purpose. There is no evidence that OACAS uses technology to involve its members in the development of policy positions; however, in line with its use of technology as a vehicle for information dissemination, all of OACAS's policy and discussion papers, as well as its media releases and documentation of its lobbying activities, are housed on the site and are easily accessible to its members. More importantly, perhaps, OACAS has found itself more easily able to support the advocacy of its members through subsections on its site that provide "key messages" and an "MPP visit kit." Electronic distribution of such materials has made it easier to apply ongoing pressure to government officials throughout the entire province, and for all CASs to ensure they are giving consistent messages to the media, public and government decision-makers.

One of the EDs. I think I was his first or second day on the job. he was called by the media on Section 43 advocacy - the repeal of the criminal code. and he phoned here. Our Director of Communication said "just go to the website. to the Facts and the $Q \& A$ 's, "and we had our backgrounder there for him and he 
was able to do the media call with very little orientation. (JL. Executive Director)

The use of technology to support OACAS core activities can also been seen through OACAS' recent foray into e-training. Accreditation and training support for child care workers across the province have long been cornerstones of OACAS' member services, and the Association is beginning to use technology to more efficiently reach and educate CAS staff from across the province. OACAS's commitment to original research can also be observed by its use of technology, as the member's only website now houses electronic versions of surveys that were at one time paper-based.

It is worth noting how OACAS' internal culture has shaped the use of technology in the network. Since 2000, OACAS has hired four individual with a keen interest in technology and who have collectively committed to a vision of technology use for the child welfare sector. The effort of these individuals is primarily responsible not only for OACAS' increasing reliance on technology, but for leading the entire Association in technology adoption.

About ten years ago George Leck told me that computers would have a dramatic impact on the child welfare sector if we allowed it. I myself had absolutely no vision of that at the time, but I was willing to listen. (E-I)

As noted above, OACAS faced an uphill battle in encouraging its members to adapt to technology. Interestingly, however, it is not only the resistance of its member agency staff that OACAS has to contend with. Within OACAS it has been difficult for the four technology "visionaries" to convince the Board and all staff that use of technology was going to enable the Association to better support its members.

The OACAS itself has struggled with making the move from hard copy to electronic. so I don't think we 're fully there from a cultural point of view where's there's just a natural acceptance of the fact that the way you communicate with the world is electronically. And so it's hard when you don't have it totally inside. So it's not just resources, it's a cultural issue, and then 
those resources issues would be addressed more readily if the cultural issues were dealt with and the values were such that they see electronic communication as the key to the whole thing. (GL. Director, Information Services)

Indeed, many staff have been reluctant to adopt technology in the way the OACAS visionaries have been hoping. These staff, according to the Webmaster, create a barrier to effective use of technology by members and frustrate OACAS' attempts to develop mechanisms to track and archive internal communication.

The organizational culture of the OACAS network has also significantly influenced the institutionalization of technology. OACAS works with its members in multiple ways and many respondents indicated that the child welfare sector in Ontario has become increasingly collaborative and cohesive in the past few decades in large part due to the work of the Association. OACAS hosts a conference every other year and meets with the Executive Directors, Boards and senior management staff of CASs three times a year at its consultations in Toronto. OACAS also convenes a complex web of committees, task forces, working groups and networks to address various issues and to ensure that members are playing an active role in the activities of the Association. In general, respondents report that membership in OACAS is extremely important to their agency and indicate that the relationship is a close one:

It's a very positive relationship. We are in frequent communication and we really appreciate what Jeanette Lewis has done since she came on board. There is a lot of information flowing from OACAS to our CAS, and we always get a positive response from OACAS staff when we contact them. The consultations are also very aseful. (GR-l)

We have a very close relationship with OACAS. We have a number of people on our staff who are doing project work with OACAS. I would say it's a good working relationship - a valuable and important relationship (E-2)

Our relationship with OACAS is very positive. OACAS is truly an expert in communication, and effectively engage their members and determine what 
information from government is of relevance and should be conveyed to the sector $(E-1)$

Relationships among members themselves also appear to be quite positive throughout the network. Unlike the other cases, OACAS network members each operate in a geographically defined territory and are therefore not in competition with one another. Moreover, OACAS members are relatively homogenous, pursuing an identical mandate in different parts of the province. The value placed on member-member relationships is evident by the number of collaborations and frequency of communication among member agencies. Members meet with one another regularly during the Zone meetings, at the Consultations in Toronto, and through the Ministry of Children and Youth Services' own regional meetings. All in all, members report strong and collegial relationships with one another, working together on various projects and communicating regularly even outside of OACAS's formal structures.

Figure 5 depicts the OACAS network. As the smallest and most cohesive of the three networks, members are close to the coordinating agency and to one another. Members have several interconnections, based primarily on region and staff role.

\section{Figure 5. OACAS Network}

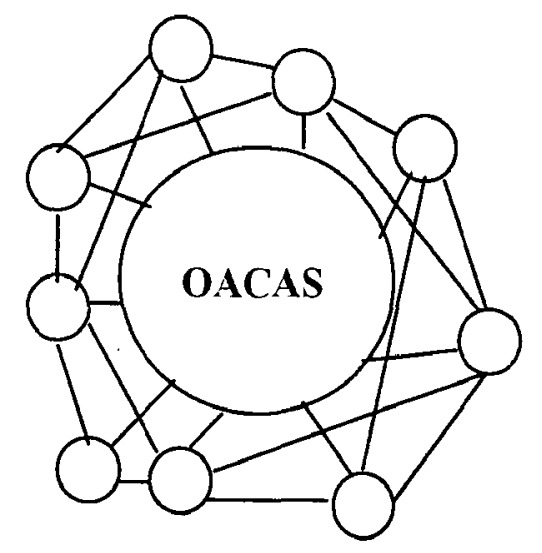

The structure and culture of the OACAS network is reflected in the institutionalization of technology. Members are close to the coordinating agency and have depended on OACAS for 
their information needs for over eight decades. This is reflected in member's clear sense of the purpose of the site and their increasing acceptance of technology as their primary means for communication with OACAS. Its Zone networks, despite being well entrenched as an inperson mechanism for communication among members, have not shaped the use of technology within the network; there are no Zone-specific email lists or discussion boards, and the website is not used to house the minutes or agendas of the different Zone meetings. Its web of network groups and committees, on the other hand, have manifested on the member's only site.

OACAS has established 23 separate forums for these groups, variously offering meeting agendas and minutes, news updates, information resources and other announcements. In two of these forums OACAS has built discussion boards that enable members to pose questions and respond to one another. One, the Finance discussion board, remains untouched: the other, the Human Resources discussion board, is actively used and has become an indispensable resource for members of that group.

The difference in usage among the two forums can be attributed to several factors. Most prominent among these are the differences in the working culture and leadership of the two groups. A member of the finance group made a request to have the forum hosted on the OACAS member website. However, staff respondents at OACAS indicate that the leader of that group - an OACAS staff member - is not particularly computer literate and has been dragged "kicking and screaming" into the information age. As such, use of the forum immediately fizzled in this group as the leadership did not make any effort to move away from previous practices of inter-agency communication. The Human Resources group's experience, on the other hand, has been radically different.

It's leadership in the group itself. One of the reasons why the HR forum has taken off so well is because some of the people on the Executive are really 
enthusiastic about electronic communication and have sort of taken some sort of leadership role in making that work. In fact. given the size of the staff here at OACAS, that's the only thing that's going to make those forums work or not work. It really is leadership from Agency people. it's leadership from those network groups. (GL. Director. Information Services)

I build it. but I can 't make it go. And so people have to take responsibility. So with OnLAC [a recently launched portal website]. I sent an email yesterday to Gail and Jane and Susan saying. 'this is really your website and the members aren't going to use it unless you guys help them along and post articles. post discussion topics and stuff. There has to be some ounership there. (KK. Web Coordinator)

One of the Executives of the Human Resources network group tells the following story:

Over the past twenty years the HR group would meet about five times a year in Toronto. We also used to have an annual OACAS survey, but we felt that wasn't helpful enough because it would be out of date. We had also been surveying each other" over the past five years via email. We thought. "we need a way to connect. I want a holding place for all of the information we need. and a way to reduce the number of emails I was receiving. "And that's where it started. (HR1)

Devoted to the idea that agencies should be sharing information and working with one another, this individual enlisted the support of two other Executives who were willing to lead the transition to an electronic platform of exchange. Strongly supported by the OACAS webmaster, who was thrilled to see members considering such progressive use of new technology, the discussion board was established in late 2004. Using a regular meeting as the launch pad for the forum the Executives of the Human Resources network group insisted that network members use the forum to get the meeting minutes and agendas. In her words, "I gave them a carrot." While it took some time for members to adapt to the new system, the Executives consistently prodded the members and insisted that they rely on the new technology. Although some members were hesitant at first, the discussion board has since become a fundamental means of exchange among the Human Resources network group and currently has over 380 posts in twenty forums. The Human Resources group has been buoyed 
by the tremendous support of the OACAS Webmaster and the promise of additional functionality in the coming years. When asked why their forum had become such a tremendous success while the Finance group's forum remained wholly unused, representatives of the Human Resources network group point to their leadership and to a long history of collaboration and consultation with one another, factors which they perceived to be lacking in the Finance group.

The characteristis... the ().ACAS network are reflected in its approach to and use of technology. OACAS MM-1 - urpurt its member agencies and this support is most prominent through its information-pundm: $m$ lnd advocacy role. With regard to the former, OACAS has used technology as a mi.m-1. m.Mre and disseminate information throughout the network with unprecedented eals $\quad$,,$\ldots .11$ 小 the latter, OACAS has used technology to more efficiently apprise membi... need to effectively lobb! al a f icill level and respond to media and public with consistent and powerful messaging. OAC $1 \mathrm{~S}$ has begun using technology to support its training and research work and has built mechanisms to facilitate inter-agency exchange. This has manifested in the development of forums for its various network committees and working groups, and in the building of discussion boards. one of which has seen significant success owing to its leadership and dynamic collaborative culture. The overall cohesion of the network is reflected in members' clear sense of the purpose of OACAS' electronic communication vehicles and their collective reliance on technology as the primary means of communication.

\section{Research Question \#3}

How do information and communication technologies shape network characteristics? 
As an umbrella organization OACAS has assumed a leadership role when it comes to the adoption of technology in Ontario's child welfare sector. OACAS staff feel a responsibility to model effective technology use so that member agencies can learn to use technology to increase their capacity to pursue their missions. This has created a new role for the Association, which must now invest in the training and infrastructure necessary to effectively lead CASs throughout the province. Technology has also had a substantial impact on OACAS' core function of information dissemination. OACAS has transitioned from a hard copy method of distribution to an electronic one, enabling the Association to circulate information resources among its members with far greater efficiency, speed and reach than ever before.

I think one of the things that [technology has] done is engendered a feeling that as soon as we know it they should know it. Insteat of sending it on Thursday, if we know it on Monday we tell them on Monday. So it's engendered a just-intime mentality. (GV. Director. Communications and Quality Assurance)

I'm not sure it's had any impact on our' organization. But it has impacted my work. I have a much faster and easier understanding of provincial issues. When I need the information. I know' it's right there and I don 't need to make ten phone calls. The information is much more accessible. (E-2)

We have quick access to late-breaking news. This week an announcement regarding a new piece of legislation came down. In 24-36 hours we can communicate OACAS" summary among all of our staff. (SW-3)

We have much more access to information as a result of email and the website. In the past we would have waited weeks or months for reports that now arrive immediutely. $(S W-I)$

Not only is the information reaching its members more quickly than ever before, but the member's only website makes this information available at all times of the day and to all levels of staff. Whereas at one time the Thursday Mail was reaching only 52 EDs who would or would not distribute this material depending on their own practices, the website now makes 
information potentially accessible to OACAS' entire audience of over 7,500 staff. This was a key motivation of OACAS' deployment of technology, as staff respondents indicated they sought to "level the playing field" and perceived the internet as a "more democratic" means of information dissemination. Based on the responses of members this goal is being achieved. Members report that their boards and staff at levels have much improved access to information, supplying them with the tools they need to more effectively conduct their work.

As indicated above, the fast adoption of technology by OAC.AS led to an initial rift between the Association and some of its members. While the legacy of this rift is still apparent in the comments of some of the interview subjects, the initial challenges seem to have been addressed and OACAS is now working more effectively with its members to ensure they are comfortable with the transition to electronic modes of communication. On the whole, OACAS staff report that communication technology has improved their relationship with members, drawing members closer to the work of the Association. Members themselves had mixed assessments of the impact of technology on their relationship with OACAS. For some members, technology had a clear positive impact:

[Technology] has increased the level of communication in both directions. I'm more in touch with what OACAS is doing. I find it's much easier to turn on a computer and connect with information than it is with a paper envelope. (E-I)

The good work that OACAS is doing is now more accessible to agencies such as our's. Now it's arailable to us at the flick of a finger. So I would say it's enhanced the relationship. and I think it has highlighted the importance of OACAS to a remote agency such as ours. $(N-2)$

I would say [technology has] strengthened our relationship with $O A C A S$. We are in such frequent communication now. A question is posed and we get a response immediately, so the turnaround time has really improved. We also seem to rely on OACAS more often now' that they 're only an email away. $(S W-3)$ 
It's definitely changed our relationship with OACAS: I think that as a result of technology the network has become more cohesive. It's like the geography has collapsed and we are more closely knit. Email and the website have both been factors in this. (SW-I)

A few members, however, report challenges to their relationship with OACAS as a result of technology. In particular, these individual find they have less personal contact with OACAS staff and indicate that, while the yuantity of information circulating among the network has

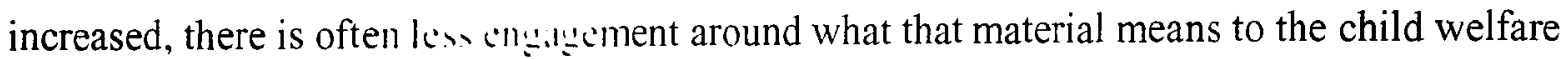
sector

With respect to thill $1.111,1$ hhip with one another, members again provide mixed

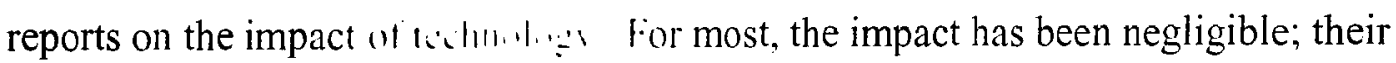
relationships with each "wh.: h..1: m.n been altered and technology has played no role in increasing frequency of cintul w the number of colleagues with whom they are in touch. For others, technology has in fac m mprred their ability to communicate with other CASs:

I communicate mori and on a broader base with other members as a result of email. We're on th' compututer far more than we are on the telephone. (GR-2)

Email has probuhly increased communication among members. It used to be face to face or by thelume. but now email allows for more immediate contact. It goes in waves. Somctimes there's a lot of emails exchanged around a given issue. $(N-3)$

Email has made an impat providing instant contact. It's been very positive for the Northern region. He can pose questions to each other. I'd say I have quite frequent email comtact with 2-3 other agencies that are similar to my own. $(N-1)$

It has changed our relutionship with other member's. There's more immediacy of answers. conversation. Sometimes EDs have ongoing email conversationthis would be a subset of the member EDs. Our zone will use email to discuss issues as a group. (SW-3)

Unsurprisingly, members of the Human Resources network group report considerable improvement to the quality of their exchanges as a result of their use of the discussion boards. 
The most frequently cited complaints around the impact of technology concerned the sense of "information overload" and the decrease in personal contact. Member respondents felt frequently "overwhelmed" by the amount of information that they now had to contend with and indicate that it is an ongoing challenge to prioritize the information that is received. One respondent went so far as too indicate that he barely ever checks the website out of the feeling of guilt he experiences when he sees how much information he is missing. Those respondents who identified the decrease in face-to-face interaction as a negative result of technology stated that technology has had a depersonalizing effect on the network and threatens to erode existing relationships unless the Association makes an active effort to supplement technology use with opportunities for personal contact.

The OACAS network has been somewhat influenced by the introduction of communication technologies. As one may have expected, this is predominantly seen in the improved circulation of information, which not only reaches its members more quickly but has allowed OACAS to communicate directly with multiple levels of staff at its member organizations. Some members report an improved relationship with OACAS as a result of technology, which allows them to more easily interact with the Association and access the resources necessary to their work. Others are concerned about the depersonalizing effects of technology and note that they are engaging less with staff at the Association. Members offer mixed assessments of the impact of technology on their relationships with one another, and the most frequently cited detriments of technology have been the loss of personal contact and the sense of information overload. 


\section{Discussion}

The structurational model of technology posits a recursive relationship among technology, human activity and institutional properties. Technology is considered both the product and medium of human action, and organizational properties are understood to influence, and be influenced by, the institutionalization of technology. Unfortunately, there is a limited pool of research that uses the structurational model of technology to probe the experiences of different organizations. Existing studies have applied the model to the implementation of Lotus Notes in services firms (Orlikowski 1992b; Orlikowski 2000), the implementation of enterprise resource planning software in the manufacturing industry (Volkoff 1999), the introduction of computer-aided design systems in industrial design companies (Brooks 1997), and to groupware use and impact in local government structures (Josefsson and Nilsson 1999). However, no existing studies consider the unique case of networks of organizations. As evident from the findings above, this structural form displays several unique characteristics that amplify and extend the existing model.

Most significantly, we observe that technology does not come to assume a uniform role within the network as a whole but assumes different roles within different "pockets" of the network, depending on the institutional properties and behaviours of actors therein. As Orlikowski writes, "technology is interpretively flexible, hence the interaction of technology and organizations is a function of the different actors and socio-historical contexts implicated in its development and use" (Orlikowski 1992a: 405). This conclusion, however, is based on the study of independent organizations and is therefore an insight into how a given technology may be institutionalized differently in different organizations. But within the flexible configuration of network organizations we see "different actors and socio-historical contexts" 
within the same network structure. We therefore extend the structurational model by forcing it to contend with a variable structure in which technology is institutionalized differently within the same network.

Indeed, we see as much variation in the institutionalization of technology within each case study as we do across the networks. Within OAYEC, differences in the organizational cultures among the regions are reflected in the adoption of technology. The Southwest and Northwest regions, with a tradition of working collaboratively, have institutionalized the Workspaces as a means for ongoing communication between regular face-to-face meetings. The East, finding email easier than the Workspaces, have institutionalized email as a means for collective communication among the principals of member agencies in that region. The Central region, lacking a spirit of camaraderie and in competition with each other for funding and for clients, has not institutionalized any technology as a means for inter-agency communication.

Within the OCASI network we may observe more evenly institutionalized adoption of the Issues List and the Settlement.Org for Newcomers website. With Settlement.Org at Work, however, there are considerable discrepancies in use, with the majority of respondents never visiting the site or even being aware of its existence and a minority accessing the site on at least a weekly basis to support their work. Moreover, there are differences in the institutionalization of the At Work website among the staff at member agencies. Some respondents report that settlement counsellors make active use of the site while others indicate that their front-line staff have never used the site. The responses received directly from staff at this level validate these comments. 
In the OACAS network, variations among the operating cultures of different role-based working groups manifest in the discrepancy of the institutionalization of discussion boards. The Human Resource inter-agency group, with a strong tradition of collaboration and exchange, and led by an Executive with a keen interest in technology, has institutionalized the discussion boards as an indispensable means to support their communication. The Finances group, lacking any commitment to technology by its Executive and by all accounts a less dynamic group with a limited history of inter-agency communication, has ignored its discussion board which now sits unused on the website. As with OCASI, we also see in OACAS the variable institutionalization of technology as a reflection of the internal operating culture of its member agencies. Some members actively distribute the Weekly Index throughout their organization and encourage staff access to the site, while others do not promote such resources and the website and Index remain tools for the exclusive use of senior staff.

In all three cases we may also observe one other unique characteristic of network organizations that has implications for the structurational model of technology. According to existing studies the institutionalization of technology results in part from the ways in which staff of an organization interact with, appropriate, and adopt the features of technology. But within networks of nonprofit organizations another layer is added - the motivations, circumstances and capacity of members. Thus, we can observe that the institutionalization of technology within the three networks is not simply a matter of members adopting the communicative practices projected and encouraged by the coordinating agencies. Members frequently modified, or necessitated the modification of, the originally intended uses of the technology. In the case of OAYEC, members' organizational focus necessitated a 
reconfiguration of the Shared Resources Database from a partnership with the existing Content Sharing Constellation to an OAYEC-specific resource. Members' own capacity limitations precluded adequate contribution to the database and the feature was left largely unused. The OAYEC website, originally intended to be a platform of information provision and exchange, is used predominantly by members as a means to search for the contact information of other agencies to provide referrals to their own clients. The Workspaces, originally envisioned to facilitate ongoing exchange among members across the network, were reconfigured and institutionalized as a series of regional discussion boards in response to the interests of member agencies.

Within the OCASI network, members have consistently thwarted efforts to institutionalize technology as a mode of inter-agency exchange. Neither the Issues List nor discussion boards have been self-sustaining as members have refused to actively use these media to communicate with their colleagues. The Settlement.Org at Work site, intended to provide information resources so that managerial and front-line staff can more effectively perform their work, remains unused by many members. OACAS has been more successful in integrating its technological platform into member's work processes although this appears to vary by agency, staff level and staff role. The discussion board has become an indispensable resource for the Human Resources network group while it is completely untouched by members of the Finance group. The member's only website is accessed with varying frequency and for various purposes among the different agencies and staff. The Weekly Index is read and appreciated by the majority of Executive Directors in member agencies, who have their own institutionalized systems for disseminating the information within their agencies. 
Finally, it is worth recalling that the format of the Weekly Index itself is a result of negotiation between the coordinating agency and the network members.

These modifications of the originally intended uses of technology are anticipated by the structurational model of technology. The structurational model sees artifacts as potentially modifiable throughout their existence; designers embed technologies with certain predispositions which are subsequently appropriated by users during their use of technology. In networks of organizations, however, it is not only one set of users that modify the technology but two: coordinating agencies and their members. Therefore, while coordinating agencies may implement certain technologies with prescribed uses, and subsequently modify the technology to serve the particular needs of their network, it is the members themselves who are the final arbiters of its use. Certainly, this is similar to solitary organizations in which end-users (i.e., staff) may appropriate technology in a manner that was not anticipated by the designers. However, within networks of organizations this appropriation is multiplied. First, members of a network structure are more likely to possess disparate characteristics than units within a single firm. Second, within the member organizations there may be a variety of units and staff levels that possess their own distinct characteristics; technology is appropriated at each of these levels. Finally, network members possess more autonomy than staff of an organization and are therefore less compliant to the directives or desires of those leading the implementation of technology.

We may thus conclude that technology is not institutionalized uniformly within these three network structures and that this appears to be a reflection of the inherent variability of network configuration and the ways in which this variability manifests in the different operating cultures, practices and behaviours of members in different pockets of the network. 
This conclusion is supported by the structurational model of technology, which sees technology in part as the product of human action and the reflection of institutional properties. Through its application to networks of nonprofit organizations, this thesis extends the structurational model of technology by demonstrating that the diverse institutional properties and multiplicity of human activity that exist within a single organizational network influence the institutionalization of technology.

However, the structurational model also predicts that technology will influence human action and the institutional properties of an organization. And indeed, we do see evidence of this process as well. Within the OAYEC network, regions already experiencing positive interagency relations were further supported by the implementation of technology. Similar findings emerge from OACAS, where the Human Resources network group's long history of collaboration was buttressed by the introduction of discussion boards. Technology appears to have the additional benefit of drawing the networks closer together, as the majority of respondents in all three cases report increased communication with other members and with the coordinating agency.

In a few examples we can observe more substantial impact of technology on institutional properties and human activity. In the Northern region of the OAYEC network member agencies were challenged by the vast geographic distances between them and the declining funding available to support in-person meetings. Despite their positive relations members reported that they were meeting with decreasing frequency each year. The introduction of the OAYEC Workspaces had dramatic influence on inter-agency communication, allowing them to exchange with one another at no cost and on an ongoing basis. Similarly, the Human Resources network group of the OACAS network experienced 
significant gains to their work processes. Despite a tradition of collaboration, existing methods of communication were proving cumbersome and, in the eyes of the Executive, inefficient. The introduction of a discussion forum that could house documents and archive an ongoing discussion allowed this group to work together with greater ease than ever before.

Technology has also influenced the institutional properties of member organizations to varying degrees across the three cases. In all three cases, members report an increase in information access and circulation as a result of new technology. These respondents indicate that this material has enabled them to better pursue their missions, but also note the threat of information overload as a result of more frequent communication. As regards the coordinating agencies, technology reinforced most of their main roles and activities, such as research, information provision, and advocacy.

In light of the discussion above, the unique case of networks of nonprofit organizations merits an extension of the structurational model of technology, depicted in Figure 6.

\section{Figure 6. Structurational Model of Technology, Extended}

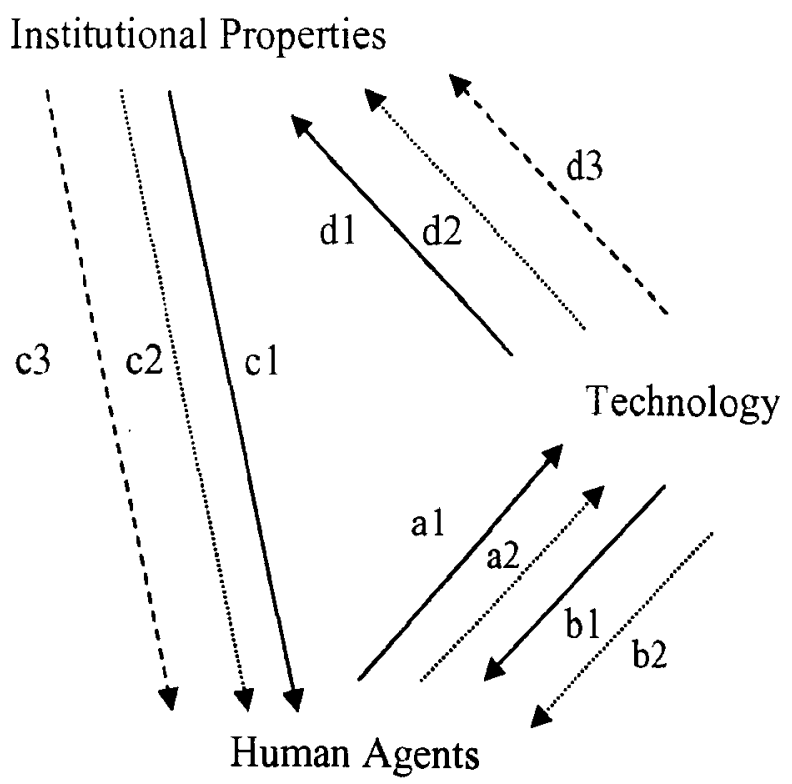


Here, we see a revision of Orlikowski's original depiction (see page 15). The solid lines, indicated by their respective letter and the digit 1 , are identical to the original model. In this revised figure, however, this solid line refers specifically to the coordinating agency. The dotted lines, indicated by their respective letter and the digit 2. refer specifically to the network members. Finally, the dashed lines, indicated by their respective letter and the digit 3 , refer to the network as a whole, which has institutional properties distinct from those of the member organizations and the coordinating agency.

As in the original model there are four principal effects; however, these effects are multiplied by the complexity of the network configuration. This modification is explicated in the following table:

Table 6. Structurational Model of Technology, Extended

\begin{tabular}{|c|c|c|}
\hline Arrow & Type of Influence & Nature of Influence \\
\hline a2 & $\begin{array}{c}\text { Technology as a Product of } \\
\text { Human Action }\end{array}$ & $\begin{array}{l}\text { a1) Technology is an outcome of its intended and subsequent } \\
\text { use by staff at the coordinating agency. } \\
\text { a2) Technology is an outcome of its modification or use by staff } \\
\text { at the member organizations. }\end{array}$ \\
\hline b1 & $\begin{array}{c}\text { Technology as a Medium of } \\
\text { Human Action }\end{array}$ & $\begin{array}{l}\text { b1) Technology shapes the activities of staff at the coordinating } \\
\text { agency. } \\
\text { b1) Technology shapes the activities of staff at the member } \\
\text { organizations. }\end{array}$ \\
\hline $\begin{array}{l}\mathrm{c} 1 \\
\mathrm{c} 2\end{array}$ & $\begin{array}{l}\text { Institutional Conditions of } \\
\text { Interaction with Technology }\end{array}$ & $\begin{array}{l}\text { c1) The institutional properties of the coordinating agency } \\
\text { influence how staff members interact with technology. } \\
\text { c2) The institutional properties of the member organizations } \\
\text { influence how staff members interact with technology. } \\
\text { c3) The institutional properties of the network as a whole } \\
\text { influence how staff at the coordinating agency and member } \\
\text { organizations interact with technology. }\end{array}$ \\
\hline & & \\
\hline
\end{tabular}




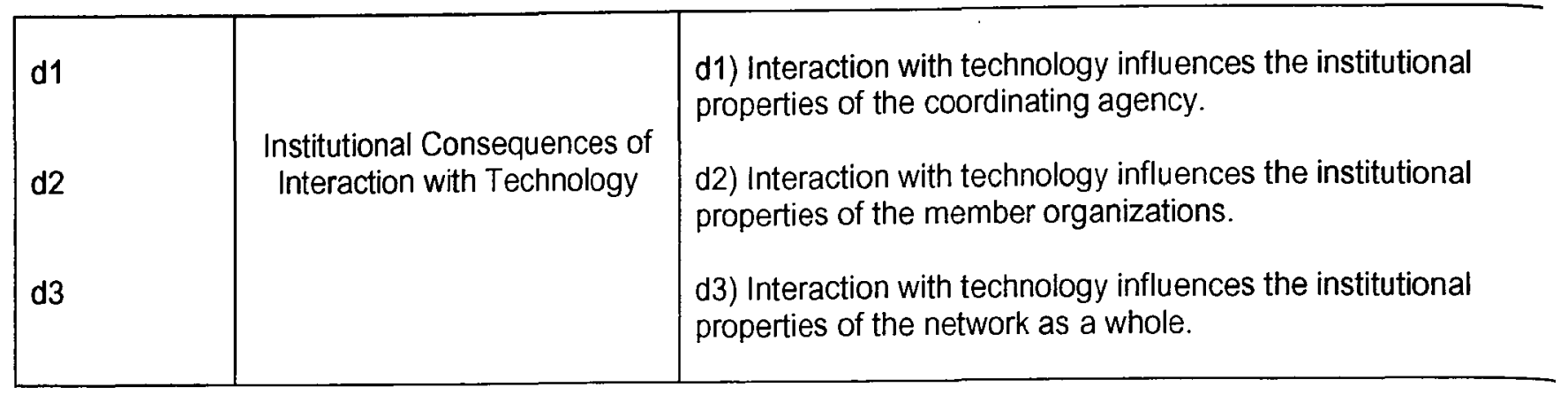

Thus, the structurational model is extended through its application to networks of nonprofit organizations. The three cases outlined above provide ample support for this extension, demonstrating the additional complexity of the institutionalization of technology in networks of organizations, where essentially three loci of influence exist: the coordinating agency's institutional properties and staff activity; the member organizations' institutional properties and staff activity; and, the institutional properties of the network structure as a whole. In fact, it is reasonable to speculate that this extension would apply to networks of forprofit organizations. It is not the unique orientation of nonprofit organizations that extends the structurational model of technology but the particular network configuration of the cases under review. Thus, we can assume that the processes of the institutionalization of technology would be similar within any organizational network based on a hub-member model.

Theories of institutionalism further help to illuminate the findings of the three cases. As indicated in the above literature review, organizations establish practices and structures that suit the demands of institutional players and other environmental conditions. The same can be said of organizational networks. However, an organizational network is itself the institutionalized environment of its member organizations. As such, the variable institutionalization of technology within the three cases is reflective of the member agencies' response to the properties and culture of the network, including the coordinating agency and 
other network members. Technology is institutionalized through one of several routes as members respond to their institutional environment.

For example, we see instances where technology is institutionalized in response to efficiency concerns. In the Northern region of the OAYEC network, members were experiencing a decline in funding which was reducing their ability to meet in person with one another. Seeking a solution to their dilemma, members of this region began exploring potential information and communication technologies. The coordinating agency offered the Workspaces to this region at no cost and the technology was subsequently adopted and institutionalized, proving to be an effective mechanism to address their geographic distances and capacity limitations. Within the OACAS network the Executives of the Human Resources network group institutionalized technology in a similar fashion. Concerned about the low frequency of communication among members and the inefficiencies of circulating documents by email without an archived history of communication, these Executives approached OACAS with a request for a private forum. This forum was created and institutionalized among the network's human resources professionals as an essential element of their communicative practices.

The experiences of OACAS's Human Resources network group also demonstrate the role of coercive processes of institutionalization. Powell and DiMaggio (1991) note the existence of formal and informal pressures that influence the behaviour of organizations within the institutional setting. These pressures took the shape of forceful coercion in OACAS' human resources discussion forum, as the Executives of that group insisted that members began using the new technology; a failure of members to do so would mean alienation from the communication and activities of the Human Resources network group. As a result, it was 
only a short time before even the most reluctant members adopted the technology. Similarly, the distribution of the Weekly Index provides another example of coercion in the case of OACAS. Long used to the distribution of the hard copy Thursday Mail, many members had a difficult time adjusting to the new electronic format and requested to continue receiving paper copies of the documents. O.AC AS insisted in turn that its members accept the new delivery format, refusing to circulate hard copies and forcing members to adapt to the email and website versions, which hill : vinciyuently been institutionalized throughout the network.

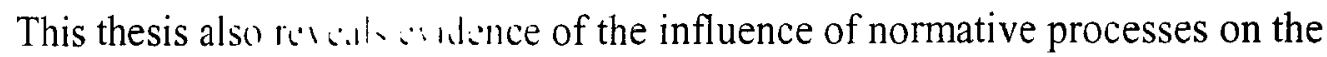

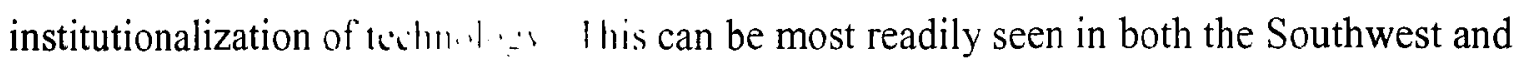
Northern regional mant:.... - w... their respective Workspaces. In both instances, members established their own prin......... $\cdots \cdots$. outlining the expectations they had of one another when

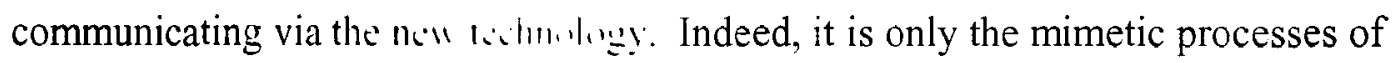
institutionalization which arc nut apparent in the three networks. There is no indication that any members adopted use of a particular technology as a result of modeling the example of other network members.

The processes of the institutionalization of technology within the three networks are a response to the institutional environment - i.e., the characteristics of the network-in which members operate. The diffusion of technologies throughout the network is not a uniform process as the individual members and member organizations exert more autonomy and display more disparate characteristics than is typical in a solitary organizational setting and therefore institutionalize technology to varying degrees. Importantly, institutionalization of technology within networks of organizations is not an "all-or-nothing" experience, but is better understood as happening along a continuum, occurring at differing rates and to varying 
degrees in different pockets of the network. Studies of the diffusion of technology in organizations have usually focussed on top-down hierarchical structures in which the issue is more one of implementation than diffusion - i.e., key decision makers within the organizations make the determination to implement a technology and then instigate this process across the organization (Frank, Zhao and Borman 2004). But in network structures members have more independence than in their hierarchical counterparts. The diffusion and subsequent institutionalization of technology is therefore a far more variable process.

Collectively, the findings discussed above offer several valuable lessons for networks of nonprofit organizations seeking to employ ICTs to support their work. First, the fact that technology is not institutionalized consistently within the network should be acknowledged and embraced. Coordinating agencies would be wise to accept this reality and not seek to impose a uniform technological solution across the network. Instead, staff at these agencies should find ways to map technologies onto the pre-existing characteristics or structural elements of the network, for example creating role-based or regionally-based technologies. Further, coordinating agencies should introduce technologies that are flexible enough to accommodate the varying conditions of these groups. Rather than deploy rigid technologies that can be used only in a prescribed way, coordinating agencies should empower their network with technology that can be modified to suit the unique circumstances of member organizations and member groups.

The variable institutionalization of technology is, of course, a reflection of the different operational contexts into which a given technology is deployed. This point must be emphasized. Technology appears much more likely to reflect and reinforce existing organizational characteristics than it is to radically change them. The Southwest and Northern 
regions of OAYEC had a strong pre-existing tradition of inter-agency communication and collaboration. The Human Resources network group of OACAS displayed similar characteristics. On the other hand, OAYEC's Central region and the OACAS Finances group lacked such camaraderie and both groups ignored technology that was meant to stimulate and support their communication. Thus, organizations seeking to deploy technology within a network structure must recognize the limitations of technology and find ways to use technology to augment existing characteristics: technologies will have the most success in situations where they are appropriately matched to the circumstances to which they are introduced.

The notion that technology reflects institutional properties occurs not only at the microlevel of member organizations and their groupings, but also at the macro- or network-wide level. OACAS, the tightest network among the three cases, has had the greatest success in institutionalizing technology, most notably its website, within the network. OCASI, a far more diffuse network in which members report only moderate ties with the coordinating agency, has not been able to institutionalize its member's website or discussion boards. Coordinating organizations must therefore carefully consider the institutional properties of the network before deciding on their technology investment. Again, technology is unlikely to solve existing problems or radically alter existing conditions. Instead, a frank appraisal of institutional properties should inform expectations and identify areas in which technology can be of most assistance. Most particularly: What is the need for the technology and in what ways will it assist the network in general and member organizations in particular?

The pre-eminent role of members must also be deeply considered by networks of organizations seeking to implement ICTs. Not only do members operate in different contexts 
than the coordinating agencies, but members themselves differ in their capacity, motivations and needs. It is of critical importance that these considerations are addressed and that coordinating agencies work to include members in their technology strategy. This last point is most dramatically illustrated in the OACAS network, in which members were not apprised in advance of the transition to technology and responded with a negativity that has taken several years to subside. Members should not only be informed in advance of such plans but should be involved in their formulation. Through research that carefully assesses the needs and capacities of member organizations, coordinating agencies can better ensure that their technology plans are well grounded in the network and will subsequently stand a greater chance of success. Additionally, sufficient resources should be allocated to technology training and promotion. Building a technology platform does not necessitate its use and efforts must be made to assist the adoption of technology among the network members. Involvement of members is an ongoing and informative process, involving strategy development, design, testing, training, promotion, and subsequent modification.

More generally, the experiences of the three cases reflect existing literature on the deployment of technology in network organizations and in the nonprofit sector. Leadership is critical to the successful institutionalization of technology and buy-in from internal staff and member organizations are of utmost importance. Resource and capacity limitations must be carefully considered, especially for a sector in which funding can be erratic and infrastructure under developed. This is particularly important when considering the sustainability of a project, which must outlast its initial funding and exist to provide ongoing support to the network. Finally, networks of nonprofit organizations would be wise to tread carefully, slowly 
deploying and testing technology before making a costly investment that may drain valuable resources and ultimately prove a poor fit for the network. 


\section{Limitations of the Research}

The investigator is obliged to identify a few of the inherent limitations of this research project. First and foremost is the investigator's inability to fully explore the experiences of different network members and the different staff within the member agencies. The researcher was unable to speak with all members of a given network and it is therefore impossible to conclude with confidence that the research findings accurately assess the totality of member experiences within the networks. Indeed, only a fraction of the total number of member agencies participated in the interviews: $10 \%$ of OCASI members, $20 \%$ of OAYEC members, and $27 \%$ of OACAS members. It is possible that the experiences of other members would be different and this presents a potential challenge to the validity of the findings.

Resource limitations also prevented a thorough exploration of the different staff levels within member agencies. It is quite apparent that technology is institutionalized differently among different staff at member agencies and that this is a critical intervening variable in an overall assessment of the institutionalization of technology within the network. This thesis relied in part on the Executive Directors to convey the experiences of their staff, which implies a potential challenge to the accuracy of those comments. Additionally, those staff members who did respond directly to the email surveys had opted-in to the research project and this bias may have influenced the results. It must be mentioned, however, that an increase of scope of this nature would necessitate alternate research methods as one would be challenged to assess the experiences of over 7,500 staff, as is the case in the OACAS network.

A second challenge to the research is the duration of the study. This thesis provides only a snapshot of the processes of institutionalization of technology, which had already begun before the investigator arrived and will no doubt continue long after he has departed. A 
longer-term assessment of the experiences of the network would certainly produce additional fruitful findings. The investigator has been forced to rely on document analysis and respondent accounts to get a sense of what the organizational environment was like before the introduction of new technologies. This carries an inherent weakness and the investigation would have been better served by a diachronic analysis that directly considered changes over time.

Finally, it is worth directly addressing the charge that the results of case study research are not generalizable to other cases. This thesis has examined three cases of networks of nonprofit organizations; the applicability of these findings to any other case cannot be ascertained. Case studies are frequently criticized for their focus on the specific situation and an inherent inability to apply the findings to other cases. However, it is unjust to apply measures of quantitative research to a qualitative mode of inquiry that was never intended to achieve the same goals. As Merriam asserts, "rather than transplanting statistical, quantitative notions of generalizability and thus finding qualitative research inadequate, it makes more sense to develop an understanding of generalization that is congruent with the basic characteristics of qualitative inquiry" (Merriam 1985: 2012). Yin (1999) offers the basis for such an understanding by remarking that case studies "are generalizable to theoretical propositions and not to populations or universes" (pp. 31). So while these findings may not be generalizable to all networks of nonprofit organizations, they do produce inroads into theory that can be further refined through the investigation of other cases.

Despite the limitations described above the investigator remains confident that the thesis has achieved its goals of description and exploration. The decision to sacrifice comprehensiveness of a single case for a comparative approach of three cases remains a valuable one, as preliminary findings indicate that there are strong similarities among the 
experiences of networks of nonprofit organizations. While it may be difficult to generalize beyond the cases at hand, this research has identified the initial threads of a theory of the institutionalization of technology in networks of nonprofit organizations and has helped define an agenda for further exploration. 


\section{Recommendations for Further Research}

This section identifies three primary areas for future research. While there are numerous avenues of potential exploration, the investigator finds that the following three will be most fruitful in contributing to the body of knowledge on the institutionalism of technology and to the practical application of those findings.

Increasing Comprehensiveness - Multiple Levels and Longitudinal Analysis

Flowing out of the limitations of this research there is clear benefit to additional and more comprehensive case studies on this topic. The more cases which are explored the better the opportunity to comprehend the institutionalization of technology in networks of nonprofit organizations and to contribute to theories of institutionalism and to structurational models of technology. In particular, future researchers should bear two considerations in mind. First should be efforts to increase the comprehensiveness of the research by ascertaining the experiences of different types of members and of different staff within the member agencies. Within the networks described above it is clear that the institutionalization of technology varies across these factors. Future research should endeavour to identify the different variables that influence the institutionalization of technology and assess the impact of these characteristics on the institutionalization of technology.

Second is the need for a diachronic perspective. Structurational theorists emphasize the need for such analysis, arguing that the structuration of technology is a process that occurs over time, most particularly with ICTs which are by nature modifiable throughout their existence. Fortunately the pace of change in communication technology provides ample opportunity to study the introduction, adoption, and subsequent modifications of new technologies in a network setting. Researchers should be prepared to observe the processes of 
institutionalization over time, paying particular attention to the recursive relationship between technology and the characteristics of the network.

\section{Different Network Configurations}

This thesis explored a particular network type - a model in which network members were served by a central hub unit. However, networks are multifarious and one can presume that the processes of institutionalization of technology would differ among these configurations. What of network models in which there is no centralized coordinating agency, or in which multiple agencies collectively assume a leadership role? What of networks operating in a common geographic area instead of a common sector? Such radically different structures will have varied experiences of technology implementation and use; scholars should use the theoretical tools of institutionalism and structuration to explore the implications of such differences.

Additionally, the three cases that participated in this study were each formed prior to the advent of the internet. They were subsequently forced to adapt to changes in technology and this has permitted an assessment of the impact of the internet on the operations of the network. But networks of nonprofit organizations are forming all the time and those created in the past ten years have used the internet as part of their communicative resources since their inception. What is the experience of networks that have relied on the internet as part, or central to, their operation? Potential differences in activities and structural arrangements merit additional attention and will increase our understanding of the recursive relationship between organizational structure and technology.

Further, distinctions between networks of nonprofit organizations and networks of forprofit organizations merit attention. The bulk of existing research on institutionalism and on 
structurational models of technology concentrates on the for-profit sector. However, differences in network structure and purpose, and differences in the motivations and roles of network actors, in for-profit and nonprofit organizational networks would likely have substantial impact on the institutionalization of technology. Comparative investigation of these differences would yield additional insight into the processes of technology institutionalization.

Action Research

Finally, this topic is aptly suited for action research. The research process revealed several opportunities for improved implementation of technology gleaned from critical observation of the case at hand and from the experiences of the other cases. Given the typically limited resources of nonprofit organizations and the good work they aspire to perform, outside analysis and support can be a great boon to the successful deployment and adoption of technology. Future researchers should explore this topic not only to contribute to our theoretical understanding of technology and organizations, but with an eye toward making a contribution to the performance of the networks under review. The practical application of findings not only returns some benefit to the participating cases, but opens up additional avenues for research as the results of such efforts are evaluated for their practical and theoretical consequences. 


\section{Conclusion}

This thesis has applied concepts of institutionalism and the structurational model of technology to three networks of nonprofit organizations. The aim of the research has been to contribute to theory on technology and organizations and to contribute to the improved use of technology within networks of irymizations in the nonprofit sector. Clearly, the experiences of the three cases under rखル themselves contributed w h. lw. 1 utre on these theories. In particular, this thesis has extended the structuration.1 $\ldots$. W . if technology by demonstrating the complexity of the

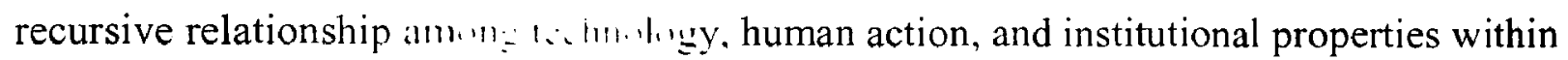

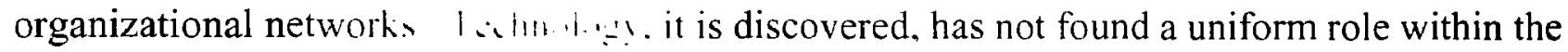
three networks but is inskin m mutum malized differently in different parts of the network - a reflection of network structur: 11 :-neral and organizational characteristics in particular. While this finding makes il cumtribution to theories of the interaction between technology and organizations, it is also of practical benefit to the nonprofit sector. Nonprofit organizations can make more effective use of ICTs by accepting and leveraging the variable roles of technology within their organizational networks.

This is an area of research that merits greater attention. Networks of nonprofit organizations provide ideal ground for the confluence of theoretical and practical study, and future researchers should continue to explore this unique organizational form with an aim of contributing not only to the development of theoretical constructs, but to improving the way in which these networks employ technology in pursuit of their missions. 


\section{Appendix A - Data Source: Documents}

\section{OAYEC}

2003 Annual Members Satisfaction and Research Survey (2003). Toronto: Ontario Association of Youth Employment Centres

Annual Report 2003-4 (2004). Toronto: Ontario Association of Youth Employment Centres

Annual Report 2002-3 (2003). Toronto: Ontario Association of Youth Employment Centres

Annual Report 2001-2 (2002). Toronto: Ontario Association of Youth Employment Centres

Doing it on Purpose: Strategic Plan, 2004-8 (2004). Toronto: Ontario Association of Youth Employment Centres

Donaldson, Stephanie and Jesse Boyd (2005). Technology Review: Toronto: Ontario Association of Youth Employment Centres

Donaldson, Stephanie (2004). OAYEC 2004 Annual Member Survey. Toronto: Ontario Association of Youth Employment Centres

e-Bulletin (May 2002) Toronto: Ontario Association of Youth Employment Centres e-Bulletin (June 2002) Toronto: Ontario Association of Youth Employment Centres

McCool, Fiona (2004). E-Learning: Four Case Studies with Youth. Toronto: Ontario Association of Youth Employment Centres

Network Members Profile (2004). Toronto: Ontario Association of Youth Employment Centres

Network Member Profile - Synthesis (2004). Toronto: Ontario Association of Youth Employment Centres

OAYEC's e-Strategy Project Overview' (2002). Toronto: Ontario Association of Youth Employment Centres

Organizational Chart (2002). Toronto: Ontario Association of Youth Employment Centres Organizational Chart (2005). Toronto: Ontario Association of Youth Employment Centres Promotional Brochure (2004). Toronto: Ontario Association of Youth Employment Centres Quarterly Policy Update (2005). Toronto: Ontario Association of Youth Employment Centres Quarterly Knowledge Transfer (2005). Toronto: Ontario Association of Youth 
Wood, Matt (2005). Letter to Minister of HRSDC regarding changes to the call for proposals process. Toronto: Ontario Association of Youth Employment Centres

Volunteer@ction.Online Program Application (2001). Toronto: Ontario Association of Youth Employment Centres

Volunteer@ction.online Final Report (2002). Toronto: Ontario Association of Youth Employment Centres

Wansborough, Paula (2004). E-Business Internet-based Tool Inventory. Toronto: Ontario Association of Youth Employment Centres

Wansborough, Paula (2004). Environmental Scan of Employment Sector e-Services. Toronto: Ontario Association of Youth Employment Centres

Wansborough, Paula (2004). Providing Effective e-Services for Job Connect Clients and their Potential Employers. Toronto: Ontario Association of Youth Employment Centres

Youth Website Proposal (2004). Toronto: Ontario Association of Youth Employment Centres 


\section{OCASI}

Annual Report 2003-4 (2004). Toronto: Ontario Council of Agencies Serving Immigrants Annual Report 2002-3 (2003). Toronto: Ontario Council of Agencies Serving Immigrants Annual Report 2001-2 (2002). Toronto: Ontario Council of Agencies Serving Immigrants Annual Report 2000-1 (2001). Toronto: Ontario Council of Agencies Serving Immigrants Annual Report 1999-20101 (20101 Toronto: Ontario Council of Agencies Serving Immigrants

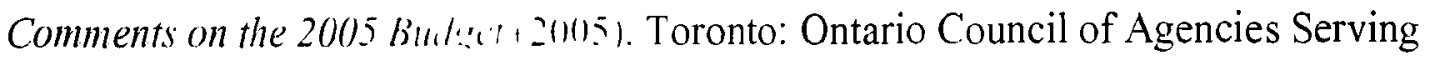
Immigrants

Computer Truining Optum, h: ( Mirurio's ISAP/HOST Program Funded Agencies (1998). Toronto: Ontario ( num it . Igencies Serving lmmigrants

Computerization of IS:II' a I/A M Prrerram Funded Agencies in Ontario - Project

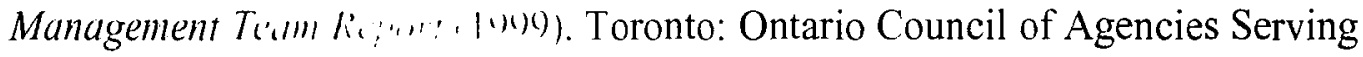
Immigrants

ISAP Program review: Fimal Ripun and recommendations (2003). Toronto: Real World Systems

Kerr, Gillian, Anne Simard and I uri Powers (2002). Evaluation of the OASIS Computerization Project-Final Repurt. Toronto: Real World Systems

Managing in a Computerized Emiromment (MICE-2) - Final Report (2002). Toronto: Ontario Council of Agencies Serring Immigrants

Notes from Settlement. Org firctis groups (July 2003). Toronto: Ontario Council of Agencies Serving Immigrants

Promotional Brochure (2004). Toronto: Ontario Council of Agencies Serving Immigrants

Proposal to Undertake a Computerizution Needs Assessment and Feasibility Study (1997). Toronto: Ontario Council of Agencies Serving Immigrants

Report on Activities Conducted April 2001-March 2002: Computerization of ISAP \& HOST Program Funded Agencies in Ontario (2002). Toronto: Ontario Council of Agencies Serving Immigrants

Report on Computerization of ISAP \& HOST Program Funded Agencies in Ontario (1998).

Toronto: Ontario Council of Agencies Serving Immigrants 
Settlement.Org Annual Report (2004). Toronto: Ontario Council of Agencies Serving Immigrants

Simeone, John B. and Michael Miloff (1998). Options for Providing ISAP Funded agencies with Internet Access. Toronto: Ontario Council of Agencies Serving Immigrants 


\section{OACAS}

Achieving a Better Balance - Response from OACAS Member Agencies to Accountability

Discussion Paper: Finding the Right Balance (2004). Toronto: Ontario Association of Children's Aid Societies.

Adopting a Child (2004). Toronto: Ontario Association of Children's Aid Societies.

Annual Report 2004-5 (2005). Toronto: Ontario Association of Children's Aid Societies.

Annual Report 2003-4 (2004). Toronto: Ontario Association of Children's Aid Societies.

Annual Report 2002-3 (2003). Toronto: Ontario Association of Children's Aid Societies.

Annual Report 2001-2 (2002). Toronto: Ontario Association of Children's Aid Societies.

Becyming a Foster Fumily (2004). Toronto: Ontario Association of Children's Aid Societies.

Board to Board Newsletter (November 2004). Toronto: Ontario Association of Children's Aid Societies.

Board to Board Newsletter (January 2005). Toronto: Ontario Association of Children's Aid Societies.

Children's Aid Society Facts. April 2003 - September 2003 (2004). Toronto: Ontario Association of Children's Aid Societies.

Communication/Information Services: Audit Report (2005). Toronto: Ontario Association of Children's Aid Societies.

Conference Program (2004). Toronto: Ontario Association of Children's Aid Societies.

e-Business Readiness Assessment (2005). Toronto: The Braegan Group

If your Child is in our Care (2004). Toronto: Ontario Association of Children's Aid Societies.

Kofoed, Kristine (2005). HR OnLine: OACAS HR Forum Development. Toronto: Ontario Association of Children's Aid Societies.

Minutes of the meeting of the Inter-Agency Human Resource Committee. (2005). Toronto: Ontario Association of Children's Aid Societies.

OACAS Factsheet (2004). Toronto: Ontario Association of Children's Aid Societies.

OACAS Journal (Spring 2004). Vol 48, No 1. Toronto: Ontario Association of Children's Aid Societies. 
OACAS Journal (Spring 2004). Vol 48, No 2. Toronto: Ontario Association of Children's Aid Societies.

Service Plan 2004-5. Toronto: Ontario Association of Children's Aid Societies.

Supporting Children and Families (2004). Toronto: Ontario Association of Children's Aid Societies. 


\section{Appendix B - Data Source: Websites}

\section{OAYEC}

OAYEC has one website (www.oayec.org), with password protected access to the OAYEC Workspaces (discussion boards). There are approximately seventeen Workspaces and the principal researcher was given access to eleven Workspaces. Of these, six had no postings, three had a few postings, one had twelve postings and the final Workspace (the Southwest Managers Workspace) had over one hundred postings. The postings were read for a sense of the frequency and type of communication, and to compare against the comments of the interviewees. The researcher did not have access to the Northern Managers Workspace

Website usage statistics for a random one week period (February 28 - March 6, 2005) were also reviewed.

\section{www.oayec.org - Site Map}

\section{Home Page}

\section{OAYEC Members}

- Member Listing

- Become an OAYEC Member

- Application Form

- Member Profiles

\section{Professional Development}

- OAYEC Annual Conference

- PD Opportunities and Resources

\section{Research}

- Current Projects

- Just Released

- Complete Research Listing

\section{Programs}

- Current Programs

- EVIDENCE

- OAYEC Website for Youth

- Past Programs 
News

- News

- OAYEC Bulletin - Knowledge Transfer and Policy Updates

- OAYEC e-Bulletin Archives

Events \& Jobs

- Events

- Job Listings

Resource Library

- Resource Library Database

- HR Management Tool-kit

Youth Services Directory

- Central Region

- Eastern Region

- Northern Region

- South West Region

Work Space

About OAYEC

- Vision and Values

- Partnerships

- Board of Directors

- Reports

\section{Contact Us}

\section{Search}

Terms of Use

Web site Credits 


\section{OCASI}

OCASI has three websites. The main OCASI website (www.ocasi.org) was thoroughly reviewed for content, structure and features. The Settlement.Org for Newcomers website (http://www.settlement.org/index.asp) was briefly reviewed for content and features, and the Settlement.Org at Work website (http://atwork.settlement.org/atwork/home.asp) was thoroughly reviewed for content, structure and features. There are a total of thirteen discussion forums containing 44 posts on the Settlement.Org at Work website. All of the discussion boards on the Settlement.org at Work website are publicly accessible, and the contents therein were reviewed as part of the research.

\section{www.ocasi.org - Site Map}

\section{Home Page}

\section{About OCASI}

- A Message from the President and Executive Director

- Statement of Principles and Objectives

- Annual Report

\section{Advocacy}

- Public Education

- Policy and Research

- Training and Professional Development

- Technology

- Media Room (Press Releases)

- Press Release Archive

- Membership

- OCASI's Members

- Membership Benefits

o How to Become an OCASI Member

\section{OCASI Monthly Reports}

\section{Publications}

- Settlement Worker Training Guide

- Splash and Ripple: Outcome Measurement Manual

\section{Staff Directory}

\section{Board of Directors}


Contact Us

Privacy Statement

Terms and Conditions

http://atwork.settlement.org/ - Site Map

Home Page

Headlines

Events

Jobs

News

Research

Web Tools

Assisting Clients

- Access and Equity

- Community Development and Networking

- Counselling and Case Management

- Information and Referral

- Serving Specific Groups

\section{Assisting Staff}

- Administration

- Agency Management

- Funding and RFPs

- Professional Training and Development

- Program-Specific Information and Resources

- Sector Issues

- Self-care, Self-knowledge

Settlement.Org for Newcomers

\section{Submit a Resource}


Feedback

About this Site

Contact Us

Search

Discuss 


\section{OACAS}

OACAS has two websites. The OACAS public website (http://www.oacas.org/) was reviewed for content and features. The OACAS password protected Member's Website (http://www2.oacas.org/) was reviewed for content, features and structure. OACAS has three discussion forums for members. of which only one (the HR Forum) is active. Access to this forum could not be granted so in interview was conducted with one of the Executives of the HR Forum to learn more ahout the experiences in using this feature (see below). OACAS Member's Website statistic , fir the period January 1.2005-March 31, 2005 were also reviewed.

\section{" ww.oacas.org - Site Map}

\section{OACAS Home}

\section{About OACAS}

- Mission

- Board of Direchm

- OACAS Managen

- History of OAC $1 \mathrm{M}$

- Annual Report

\section{Programs}

- Accreditation

- Foster Care

- Information and Teclunology

- Looking After Children Project

- Looking After Children FAQ

- Ontario Child Protection Training Program

- Services en français

- Youth in Care Connections Across Ontario

\section{Child Welfare Resources}

- History of Child Welfare in Ontario

- What is a CAS?

- How and when to report child abuse

- Risk Assessment Model for Child Protection in Ontario

- Ontario Child Welfare Eligibility Spectrum

- CASs in Ontario

- Child Welfare Links 
- Child Welfare Statistics

- OACAS Journal Online

- Positive Parenting Package

- Purple Ribbon Campaign

\section{What's new?}

- Child welfare issues in the news

- OACAS Announcements

\section{Careers in Child Welfare}

Search

Contact Us

\section{http://www2.oacas.org/ - Site Map}

\section{Home \\ Help \\ Calendar \\ Site Map \\ Contact Us}

\section{Training}

- Announcements

- Trainer Application Package

- ATD Memos

- Attachments

- Course Descriptions

- Meeting Agendas \& Minutes

- OCPTP Online Registration

- P.R.I.D.E.

- Training Schedule: New Worker

- Training Schedules: Authorized Worker \& Manager/Supervisor

- Training Schedules: Train the Trainer

- Trainer's Forum

- Training Staff

\section{Resources}

- Archived Announcements

- Awareness Resource Kit

- Calendar

- CAS Facts 
- Contact Lists

- Contracts

- Discussion \& Policy Papers

- Forums

- Frontline Resources

- Inquest Updates

- Job Postings

- Journal Online

- Key Messages

- Links

- MPP Visit Kit

- OnLAC

- P.R.I.D.E.

- Section 43

- Surveys

- Training Opportunities

\section{Databases}

- Annual Awards

- Contracts

- Inquest Recommendations

- Provincial Projects

\section{Special Events}

- Consultation

- Foster Family Week

- LD/DOS Conference

- Purple Ribbon Campaign

\section{OACAS}

- About OACAS

- Annual Report

- Board Members

- Our Members

- Our Managers

- Our Staff

- Contact Us

\section{Surveys}




\section{Appendix C - Data Source: Respondents}

\section{OAYEC}

\section{Interviews with representatives of the Coordinating Agencies}

Four 90-minute in-person interviews were held with OAYEC staff:

- Matt Wood, Executive Director (MW)

- Stephanie Donaldson. Seminr Research Analyst (SD)

- Jesse Boyd, Technicil Suppiri (JB)

- Deanna Yerichuck. Risith and Communications* (DY)

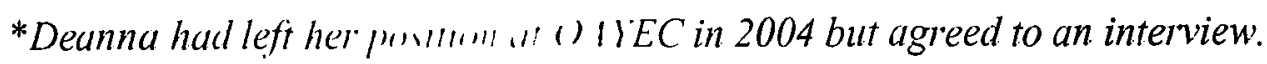

\section{Interviews with Menlocr}

A total of fourteen 30-mmun: $1.1 \cdot$ phlmme interviews were conducted with OAYEC's principal contacts at their member at:-llk

- Central Region: 1 interrkw

- Eastern Region: 4 intcriculls

- Northern Region: 4 intervicus

- Southwest Region: 5 interview's

Approximately $80 \%$ of OAY'EC members deliver JobConnect. Twelve of fourteen interviewees represented lobc onnect deliverers and two did not.

OAYEC Member respondents are referred to in the report by their region and a randomly assigned number. For example. SW-2, E-4, etc.

\section{Ethnography/Focus group}

I observed a meeting of the Central region representatives. At the end, I conducted a brief thirty minute focus group with the six participants. 


\section{OCASI}

\section{Interviews with representatives of the Coordinating Agencies}

Five interviews were held with OCASI staff. The Executive Director was interviewed by telephone for 60 minutes and the remaining staff were interviewed in person, from 90 to 120 minutes.

- Debbie Douglas, Executive Director (DD)

- Paulina Maciulis, Manager, Policy and Programs (PM)

- Martha Orellana, Membership Coordinator (MO)

- Marco Campana, Policy Analyst \& Communications Coordinator (MC)

- Christopher Wulff, Information Technology Transition Coordinator (CW)

\section{Interviews with Members}

A total of sixteen telephone interviews were conducted with OCASI's principal contacts at their member agencies:

- Central East Region: 1

- Central West Region: 2

- Toronto Region: 5

- North Region: 2

- South Region: 2

- East Region: 2

- West Region: 2

Approximately $50 \%$ of OCASI's membership delivers the ISAP program. Nine of the 16 interviewees represented agencies that deliver this program.

OCASI Member respondents are referred to in the report by their region, a randomly assigned number, and a letter for their ISAP designation. For example. E-2-I represents eastern region agency number two. which is an ISAP deliverer. T-3-NI represents Toronto region agency number three, which is Not an ISAP deliverer. 


\section{OACAS}

\section{Interviews with representatives of the Coordinating Agencies}

Four 60- to 90-minute in-person interviews were conducted with staff of OACAS:

- Jeanette Lewis, Executive Director (JL)

- George Leck, Director, Information Services (GL)

- Gail Vandermeulen, Director, Communications and Quality Assurance (GV)

- Kristine Kofoed, Web Coordinator (KK)

\section{Interviews with Members}

A total of fourteen 30-minute telephone interviews were held with the principals at OACAS member agencies:

- Central Zone: 2

- Eastern Zone: 2

- Northeast Zone: 1

- Northern Zone: 3

- Southwest Zone: 3

- Grand River Zone: 3

Approximately $20 \%$ of OACAS agencies are multi-service agencies, providing services in addition to child welfare. Three of these multi-service agencies were interviewed.

OCASI Member respondents are referred to in the report by their region and a randomly assigned number: For example. SW-2, GR-1. etc.

A second staff member participated on four of the telephone interviews. In addition, four managers of front-line workers responded to an email survey that had been forwarded by their Executive Director following the teleconference.

One member respondent took it upon himself to email his staff with a mini survey about the use of the Weekly Index. Nineteen responses were received and considered into the analysis.

Finally, a separate telephone interview was conducted with the Director of Human Resources at the Catholic Children's Aid Society in Toronto. This interview was conducted based on this individual's key role in the HR discussion forum, aiming to better understand that particular technology. This individual is referred to in the report as HR-1.

\section{Participation in Meeting of $H R$ Directors of Service}


The investigator also attended a meeting of the HR Directors of Service to observe their interaction and discussion and to ask a few questions of the group. There were approximately 25 attendees at this meeting. 


\section{Appendix D - Research Instrument: Interview Questions (Staff)}

\section{OAYEC}

1. In your own words, please describe the purpose of OAYEC

- Probe: Why does the sector need OAYEC?

2. Why do members join OAYEC?

3. How would you describe:

- The Youth Employment subsector in Ontario (how is it distinct from other sectors)?

- The culture of the association?

- The relationship among OAYEC members?

- The relationship between members and OAYEC?

4. How do you see communication technology fitting in the association - what is its role?

5. Can you describe how you see the website serving your members?

- Probe: Why do they visit the website?

- Probe: How have members and member's needs influenced the features or information offered in the network website?

6. How have you encouraged your members to make use of new technology?

- Probe: Technical training \& support

- Probe: Eleven workshops

- Probe: How have you encouraged member use of the website?

7. What is your vision for the website - what it could be?

- Probe: What need/gap could the website intended fill?

8. I'd like to discuss a little bit about how communication technology has affected what OAYEC does. What has been the most significant impact of the internet on OAYEC?

- Probe specifically for the impact of the website on:

- the roles of OAYEC within the network

- decision-making processes, strategic or policy direction (do members have more input??)

- information circulation

- network culture / building a sense of community

- relations with members

- relations among members

Value: Active and influential membership

Core finction: Public Poiicy

Core function: Professional development 
- Probe specifically for any perceived negative effects of the website, or constraints on pre-existing practices and processes.

9. Can you provide some examples of what the internet has allowed you or your members to do that would have otherwise been impossible?

\section{EVOLITION OF WEBSITE FEATURES}

"I'd like to speak a little bit more specifically about the implementation of different website features."

10. How have decisions been made about the implementation and development of the website?

- Probe: Which staff have been primarily responsible for directing the development of the website?

- Probe: What has been the role of technology vendors?

- Probe: Can you tell me a bit about the e-strategy advisory committee? What role has this committee played in the development of your internet strategy?

11. On the public side of the website, you have an events calendar and job listings:

- Did OAYEC offer these services before the Web?

- Why are these services offered?

- Are they being used?

- Any changes to its use over time?

- Probe for description of changes and perceptions of why these changes have occurred, and to what benefit.

12. On the member's access site you have the OAYEC Workspace, which is comprised of various discussion boards.

- How was the decision made to offer discussion boards?

- What was the intended purpose behind offering the discussion boards?

- Have the discussion boards been achieving their intended purpose? Why or why not?

- In what ways has the use of the discussion boards changed over time?

- Probe for description of changes and perceptions of why these changes have occurred, and to what benefit.

13. I notice that some of the discussion boards seem heavily used, while others have no postings. How do you explain variation in discussion board activity?

- How have you encouraged memher activity/use of the discussion boards?

- What are some of the reasons why members do not use the website, or do not use it more often?

- Southwest managers

14. Did you ever try/have you considered any other features in the Workspace?

- Probe: Listservs

If "no"

- Probe: Chatrooms? 
Why not? $\quad$ If "yes"
I

Please describe the experience. Why are these no longer offered?

15. Can you tell me a little bit about the Shared Resource Library Pilot project?

- What was this project intended to do?

- In what ways has the Shared Resource Library Pilot project changed over time?

- How successful has it been?

- Probe for description of changes and perceptions of why these changes have occurred, and to what benefit.

16. Can you tell me a little bit about the Contact management database? I get the sense this has evolved over time. What was the original intent and where does it stand now? Why has it changed?

17. Has your participation in the content sharing network affected your membership/ relationship with your membership?

18. What about other communication technologies, like teleconferences, videoconferences, webconferences or shared document editing? Have you ever considered these? Why or why not?

19. How have your perceptions of the Web as an instrument to serve your members changed over time?

- Probe

20. What has frustrated/disappointed you about the deployment of technology in the network?

21. What has surprised you about the deployment of technology in the network?

22. What lessons have you learned about the implementation of information and communication technologies within your network?

23. What plans do you have for implementation of new features or for changes to the use of the current website? Why?

24. Is there anything you would like to mention that we haven't had the opportunity to discuss"?

25. The Volunteer@ction Online funding really allowed you to build your website. How critical was this funding to the development of an internet platform with your members? Where would you be otherwise?

\section{OCASI}


1. In your own words, please describe the purpose of Ontario Council of Agencies Serving Immigrants.

- Probe: Why does the immigrant-serving sector need OCASI?

2. Why do members join the network? What does OCASI offer its members?

3. How would you describe:

- The culture of the network?

- The relationship among network members?

- The relationship between members and the coordinating agency?

4. How do you see technology fitting in the association - what is its role?

- What has tech allowed you to do for members that would have otherwise been impossible?

5. How have decisions been made about deploying technology at OCASI and with members?

- Probe: Which staff have been primarily responsible for directing the development of the website?

- Probe: What is your role?

6. I'd like to talk a little bit about the two websites - Settlement.org for newcomers and Settlement.org@work.

o Probe: Who are the audiences for the two sites?

- Who is the audience of (a) work? Managers vs. front-line?

7. Focus on Settlement.org@work.

- How did it start? What was impetus behind? (OASIS computerization project)

- How did OCASI get funding for settlement and extranet via OASIS - through RFP?

- Who owns Settlement.Org - government or OC.ASI? Where was funding? (contracted by OASIS)

- What is the role of the Settlement.org steering committee?

- How did they decide what content to offer? Design?

- a) assisting clients; $b$ ) assisting staff

- What do they do to modify content, design etc. what is this process like?

- Do they solicit member feedback?

\section{From Extranet to@Work}

- Why did this begin as an extranet?

- Why change? 
- What did you want the settlement@Work site to do that the extranet didn't?

- Did they engage members in the transition?

\section{Discussion Boards}

- Why offer discussion boards?

- What were discussions like on the extranet?

- What have you done to stimulate?

- Moderating? Does it work?

- Why did they open the discussion up to the public?

- Has anyone set up a private discussion forum on the new @ work site?

- Why did they offer private and how promote?

- Who's using the Discussion Boards?

- What are they using the discussion boards for?

- Do you see fluctuating levels of activity? Why?

10. Can you describe how you see the website serving your members?

- How do you envision the site fitting into the day to day activities of members?

- Probe: Why do they visit the website?

- Probe: Which features have been of most value to your members? Why?

11. Have you ever consulted members about the implementation and development of the website?

- Probe: How have members influenced the content of the website?

- Who else influences the development of the sites (what was role of OASIS report by Kerr)?

12. What has been member reaction, or "take-up," to the website?

- Probe: Do different regions use tech differently?

- Probe: Does OCASI facilitate regional use of technology?

- Probe: Have they used tech for subsector issues - women's, elderly, refugees

13. How have you promoted use of OCASI's websites among members?

- Probe: Have you done any training?

- Probe: What has worked??

14. How have you introduced the website or new features to your members?

15. What is your own vision for the ( $w$, Work website?

a. Probe: What need/gap was the website intended to fill?

b. What barriers have prevented you from implementing your vision?

16. I understand you have done a listserv for information alerts. How did that come about?

- Probe: They have a listserv (info alters) -explore

- Probe: Instant Messaging?

- Any other listservs? (probe experience)

- Chat? 
17. Have you ever done any:

- Videoconferencing?

O Webcasting?

- Teleconferences?

- E-Training?

18. OCASI has a relationship with its members which predates the internet. I'd like you think a little bit about the impact of technology on the network.

- What has been the most significant impact of technology on OCASI?

- How has technoln!: changed your relationship with members?

- Probe specilically lin the impact of the website on:

i. the rolsur () ISI within the network

ii. decisinn-m11.1 $1 n \div$ processes, strategic or policy direction (do members have more input'

iii. inform.tu, nl usulation

iv. newwh w whut: huilding a sense of community

1 1. 1.111 .11 . with members

21.111 .11 . .mong members

- How has it shupul

v. Police a kinilld:

vi. Public f dusithn.

vii. Trainm:- .ms Professional development;

viii. Adrocily.

- Probe specilicill! fir any perceived negative effects of the website, or constraints on pre-existin: practices and processes.

19. Can you provide some eximples of what the internet has allowed you to do that would have otherwise been impossible?

20. How have your perceptions of the Web as an instrument to serve your members changed over time?

c. Probe

21. What has frustrated/disappointed you about the deployment of technology in the network?

22. What has surprised you about the deployment of technology in the network?

23. What lessons have you learned about the implementation of information and communication technologies within your network?

24. What plans do you have for implementation of new features or for changes to the use of the current website? Why?

25. Is there anything you would like to mention that we haven't had the opportunity to discuss? 


\section{OACAS}

1. In your own words, please describe the purpose of Ontario Association of Children's Aid Societies.

2. Why do members join the network?

3. How would you describe:

o The culture of the network?

- The relationship among network members?

- The relationship between members and the coordinating agency?

\section{QueSTIONS ABoItT THE DEPLOYMENT OF ICTS}

4. How do you see technology fitting in your relationship with members - what is its role?

- What do you rely on the technology for?

5. Can you describe how you see the website serving your members?

- Probe: Why do they visit the website?

- Probe: How did you envision the site fitting into the day to day activities of members?

- Probe: Which features have been of most value to your members? Why?

6. What has member reaction or take-up of the website been like?

- Probe: Do you ever worry about alienation some of your less technically savvy members?

7. I notice you have put ads out in the Journal and had a booth at your most recent conference promoting the member website. Are there any other ways you have tried to stimulate member use of the website?

8. What is your vision for the website?

- Probe: What harriers are preventing you from achieving that vision?

9. How have decisions been made about the implementation and development of the website?

- Probe: Which staff have been primarily responsible for directing the development of the website?

- Probe: What has been the role of technology vendors?

- Probe: Rely on planning. strategic plans?

10. OACAS has a long-standing relationship with Children's Aid Societies which predates the internet. I'd like you think a little bit about the impact of website on the operations of the network. What has been the most significant impact of the internet on OAYEC?

- Probe specifically for the impact of the website on: 
- the roles of OACAS within the network

- decision-making processes, strategic or policy direction (do members have more input?)

- information circulation

- network culture / building a sense of community

- relations with members

- relations among members

How has it changed how you perceive/interact/service your members?

Intimacy with members?

- Probe specifically for any perceived negative effects of the website, or constraints on pre-existing practices and processes.

11. Can you provide some examples of what the internet has allowed you to do for members that would have otherwise been impossible?

\section{QUESTIONS ABOUT THE EVOLUTION OF WEBSITE FEATURES}

12. I'd like to talk a little bit about some of the features on the member's website. There is just a ton of information on there. How did you decide what belonged on the member website?

13. Have you ever consulted members over what they would like to see on the website?

14. I'd like to probe a bit around a few specific features to understand why they were offered, how they've been received, and how they've evolved over time.

- Job listings

- Events calendar

- Did you offer these services before?

- What was the intended purpose behind offering $X$ ? Why did you think it would be a good fit for your members?

- Has X been achieving its intended purpose? Why or why not?

- In what ways has the use of $X$ changed over time?

15. Much of content on the member's site is driven by OACAS. Have you ever considered using more interactive features such as...

Probe with:

- Listservs?

- Chatrooms?

- Discussion Boards?

If "no"

If "yes"

Why not?

- What has prevented you from offering $X$ ?

- What is the intended purpose of offering $X$ ? What do you think it will achieve?

16. How important is interactivity to the member's website? 
17. The Braegan report made some mention of moving to portal technology...

- Probe: Braegan indicated that OACAS wants to build a culture that encourages a dynamic collaborative environment - probe

- Probe: What direction is OACAS going in the next couple of years with the member's site?

18. I also notice that you use the member's website for information collection and analysis (i.e., member surveys). Can you tell me a bit about why and how you use the web for this purpose?

19. I notice you also do e-rrainin!. Can you tell me a little bit about that experience?

20. I noticed a few refercilci $1 \cdots, \cdots$ mething called a "Common Information System" or a "Comprehensive Child II : iturc Information System." Are these the same - can you describe this initiatic $1 . .1 \mathrm{~m}$. and explain its current status.

- Probe

\section{REFLECTIONS ON THI: ル ル I "}

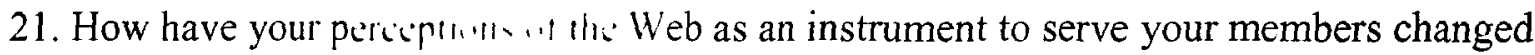
over time?

- Probe

22. What plans do you halc twr implementation of new features or for changes to the use of the current website"' "I h!!"

23. What has frustrated disippointed you about the deployment of technology in the network?

24. What has surprised you about the deployment of technology in the network?

25. What lessons have you learned about the implementation of information and communication technologies within your network?

26. Is there anything you would like to mention that we haven't had the opportunity to discuss? 


\section{Appendix E - Research Instrument: Survey Questions (Members) \\ OAYEC}

1. How would you describe your relationship with OAYEC?

2. I'd like you to rate the importance of membership in OAYEC to your organization, using a scale of one to five, where one is "Not at all important" and five is "Extremely important."

3. Why is your organization part of OAYEC - What are the primary benefits your organization receives from its membership in OAYEC?

4. How would you describe your relationship with other members of OAYEC?

- When and why do you communicate with other members?

- Probe for regional differences

5. I'd like you to rate how important is it for your organization to be able to communicate and collaborate with other members of OAYEC. using a scale of one to five where one is "Not at all important" and five is "Extremely important""?

\section{Website Use}

6. I'd like you to rate your comfort level navigating the internet (Web) on a scale of one to five, where one is not at all comfortable and five is perfectly comfortable?

7. On a scale of one to five, where one is not at all comfortable and five is perfectly comfortable, how would you rate your comfort level navigating the OAYEC website?

8. What is the purpose of the OAYEC Website?

- Probe: Who is the OAYEC website directed toward?

9. How frequently do you access the OAYEC website?

Daily A couple of times a week Weekly A couple of times per month Once a month or less

10. For what reasons do you usually access the OAYEC website?

- What is the main reason you access the OAYEC website?

- Why don't you access the website more often?

- Are there other websites you access to assist you with your work?

11. Who in your organization has access to the OAYEC website?

12. Who in your organization accesses the website?

a. Why do they use it? 
b. Do you encourage use of the website?

- Do your front-line workers/ counselors access any other websites to assist them in their work?

- Do you think a website could support your front-line workers?

\section{Workspaces}

13. Do you know about the OAYEC Workspaces?

14. What is the purpose of the OAYEC Workspaces?

15. Do you ever access the Workspaces?

If no:

16. Why not?

If yes:

17. Which Workspaces?

18. Why do use the Workspaces?

19. On a scale of one to five, where one is not at all comfortable and five is perfectly comfortable. how would you rate your comfort level using the OAYEC

Impact Workspace?

20. What impact have the OAYEC website and Workspaces had on your organization?

Probe

a. Have they affected your organizations' ability to pursue its mission?

b. Have they affected your access to information?

21. What impact have the OAYEC website and Workspaces had on your relationship with OAYEC?

Probe

a. Have they had any impact on your satisfaction with OAYEC?

b. Have they increased the sense of participation or intimacy you have with OAYEC?

22. What impact have the OAYEC website and Workspaces had on your relationship with other OAYEC members?

Probe

a. Have they increased your ability to communicate and collaborate with other OAYEC members?

23. How has email impacted your...

a. Relationship with OAYEC (probe e-bulletins and requests for feedback on policy statements)

b. Relationship with other members?

24. Have there been any negative impacts, or constraints on previous ways of doing things, that have come out of OAYEC's increasing reliance on communication technology? 
25. What could OAYEC do to make the website and Workspaces better for you? 


\section{OCASI}

1. How would you describe your relationship with OCASI?

2. Why is your organization part of OCASI - What are the primary benefits your organization receives from its membership in OCASI?

3. I'd like you to rate the importance of membership in OCASI to your organization, using a scale of one to five, where one is "Not at all important" and five is "Extremely important."

4. How would you describe your relationship with other members of OCASI?

- When and why do you communicate with other members?

- Probe for regional differences (do they speak with members from other regions?)

5. I'd like you to rate how important is it for your organization to be able to communicate and collaborate with other members of OCASI, using a scale of one to five where one is "Not at all important" and five is "Extremely important"?

6. Are you part of the OCASI Issues List?

a. What is the purpose of the OCASI Issues List?

b. Is the Issues List valuable? Why or why not?

7. Do you receive the OCASI Settlement $(a)$ Work email newsletter?

c. What is the purpose of the Settlement@Work email newsletter?

d. Is the email newsletter valuable? Why or why not?

8. I'd like you to rate your comfort level using the internet to search for information and communicate with others on a scale of one to five, where one is not at all comfortable and five is perfectly comfortable"?

9. Do you know about the Settlement.Org website?

10. What is the purpose of the Settlement.Org website?

11. Have you ever been to the Settlement $@$ Work website?

12. What is the purpose of the Settlement@Work website?

- Who is the intended audience of @ Work?

13. For what reasons do you access the Settlement $a$ Work website?

14. How frequently do you access the Settlement $@$ Work website? 
Daily A couple of times a week Weekly A couple of times per month Once a month or less

15. On a scale of one to five. where one is not at all comfortable and five is perfectly comfortable, how would you rate your comfort level navigating the Settlement@Work website?

16. Are there other websites you access to assist you with your work? Why do you visit them?

17. What are some of the reasons you don 't you access the website more often?

18. Who in your organization has access to the internet?

e. Do you feel you have enough computers for your staff?

19. Does anyone in your organization access the Settlement.Org website?

f. Why do they use it?

g. Do you encourage use of the website?

20. Does anyone in your organization access the Settlement@Work website?

h. Why do they use it?

i. Do you encourage use of the website?

\section{Discussion Boards}

21. Do you know about the Settlement@Work Discussion Boards?

22. What is the purpose of the Settlement@Work Discussion Boards?

23. Do you ever access the Settlement@Work Discussion Boards? If no:

$24 . \quad$ Why not?

If yes:

25.

Why do use the Discussion Boards?

26. On a scale of one to five. where one is not at all comfortable and five is perfectly comfortable, how would you rate your comfort level using the OCASI Workspace?

27. Do any of your staff use the $a$ Work discussion boards?

28. Do you use any other Discussion Boards? Why?

\section{Impact}

29. What impact have the OCASI websites. Discussion Boards, Settlement@Work newsletter and Issues List had on:

j. Your organization?

Prohe

- Have they affected your organizations' ability to pursue its mission? 
o Have they affected your access to information?

k. Your relationship with OCASI?

Probe

- Have they had any impact on your satisfaction with OCASI?

- Have they increased the sense of participation or intimacy you have with OCASI?

1. Your relationship with other OCASI members?

Probe

- Have they increased your ability to communicate and collaborate with other OCASI members?

30. Have there been any negative impacts, or constraints on previous ways of doing things, that have come out of OCASI's increasing reliance on communication technology?

\section{Closing Question:}

31. What could OCASI do to make the OCASI websites, Discussion Boards, Settlement@Work newsletter and Issues List a better resource or tool for you? 


\section{OACAS}

1. How long have you been ED at CAS?

m. In your CAS?

2. How many staff do you have at your organization?

3. How would you describe your relationship with OACAS?

4. Why is your organization part of OACAS - What are the primary benefits your organization receives from its membership in OACAS?

5. I'd like you to rate the importance of membership in OACAS to your organization, using a scale of one to five, where one is "Not at all important" and five is "Extremely important."

6. How would you describe your relationship with other members of OACAS?

$\circ$ When and why do you communicate with other members?

i. Probe Zone meetings

- Probe for regional differences ( do you speak with members from other regions?)

7. I'd like you to rate how important is it for your organization to be able to communicate and collaborate with other members of OACAS. using a scale of one to five where one is "Not at all important" and five is "Extremely important"?

\section{Technology Use}

8. I'd like you to rate your comfort level using the internet to search for information and communicate with others on a scale of one to five, where one is not at all comfortable and five is perfectly comfortable?

9. Do you receive the "weekly index" from OACAS - the list of articles that used to go out as Thursday mail"?

$\mathrm{n}$. Is the weekly index valuable? Why or why not?

o. What was the transition like from the paper mail to email?"

10. Have you ever been to the Member's website?"

11. What is the purpose of the Member 's website.'

12. On a scale of one to five, where one is not at all comfortable and five is perfectly comfortable. how would you rate your comfort level navigating the Member's website?

13. How frequently do you access the Member's website?

Daily A couple of times a week Weekly A couple of times per month Once a month or less 
14. For what reasons do you access the Member's website?

15. Are there other websites you access to assist you with your work? Why do you visit them?

16. What are some of the reasons you don't you access the website more often?

17. Do you ever access any of the other OACAS websites?

18. Who in your organization has access to computers and to the internet?

- Do you feel your agency has sufficient number of computers for our staff?

19. Does anyone in your organization access the Member's website?

p. Why do they use it?

q. Do you encourage use of the website?

\section{Discussion Forums}

20. Do you know about the OACAS Executive Director Forum?

21. What is the purpose of the OACAS Executive Director Forum?

22. Do you ever access the OACAS Executive Director Forum? If no:

23. Why not?

If yes:

24. Why do you access the OACAS Executive Director Forum?

\section{Impact}

OACAS has a long-standing relationship with its members that pre-dates the internet, and in recent years OACAS has increasingly relied on electronic communication.

25. What impact has the increasing reliance on electronic communication had on your relationship with OACAS?

Probe

- Website

- Email

- Has it had any impact on your satisfaction with OACAS?

- Has it increased the sense of participation or intimacy you have with OACAS?

26. What impact has the increasing reliance on electronic communication had on your relationship with other OACAS members?

Probe

- Website

- Email 
- Has it increased your ability to communicate and collaborate with other OACAS members?

27. What impact has the increasing reliance on electronic communication had on your organization? Probe

- Website

- Email

- Has it affected your organizations' ability to pursue its mission?

- Has it they affected your access to information?

28. Have there been any negative impacts, or constraints on previous ways of doing things, that have come out of OACAS's increasing reliance on communication technology?

29. What could OACAS do to make the Member's website a better tool or resource for you? 


\section{Appendix F - Research Instrument: Email Surveys (Members)}

\section{OCASI}

1. What is your title/role in the organization?

2. OCASI has two primary websites for staff at settlement agencies: "Settlement.Org" and "Settlement at Work." (If your answer is "no", please go to question \#3)

a. Have you ever heard of the "Settlement at Work" website?

b. What is the purpose of the "Settlement at Work" website?

c. Have you ever been to the "Settlement at Work" website?

d. Why do you go the "Settlement at Work" website?

e. Has access to the "Settlement at Work" had any impact on your work? Please explain.

f. Have you ever used the "Settlement at Work" Discussion Boards?

i. Why do use the "Settlement at Work" Discussion Boards?

\section{$\underline{O R}$}

ii. What are some of the reasons why you don't use the "Settlement at Work" Discussion Boards?

3. Do you think an electronic discussion board or message board that allowed you to share information and experiences with staff at other settlement agencies would be helpful to you and your work? Please explain. 


\section{OACAS}

1. What is your title/role in the organization?

2. How frequently do you access the OACAS Member's Website?

Daily A couple of times a week Weekly A couple of times per month Once a month or less

3. What is the purpose of the OACAS Member's Website?

4. What are some of the reasons that you access the OACAS Member's Website?

The following questions speak specifically to use of the OACAS Member's Website among front-line staff at your agency. It would be greatly appreciated if you could solicit their input to provide answers to the following questions:

5. Do any of your front-line staff access the OACAS Member's Website?

a. Why do they access the website?

b. How helpful is the OACAS Member's Website to their work?

c. What are some of the reasons why they are not using OAC.AS Member's Website more frequently?

d. What could be done to make the OAC.AS Member's Website a better tool/resource for front-line workers? 


\section{Appendix G - Code Book}

NC-CD

NC-MD

NC-S

NC-ST

NC-SG

NC-T
Network Characteristics: CAS Description

Description of the coordinating agency and its activities.

Network Characteristics: Member Description

Description of the member agencies and their activities.

Network Characteristics: Sector

Description of the subsector and the general operating culture.

\section{Network Characteristics: Sector Technology}

Description of the subsector, as it relates to technology capacity, take-up, etc.

Network Characteristics: Sector Government

Description of the government's role in the subsector, government-network relations.

\section{Network Characteristics: Technology}

Description of the technologies that are deployed in the network.
These segments are intended to provide the basic information about the CAS that will form the Case Description and offer insight into "organizational characteristics."

These segments are intended to provide the basic information about members that will form the Case Description and offer insight into "organizational characteristics."

These segments are intended to provide the basic information about the subsector that will form the Case Description and offer insight into "organizational characteristics."

These segments are intended to providi' the busic information about technolog. that will form the Case Description and offer insight into "organizational characteristics. "It does not attend specifically to technology within the network. hut rather technology within the sector writ large.

These segments are intended to provide the nasic information about the role of government and relation with govermment that will form the Case Description and offer insight ints "orgunizatomai characteristics."

These segments describe the technolog. that is in use within the network. It is intended to be exhaustive. dealing with the technologies and their functionality rather than perceptions or use. 
NC-MCR

NC-MMR

TD-C

TIn-C

TD-M

TD-EU

TR-C
Network Characteristics: Member-CAS Relations

Description of the relationship between members and the coordinating agency.

\section{Network Characteristics: Member-} Member Relations

Description of the relationship between members.

\section{Technology Deployment: CAS}

The processes of deploying technology in the network - which staff are involved. how decisions are made, how consultants are involved, barriers, etc.

\section{Technology Intent: CAS}

The anticipated and intended benefits and uses of technology, from the perspective of the coordinating agency, including broad visions of technology use and value.

\section{Technology Deployment: Members}

The ways in which members are involved in the deployment of technology, including consulting over needs and testing, requests made by members, and any training or promotion.

Technology Deployment: Effective Lise

Strategies, ideas on how to better deploy and make better use of lechnology.

\section{Technology Role: CAS}

The actual uses and value of technology as it is being used. from the perspective of the
These segments are intended to provide basic information about the relationship hetween the CAS and members that will form the Case Description and offer insight into "organizational characteristics."

These segments are intended to provide basic information about the relationship among members. including regional differences, that will form the Case Description and offer insight into "organizational characteristics."

These segments specifically address the $C A S^{\prime}$ internal processes of technology deployment.

Trying to capture agency plans and intentions... hopes in how technology will be used and strategic reasons hehind its deployment.

These segments specifically address the ways in which members are involved in technologr strategy and deployment. It includes efforts on behalf of the CAS to promole ter hnology use but does not address member reaction to technology.

A broad category that captures lessons learned: sulcessses strategies and failures that provide insight for improved use and deployment of technology.

CAS staff perspectives on the fiunction that rechnology serves within the network. 
coordinating agency.

TR-M

TU-C

TU-M

TE

TC

TI-CA

TI-MA members. technology. resource capacity).

\section{Technology Role: Members}

The actual uses and value of technology as it is being used, from the perspective of the

\section{Technology Use: CAS}

The ways in which CAS staff are using technology, staff reaction to technologies, and factors that affect staff use of

\section{Technology Use: Members}

The ways in which members are using technology, member reaction to technologies, and factors that affect member use of technology.

\section{Technology Evolution}

Changes in technologies over time, or changes in technology use over time.

\section{Technology Challenges}

Challenges to deploying and implementing technology as the coordinating agency would like. Problems encountered in deploying technology, weaknesses in current arrangements (technical and

\section{Technology Impact: CAS activities}

The impact of technology on the activities of the coordinating agencies.

Technology Impact: Member Activities

The impact of technology on the activities of the network members. ats

Member perspectives on the function that technology semies within the network.

An attempt to understand the ways in which staff at the CAS have responded to technology, hinting at possible elements of a structuration process.

An uttempt to understand the ways in which members have responded to the implementation of technology within the network. hinting at possible elements of a structuration process.

An attempt to understand the ways in which technology use have change over time. hinting at possible elements of a stmucturation process.

Segments which address the challenges of technology implementation. These segments speak primarily to technical and resource capacity, and not to member or staff reactions.

Segments which evince a change in CAS role and activities as a result of use of technology.

Segments which evince a change in member activities as a result of use of technology. 
TI-IF

TI-MCR

TI-MMR

TI-C
Technology Impact: Information Flows

The impact of technology on the flow of information. and communication

exchange, within the network.

Technology Impact: Member-CAS Relations

The impact of technology on the relationship between members and the coordinating agency.

Technology Impact: Member-Member Relations

The impact of technology on the relationship between members.

\section{Technology Impact: Constraints}

Negative outcomes of increasing reliance on/use of communication technologies.
Segments which evince a change in the flow of information with and among members as a result of use of technology. Will be some overlap with IT-CA. TI-MCR and TI-MMR

Segments which evince a change in the relations between members and the CAS as a result of use of technology.

Segments which evince a change in the relations among members as a result of use of technology.

Segments that address negative outcomes or constraints imposed by the use of technology. 


\title{
Appendix H - Sample Letter to Network Members
}

\author{
Dear [member],
}

I am writing to inform you of a research project in which [name of network] is participating. The study is being completed by Eli Malinsky. a graduate student at Ryerson University, and is being sponsored by Ryerson University's Centre for Voluntary Sector Studies. The purpose of the study is to leam about how associations of nonprofit organizations in Ontario are using communication technologies such as the internet.

As part of this research you may be contacted to participate in a telephone interview. The interview will take approximately 30 minutes to complete and is primarily intended to learn about your relationship with [nume of network] and the value and impact of the [name of network] websites.

This study will be the first systematic investigation of how associations of nonprofit organizations in Ontario are using communication technologies and will compare [name of netw'ork] experience against that of two other associations. It is hoped that the findings of this research project will help [name of network] and other associations of nonprofit organizations to use communication technologies more effectively.

Participation in this study is entirely voluntary. Your choice of whether or not to participate will not influence your relations with [name of network] or with Ryerson University. Staff at [name of network] will not be aware of who has participated and will not have the opportunity to review the results or comments of individual member interviews.

More details about the interview and the research project will be provided when you are contacted by the investigator. If you have any specific questions about the research study, please feel free to contact:

Eli Malinsky, MA Candidate

Ryerson University

emalinsk@ryerson.ca

We hope you will consider participating in this research project.

Sincerely,

[Executive Director] 


\section{References}

Anheier, Helmut and Nuno Themudo (2002). Organizational Forms of Global Civil Society: Implications of Going Global. In Global Civil Socien: Yearbook 2002. London: The Centre for the Study of Global Governance. Accessed July 18. 2004:

http://www.lse.ac.uk'Depts/global.'Yearbook outline2002.htm

Anheier, Helmut, Marlies Lasius and Mary Kaldor (2001). Introducing Global Civil Society. In Anheier et al (eds.) Global Civil Socien: 2001. London: London School of Economics. Accessed July 18. 2004:

http://www.lse.ac.uk'Depts/global'Yearbook/GCS2001.htm

Bach, Jonathan and David Stark (2004). Link. Search, Interact: The Co-evolution of NGOs and Interactive Technology. Theory: Culture \& Society. Vol. 21(3): 101-117.

Barley, S.R. and P.S. Tolbert (1997). Institutionalization and structuration: Studying the Links between action and structure. Organization Studies. 18(10), 93-117.

Barley, S. (1986). Technology as an occasion for structuring: Evidence from observations of CT scanners and the social order of radiology departments. Administrative Science Quartertv. 31: 78-108.

Barr and Stowe (2005). The Rural charitable Sector Initiative Phase Two: The Capacity Challenges of Rural and Nonprofit Organizations in Rural Ontario. Toronto: Imagine Canada.

Bartling, Charles E. (1998). Strategic Alliances for Nonprofit Organizations. Washington: American Society of Association Executives.

Bradner, Erin and Gloria Mark (2002). Why distance matters: effects on cooperation, persuasion and deception. Proceedings of the 20(1)2 ACM conference on Computer supported cooperative work. pp. $226-235$.

Brooks, Laurence (1997). Structuration theory and new technology: Analysing organizationally situated computer-aided design. Information Systems Journal. Volume 7, Issue 2. 133-151.

Burt, Eleanor and John A. Taylor (2000). Information and Communication Technologies:

Reshaping Voluntary Organizations"? Vonprofit .Huinugement and Leadership. Vol, 11, No. 2 pp. 131-14.

Burt. Eleanor and John Tavlor (2003). New Technologies. Embedded Values. and Strategic Change: Evidence from the U.K. Voluntary Sector. Nonprofit and Voluntary Sector Quarterly, Vol. 32, no. 1. 
Canadian Federation of Voluntary Sector Networks Website (2005). Centre for Voluntary Sector Research and Development. Accessed March 14, 2005:

http://www.cvsrd.org/eng/federation/

Castells, Manuel (2004) The Power of Identity. $2^{\text {nd }}$ Edition. Massachusetts: Blackwell Publishing.

Castells, Manuel (2001). The Rise of the Network Society. 2nd Edition. Massachusetts: Blackwell Publishing.

Ching, Chee, Clyde W. Holsapple and Andrew B. Whinston (1996). Toward IT support for coordination in network organizations. Information and Management. Vol. 30 No. 4 (July): 179-199.

Clarke. Tony and Sarah Dopp (2001) Challenging McWorld. Ottawa: Canadian Centre for Policy Alternatives.

Connecting Canadians Website (2004). Industry Canada. Accessed February 15, 2005: http: /www.connect.gc.ca/index.htm

DeSanctis, G. \& Fulk, J. (1999). Shaping organizational form: communication. connection. and community. Newbury Park, CA: Sage

DeSanctis, Gerardine and M.S. Poole (1994). Capturing the Complexity in Advanced Technology Use: Adaptive Structuration Theory. Organization Scienc'e, Vol. 5, No. 2,121-147.

Diani, Mario (2000). Social Movement Networks Virtual and Real. Information. Communicution and Societr. Vol.3 Iss. 3 386-401.

DiMaggio, Paul J. and W.W. Powell (1991). The iron cage revisited: Institutional isomorphism and collective rationality. In W.W. Powell and P. J. DiMaggio (Eds.) The New Institutionalism in Organizational Analysis. (pp. 63-82). Chicago: University of Chicago Press.

Evans, B. Mitchell and John Shields (1998). 'Reinventing' the Third Sector: Alternative Service Delivery. Partnerships and the New Public Administration of the Canadian Post-Welfare State. CVSS Working Paper Series, Number 9.

Frank, Kenneth A., Yong Zhao and Kathryn Borman (2004). Social Capital and the Diffusion of Innovations Within Organizations: The Case of Computer Technology in Schools. Sociology of Education. Vol. 77 (April): 148-171. 
Frederick, Howard H. (1992). Computer communications in cross-border coalition-building North American NGO networking against NAFTA. Gazette: The International Journal for Mass Communication Studies, Vol. 50. No. 2-3.217-241.

Garrido, Maria and Alexander Halavais (2003). Mapping Networks of Support for the Zapatista Movement: Applying Social-Network Analysis to Study Contemporary Social movements. In M. McCaughey and M. D. Ayers. (Eds). CyberActivism: Online Activism in Theory and Practice. (pp. 165-184) New York: Routledge.

Giddens, A. (1984). The constitution of society: Outline of a theory of structuration. Berkeley: University of California Press.

Giddens, A. (1979). Central problems in social theory: action. structure and contradiction in social analysis. London: Macmillan press

Hajnal, Peter (2002). Introduction: Definitions and Background. In P. Hajnal (Ed.), Civil Society in the Information Age. (pp. 1-15). Vermont: Ashgate.

Hall, M.H. and P.B. Reed (1998). Shifting the burden: How much can government download to the nonprofit pector. Canadian Public Administration. Vol. 4. No. 1, pp. 1-20.

Hall, Michael et al. (2003). The Capacity to Serve: A Qualitative Study of the Challenges facing Canada's Nonprofit and Voluntary Organizations. Ottawa: Statistics Canada.

Hannan, M.T. and J.H Freeman (1977). The population ecology of organizations. The American Journal of Sociology. Vol. 82, 929-964.

Hatton, $\mathrm{Al}$ (2002). The importance of building civil society. In K.L. Brock (Ed.) Improving Connections between governments and nonprofit and voluntary organizations: Public Policy and the Third Sector. (pp. 39-44). Kingston: Queen's University.

Holland, C. P., and A. G. Lockett. 1997. Mixed Mode Network Structures: The Strategic Use of Electronic Communication by Organizations. Orgunizutiom Science. Vol. 8 No. 5 (September-October): 475-488.

Jepperson. Ronald L. (1991). Institutions, institutional effects, and institutionalism. In W.W. Powell and P. I. DiMaggio (Eds.) The Vew Iintitutionsalism in Organizational Analysis. (pp. 143-163). Chicago: University of Chicago Press.

Josefsson, L. \& Nilsson. A. (1999) The Progress of Groupware U'se in Local Government. In Proceeding of $6^{\text {th }}$ European Conference of Information Technology Evaluation. (pp 159-166). MCIL: London.

Keck. Margaret E. and Kathryn Sikkink (1998). Activists Beyond Borders: Advocacy Networks in International Politics. London: Cornell University Press. 
Knoke, David (2001). Networks and Organizations. In Judith R. Blau (ed.), The Blackwell Companion to Sociology. (pp. 327-341). Malden, Mass.: Blackwell.

Lebert (2003). Information and Communication Technologies and Human Rights Advocacy: The Case of Amnesty International. In P. Hajnal (Ed.). Civil Society in the Information Age. (pp. 19-36). Vermont: Ashgate.

Lebert, Joanne (2002). Information and Communication Technologies and Human Rights Advocacy: The Case of Amnesty International. In P. Hajnal (Ed.), Civil Society in the Information Age. (pp. 19-36). Vermont: Ashgate.

Leverus Annual Internet Survey for Associations and Not-for-profit Organizations: 2002 (2003). Toronto: Leverus.

Lipnack, Jessica and J. Stamps (1994). The Age of the Network: Organizing Principles for the $21^{\text {st }}$ Century. Toronto: John Wiley \& Sons.

Ludgate, Catherine and M. Surman (2004). Beyond the Box - Thinking strategically about technology grant-making in Canada's voluntary sector. A background paper for the Voluntary Sector Initiative Changing Technology Funding Practices project. Accessed October 2004: http://www.vsi-isbc.ca/eng/imit/pdf/beyond_the_box.pdf

Malinsky, Eli (2004). Connecting for a Cause: Civil Society Networks and Information \& Communication Technologies. Unpublished Paper: Ryerson University, Toronto

Meinhard, Agnes G. and Mary K. Foster (2003). Differences in the Response of Women's Voluntary Organizations to Shifts in Canadian Public Policy. Nonprofit and Voluntary Sector Quarterly, Vol. 32: 366-396.

Merriam, S. B. (1985). The Case Study in Educational Research: A Review of Selected Literature. Journal of Educational Thought. 19.3. 204-17.

Meyer, John W. and B. Rowan (1977). Institutional organizations: Formal structure as myth and ceremony The American Journal of Sociology, Vol, 83, 340-363.

Munkvold, B. E. (1999). Challenges of IT implementation for supporting collaboration in distributed organizations. European Journal of Information Systems, v.8 n.4. pp.260272.

Naughton, John (2001). Contested Space: The Internet and Global Civil Society. In Global Civil Society Yearhook 2001. London: The Centre for the Study of Global Governance. Accessed July 22. 2004:

http://www.lse.ac.uk/Depts/global/Yearbook/outline.htm 
Nohria. Nitin. (1992). Is a network perspective a useful way of studying organizations? In N. Nohria and R.G. Eccles. (eds.) Nerworks and Organizations: Structure. form and action. (pp. 4-16) Boston: Harvard University Press.

O'Brien, R. (2002). Global Civil Society Networks Online: Zapatistas. the MAI, and Landmines. In Lauren Langman (Chair). Internet Research 2.0: INTERconnections the Second International Conference of the Association of Internet Researchers. University of Minnesota. Minneapolis-St. Paul:

Association of Internet Researchers. Accessed June 4. 2004: http://www.web.net/ robrien/papers civsocnets.html

O'Connell, Kevin (2005). Association Technology Survey. Unpublished Paper: British Columbia Institute of Technology.

Office of Learning Technologies Website (2005). Human Resources and Skills Development Canada. Accessed March 14, 2005: http://www.hrsdc.gc.ca/en/gateways/nav/top_nav/program/olt.shtml

Orlikowski, Wanda J. (1992a). The duality of technology: Rethinking the concept of technology in organizations. Organization Science. Vol. 3. No. 3, 398-427.

Orlikowski, Wanda J. (1992b). Learning from Notes: organizational issues in groupware implementation. CSCW: Proceedings of the 1992 ACM conference on Computersupported cooperutive work. Toronto. Canada: $362-369$.

Orlikowski, Wanda J., \& Barley, S. R. (2001). Technology and Institutions: What Can Research on Information Technology and Research on Organizations Learn from Each Other? Management Information Systems Quarterly, 25(2), 145-165.

Orlikowski, Wanda J. and D. Robey (1991). Information technology and the structuring of organizations. Information Systems Research. Vol. 2. No. 2. 143-166.

Pace, William R. and Rik Panganiban (2002). The Power of Global Activist Networks: The Campaign for an International Criminal Court. In P. Hajnal (Ed.). Civil Socienv in the Information Age. (pp. 109-125). Vermont: Ashgate.

Pendergast. Mark and Stephen Hayne (1999, April 25). Groupware and social networks: Will life ever be the same again? Information and Software Tec/hnology (Amsterdam) Vol.41. Iss. 6, pp. 311-319.

Podolny, Joel M. and Karen L. Page (1998). Network forms of organization. Annual Review of Sociology. Vol. 24. pp. 57-76.

Powell. Walter W. (1990). Neither market nor hierarchy: Network forms of organization. Research in organizational Beharior. Vol. 12, pp 295-336. 
Roberts, Karlene H. and M. Grabowski (1996). Organizations, technology and structuring. In S. Clegg.. C. Hardy. And W.R. Nord. (Eds). Hundbook of organization studies. (409423) London and Thousand Oaks: Sage Publications.

Scott. Katherine (2003). Funding Matters: The Impact of Canada's New Funding Regime on Nonprofit and Voluntary Organizations. Ottawa: Canadian Council for Social Development.

Stake, Robert (1994). Case Studies. In Norma Denzin and Yvonna Lincoln (eds.) Handbook of Qualitative Research. (236-247). California: Thousand Oaks, Sage Publications.

Stinchcombe, A. (1965). Social Structure and Organizations. In J. March (Ed.), Handbook of Organizations. (pp. 153-193). Chicago: Rand McNally

Surman, Mark and Katherine Reilly (2003). Appropriating the Internet for Social Change: Towards the strategic use of networked technologies by transnational civil society organizations. New York: Social Sciences Research Council.

Surman, Mark (2001). From Access to Applications: How Ontario Non-Profits Are Using the Internet. Toronto: The Commons Group. Accessed August 2004: http://commonsgroup.com/docs/accesstoapps.pdf

Symon, Gillian (2000). Information and communication technologies and network organization: A critical analysis. Journal of Occupational and Organizational Psychology. Vol.73, Part 4. pp. 389-415.

Tarrow, Sidney (1998) Power in Movement: Social Movements and Contentious Politics, $2^{\text {nd }}$ ed. Cambridge: Cambridge University Press.

Thompson, Grahame F. (2003). Between Hierarchies and Markets: The Logic and limits of network forms of organization. Oxford: Oxford University Press.

Tolbert. Pamela S. and L.G. Zucker (1996). The institutionalization of institutional theory. In S. Clegg,. C. Hardy, And W.R. Nord, (Eds). Handbook of organization studies. (175190) London and Thousand Oaks: Sage Publications.

Van den Bulck. Hilde (2002). Tools for Studying the Media. In Chris Newbold, Oliver BoydBarrett and Hilde Van den Buick (eds.) The Media Book. Oxford University Press Inc. New York. NY.

Volkoff, O. (1999). Using the Structurational Model of Technology to Analyze an ERP Implementation. Conference paper delivered at Americas Conference on Information Systems (AMCIS). Milwaukee. WI.

Voluntary Sector Initiative Website (2004). Government of Canada. Accessed October 25, 2004: http://www.vsi-isbc.ca/eng/index.cfm 
Volunteer@ction Online Website (2005). Ontario Ministry of Immigration and Citizenship. Accessed February 16, 2005:

http:/www.gov.on.ca/MCZCR english/citdiv/voluntar/vao-brochure.htm

Warkentin. Craig (2001). Reshaping World Politics: NGOs. the Internet. and Global Civil Society. Oxford: Rowan \& Littlefield.

Weick, K.E. (1990). Technology as equivoque: Sense-making in new technologies. In P.S. Goodman and L. Sproull (eds) Technology and Organizations (pp. 1-44). San Francisco: Jossey-Bass.

Williamson, O.E. (1975). Markets and Hierarchies: Analysis and anti-trust implications. New York: Free Press.

Yin, Robert K. (2003). Case Study Research: Design and Methods. $3^{\text {rd }}$ edition. Applied Social Research Methods Series. Sage Publications: Newbury Park.

Zucker, Lynne G. (1987). Institutional Theories of Organization. Annual Review of Sociolog! Vol. 13, 443-464. 


\section{List of Abbreviations}

$\begin{array}{ll}\text { CAS } & \text { Children's Aid Society } \\ \text { CIC } & \text { Citizenship and Immigration Canada } \\ \text { HRSDC } & \text { Human Resources Skills Development Canada } \\ \text { ICT } & \text { Information and Communication Technology } \\ \text { ISAP } & \text { Immigrant Settlement and Adaptation Program } \\ \text { LINC } & \text { Language Instruction for Newcomers } \\ \text { MCYS } & \text { Ministry of Children and Youth Services } \\ \text { MTCU } & \text { Ministry of Training Colleges and Universities } \\ \text { NGO } & \text { Non-Governmental Organization } \\ \text { OACAS } & \text { Ontario Association of Children's Aid Societies } \\ \text { OASIS } & \text { Ontario Administration of Settlement and Integration Services } \\ \text { OAYEC } & \text { Ontario Association of Youth Employment Centres } \\ \text { OCASI } & \text { Ontario Council of Agencies Serving Immigrants } \\ \text { OnLAC } & \text { Ontario's Looking After Children program } \\ \text { V@O } & \text { Volunteer @ction.Online program }\end{array}$

$\theta \beta C+1+\alpha$ 